Check for updates

Cite this: Nat. Prod. Rep., 2020, 37, 380

\title{
Making natural products from renewable feedstocks: back to the roots?
}

\author{
Jonas Kühlborn, $\uparrow$ Jonathan Groß† and Till Opatz (D)*
}

Covering: up to mid-2019

This review highlights the utilization of biomass-derived building blocks in the total synthesis of natural products. An overview over several renewable feedstock classes, namely wood/lignin, cellulose, chitin and chitosan, fats and oils, as well as terpenes, is given, covering the time span from the initial beginning

Received 3rd July 2019 of natural product synthesis until today. The focus is put on the origin of the employed carbon atoms and on the nature of the complex structures that were assembled therefrom. The emerging trend of turning away from petrochemically derived starting materials back to bio-based resources, just as seen in

DOI: 10.1039/c9np00040b

rsc.li/npr the early days of total synthesis, shall be demonstrated.

1. Introduction

1.1. Total synthesis - a driving force for new developments

1.2. Requirements of eco-friendly synthesis

1.3. Atom origin: historical developments

2.

2.1. Natural product syntheses using renewable feedstocks Wood/lignin

2.1.1. Valorization of wood/lignin

2.1.2. Natural product syntheses using wood/lignin derived starting materials

2.1.2.1. ( \pm -Usnic acid

2.1.2.2. (+)-Garcibracteatone

2.1.2.3. Lupinalbin $\mathbf{H}$

2.1.2.4. ( \pm -Tylophorine

2.1.2.5. ( $( \pm)$-Gracilamine

2.1.2.6. Cochinchinenone

2.1.2.7. Taiwaniaquinones and taiwaniaquinols

2.1.2.8. (-)-Surinamensinol B

2.1.2.9. (+)-Monocerin

2.1.2.10. (+)-Oxycodone

2.1.2.11. Ilicifoline $B$

2.1.2.12. (-)-Viridin and (-)-viridiol

2.1.2.13. ( \pm -Latifine and $( \pm)$-cherylline

2.1.2.14. (-)-Thebaine

2.2. Cellulose

2.2.1. Valorization of cellulose

2.2.2. Natural product syntheses using cellulose derived starting materials

2.2.2.1. (-)-Hongconin

Institute of Organic Chemistry, Johannes Gutenberg University, Duesbergweg 10-14, 55128 Mainz, Germany.E-mail: opatz@uni-mainz.de

$\dagger$ Jonas Kühlborn and Jonathan Groß contributed equally.
2.2.2.2. (+)-Dairy lactone

2.2.2.3. (+)-Herbarumins

2.2.2.4. (-)-Jiadifenolide

2.2.2.5. (+)-Chloriolide

2.2.2.6. (-)-Aspergillides

2.2.2.7. (-)-Bissetone and (-)-palythazine

2.2.2.8. (+)-Castanospermine

2.3. Chitin and chitosan

2.3.1. Valorization of chitin and chitosan

2.3.2. Natural product syntheses using chitin/chitosan derived starting materials

2.3.2.1. (-)-Rhizochalinin C

2.3.2.2. (-)-Pochonicine

2.3.2.3. (-)-Allosamizoline

2.3.2.4. Proximicin A

2.4. Fats and oils

2.4.1. Valorization of fats and oils

2.4.2. Natural product syntheses using fats and oils derived starting materials

2.4.2.1. (+)-Azimic acid and (+)-julifloridine

2.4.2.2. (-)-Panclicin D

2.4.2.3. (+)-Prosophylline and (+)-prospinine

2.4.2.4. (+)-Jaspine B

2.4.2.5. (+)-Pancratistatin

2.4.2.6. Ophiocerins and (-)-botryolide E

2.5. Terpenes

2.5.1. Valorization of terpene feedstock

2.5.2. Natural product syntheses using terpene feedstock starting materials

2.5.2.1. Thymol

2.5.2.2. (+)-Grandisol

2.5.2.3. (-)-Majucin and (-)-jiadifenoxolane A 
2.5.2.4. (+)-Mikanokryptin

2.5.2.5. (+)-Pseudoanisatin

2.5.2.6. (+)-Cardamom peroxide

2.5.2.7. (+)-Paeonisuffrone

2.5.2.8. (+)-Yingzhaosu A

2.5.2.9. (+)-Omphadiol

2.5.2.10. (-)-Bolivianine and (+)-onoseriolide

2.5.2.11. (+)-Welwitindolinone $A,(-)$-fischerindole I and $\mathbf{G}$

2.5.2.12. (+)-Cubitene

2.6. Miscellaneous

2.6.1. L-Rednose-containing antibiotics

2.6.2. (+)-cis-Nemorensic acid

2.6.3. Macrolide precursor for glucolipsin synthesis

2.6.4. ( \pm -Lasiodiplodin from Cashew Nut Shell Liquid (CNSL)

3. Future challenges and outlook

4. Conflicts of interest

5. Acknowledgements

6. Notes and references

\section{Introduction}

\subsection{Total synthesis - a driving force for new developments}

The synthesis of organic compounds of natural origin from simple starting materials - the so-called total synthesis - has attracted and fascinated chemists ever since the successful synthesis of "organic" urea from inorganic silver cyanate and ammonium chloride by Wöhler in $1828 .^{1}$ It should not be forgotten that the earlier isolation of pure morphine from opium by Sertürner in $1806^{2}$ and his preparation of morphine salts in $1817^{3}$ were further defining moments in organic chemistry. Total synthesis has since emerged to be one of the most challenging and prestigious disciplines among the chemical sciences, as underlined by the Nobel prizes awarded to R. B. Woodward and E. J. Corey.

The fascination with this field arises from the diverse opportunities available in the application of natural products, combined with the possibility to provide these natural products independent of their natural source and to modify their structures at will.

Natural products have always served as an inspiration for the development of new pharmaceuticals, pesticides and herbicides or dyes - and total synthesis is often the only way to provide access to such products in sufficient quantities for extensive investigation, let alone commercial endeavours. ${ }^{4-6}$ Therefore, total synthesis, natural product isolation and structure elucidation have close ties. The search for new compounds with attractive biological activities or chemical structures has fueled the development of new analytical methods and synthetic chemists were never shy to tackle any attractive target molecule virtually regardless of its size. In contrast, the more challenging the target molecules were, the more effort was put into the development of new methods, technologies and theoretical concepts to make their preparation possible. ${ }^{7,8}$ This has made total synthesis an ideal proving ground for the utility of new synthetic developments. Furthermore, the ab initio synthesis serves to verify or correct a proposed structure and the structures of numerous compounds had to be revised when total synthesis proved the originally proposed structure to be incorrect, often in terms of relative or absolute stereochemistry. ${ }^{9-20}$

Working on total synthesis projects provides excellent training for synthetic chemists and is generally appreciated by future employers in the chemical and pharmaceutical sector because of the profound experience gained. ${ }^{21}$ The extensive and diverse challenges of organic synthesis provide a "feeling" for the reactivity of chemical compounds and profound knowledge on how to extract the literature to solve the numerous problems encountered on the way to the target. Although the number of total synthesis publications dwelling on the detours and problems encountered which contribute to the unmatched challenge of this discipline seems to be, unfortunately, declining, the successful pursuit of a total synthesis project is frequently associated with high skills in problem-solving and high levels of tolerance for frustration by the practitioner. ${ }^{22}$

\subsection{Requirements of eco-friendly synthesis}

The increasing awareness of sustainability in our modern society has also led to reverberations in chemical research and industry which culminated in the Rio Declaration on Environment and Development from The United Nations Conference on Environment and Development in $1992 .{ }^{23}$ Based on this declaration, Anastas and Warner have developed their twelve principles of green chemistry in $1998,{ }^{24}$ just as Anastas and Zimmermann phrased the related twelve principles of green engineering five years later. ${ }^{25}$ Both catalogues are meant to be guidelines for the development of more eco-friendly syntheses, methodologies, technologies as well as processes and these are applicable to numerous facets of chemical research and production. However, the considerable potential of biocatalysis for "green" organic synthesis is not discussed therein. The present review will mainly focus on the use of renewable resources for the production of chemical building blocks and their value for organic synthesis. The reader shall also be referred to the rich body of existing literature providing more detailed information on the essence of green chemistry. ${ }^{26-52}$

Furthermore, during the course of this paradigm shift in the world of chemistry, a number of terms and metrics to describe the extent of sustainability and "greenness" of certain reaction or process have been introduced. ${ }^{53}$ The first metric that has been introduced is the Atom Economy concept of Trost, soon followed by the Environmental (E) factor of Sheldon. The former is defined as the ratio of the molecular mass of the desired product and the sum total of the molecular masses of all substances produced according to the stoichiometric equation. ${ }^{5,55}$ The latter, introduced in 1992, is the mass ratio of total waste and product and therefore indicates the efficiency and the environmental impact of a given process. ${ }^{56-58}$ These two and further metrics have been widely applied and discussed in detail elsewhere. ${ }^{59-61}$ Researchers of GlaxoSmithKline have recently developed the carbon efficiency, which is the percentage of carbon atoms remaining in the product relative to 
all carbon atoms present in the entirety of reactants. ${ }^{62,63}$ Since organic synthesis is about constructing carbon skeletons, the origin and fate of carbon atoms significantly contributes to the sustainability of a certain organic product. Thus, the renewability of (starting) materials is a major aspect of green chemistry.

With few exceptions, chemical raw materials are currently produced from the fossil resources such as natural gas, coal and petroleum. Depletion of underground deposits, growing ecological risks associated with production as well as the carbon imbalance in the ecosphere resulting from the usage of these feedstocks makes them less favorable. Furthermore, the chemical diversity initially available from these sources is small and this has led to sometimes lengthy production processes but also to a rather limited primary product portfolio comprising alkanes, alkenes, alkynes and arenes. Any further functionalization such as the introduction of heteroatoms like oxygen, nitrogen, sulfur, phosphorus or halogens to generate advanced building blocks requires additional synthetic steps, often in the form of multistep cascades, which lead to additional waste production and energy consumption. In spite of these shortcomings, there was little incentive so far to change this traditional and irreversible chemical carbon flow.

In contrast, biomass-derived renewable starting materials often carry an appreciable degree of functionalization (heteroatoms, stereocenters) and can therefore represent useful advanced building blocks for synthesis. Because of their biogenetic relation or at least their structural proximity to nature-derived or -inspired target molecules, the step count required to convert them into suitable synthetic building blocks can be shorter than that available in the usage of their petrochemical counterparts. In addition to the renewability aspect and the option to close the carbon cycle, this is another advantage of bio-based starting materials. Here, we will mainly focus on the origin of the starting materials required to construct the carbon skeleton of natural products in order to illustrate their utility in total synthesis and organic synthesis of complex molecules in general.

Along with the utilization of biomass for fuel and energy production, the search for new sources of chemical feedstocks is a growing field in current chemical research. Numerous recent publications deal with the production of low molecular weight compounds from biomass and the valorization of these renewable feedstocks for synthetic purposes, although commodities such as adipic acid, acrylic acid or butanol currently still dominate the field. ${ }^{64-67}$

\subsection{Atom origin: historical developments}

The concept of producing starting materials from natural resources is by no means new. In fact, before petroleum oil and coal deposits were discovered and exploited, the only available sources for pure organic compounds such as camphor, ethanol, methanol, hexadecanol, acetic acid, benzoic acid or benzaldehyde were microorganisms, plants and animals. Therefore, the young field of organic synthesis was initially restricted to these natural feedstocks and chemists have sought out to expand this portfolio. Nevertheless, early-day chemists managed to synthesize natural products - some remarkable examples like von Baeyer's alizarin and quinalizarin ${ }^{68}$ as well as indigo synthesis, ${ }^{69-71}$ Ladenburg's coniine synthesis $^{72,73}$ or the synthesis of tyrian purple by Sachs and Sichel ${ }^{74-76}$ are depicted in Schemes 1-4.

During this period, industrial organic chemistry was intensely focused on the production of dyes and pigments and the demand was growing for synthetic approaches instead of reliance on natural sources of these products. Therefore, productive sources of raw materials were needed and the industrial production of petroleum oil and coal provided the required carbon sources. These petrochemicals were available in quantities sufficient to satisfy the needs of the expanding chemical industry. Synthetic routes and products were planned according to the starting materials available from those sources. A prime example is the manufacturing of indigo which was at first obtained from plant sources at an annual rate of $19000 \mathrm{t}$ in 1897 which dropped to $1000 \mathrm{t}$ in 1914 as synthetic methods based on petrochemicals became available. ${ }^{77}$ Around the same time, the industrial production of synthetic pharmaceuticals gained importance, e.g. the industrial scale production of acetylsalicylic acid $^{78}$ and of salvarsan, ${ }^{79}$ which were both already produced from petrochemicals. The chemical industry developed to an important basis for economic growth in Western countries.

Despite the shift towards petrochemicals as new starting materials, biomass-derived feedstocks never were completely eliminated. The chiral pool, which is the collection of chiral terpenes, amino acids and carbohydrates and other chiral compounds available from nature, ${ }^{\mathbf{8 0}}$ was for many decades the only source of enantiopure catalysts and building blocks. ${ }^{81}$ The chiral pool was crucial for the synthesis of many natural products and other chiral nonracemic organic compounds. ${ }^{82-87}$

The anthropogenic rise in atmospheric $\mathrm{CO}_{2}$ levels casts shadows upon the continued extensive use of petrochemical

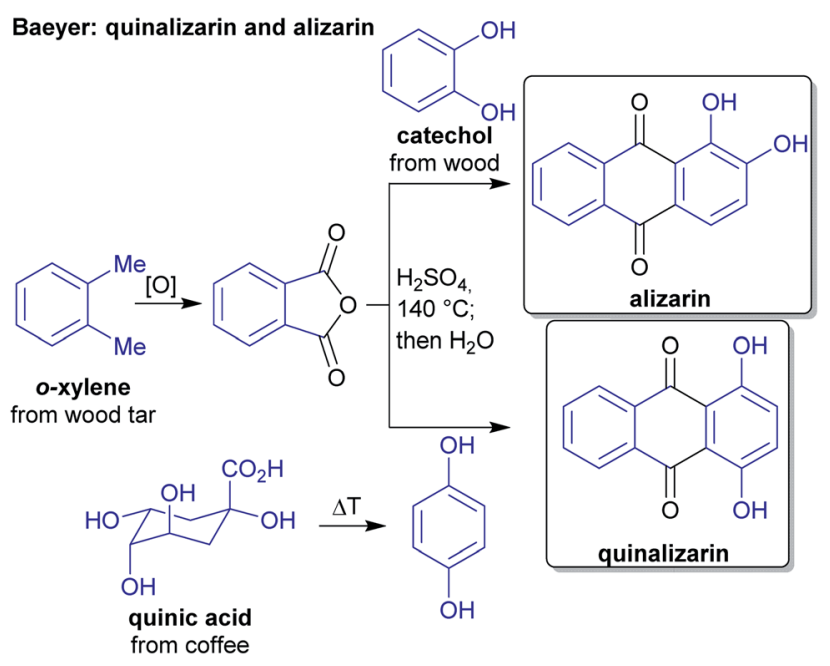

Scheme 1 Baeyer's alizarin and quinalizarin synthesis from phthalic anhydride and catechol/hydroquinone. 


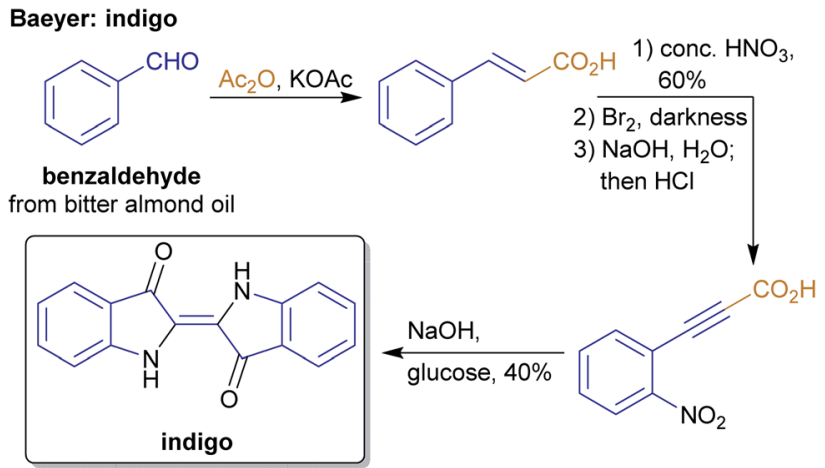

Scheme 2 Baeyer's indigo synthesis from cinnamic acid.

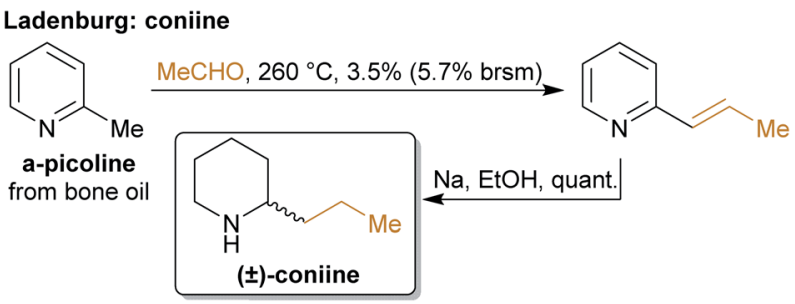

Scheme 3 Ladenburg's coniine synthesis from $\alpha$-picoline.

Sachs and Sichel: tyrian purple

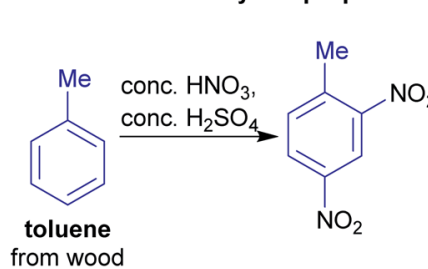

1) $p$-Nitrosodimethylaniline $\mathrm{EtOH}, \mathrm{Na}_{2} \mathrm{CO}_{3}$ $\underset{\mathrm{PhH}, 73 \%}{\mathrm{PhO}}$
$\stackrel{83 \%}{\mathrm{HNO}_{3}(27 \%),}$<smiles>O=Cc1ccc([N+](=O)[O-])cc1[N+](=O)[O-]</smiles>
from wood

1) $\mathrm{NH}_{2} \mathrm{OH} \bullet \mathrm{HCl}, \quad$ 3) $\mathrm{HBr}$, $\mathrm{EtOH}, 96 \%$

2) $\mathrm{NH}_{4} \mathrm{SH}, \mathrm{EtOH}$ $\mathrm{H}_{2} \mathrm{O}, 66 \%$ $\mathrm{NaNO}_{2}$, $\mathrm{H}_{2} \mathrm{O}, 84 \%$

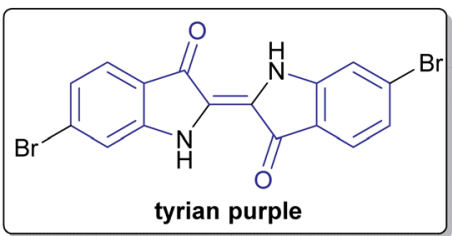

1) $\mathrm{Me}_{2} \mathrm{CO}$, $\mathrm{Na}_{3} \mathrm{PO}_{4}$ $\mathrm{H}_{2} \mathrm{O}$, quant. 2) $\mathrm{NaOH}$, $\mathrm{H}_{2} \mathrm{O}$, quant.
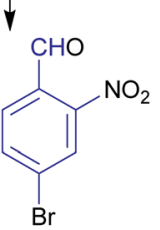

Scheme 4 Sachs' and Sichel's synthesis of tyrian purple from xylochemical toluene.

resources. ${ }^{88}$ With the largest fraction of fossil fuels being used for heating and/or cooling and transportation, the opinion that the use of fossil resources for chemistry will always be possible in future economic settings is still widespread. This is at least in part based on the assumption that mankind will acknowledge the overriding importance of synthetic chemistry and that this area will remain unaffected by any future changes in our carbon economy, hence making any adaption of feedstocks towards a higher sustainability obsolete. On the other hand, it is entirely possible that this belief will suffer the same fate as the presumption that chlorofluorocarbons or tetrachloromethane

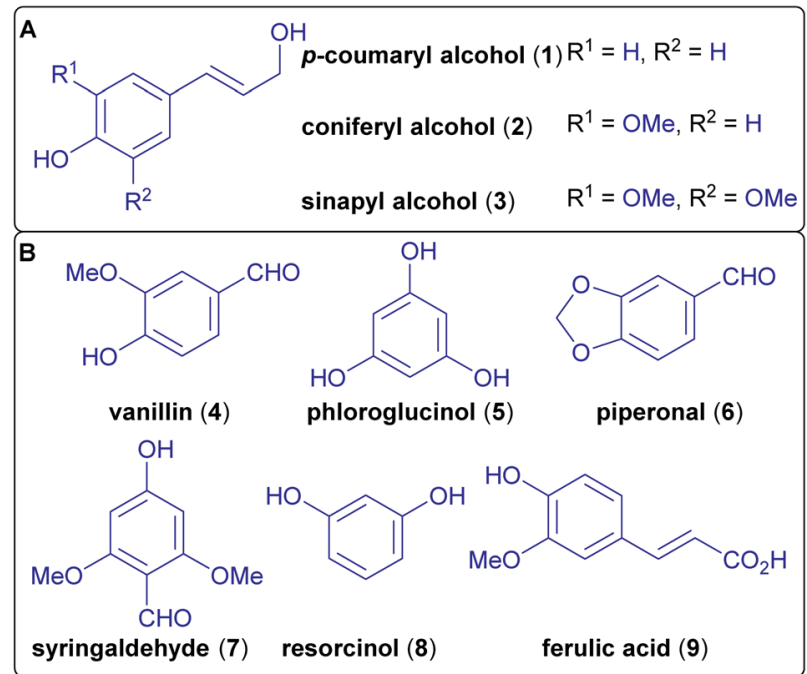

Scheme 5 (A) Biosynthetic monomers of lignin. (B) Several woodderived compounds used in natural product synthesis.

will always be available at a reasonable price for laboratory-scale applications or that the number of chemicals available from commercial suppliers cannot ever decrease. It thus makes sense that researchers are now reviving the use of natural feedstocks in organic synthesis which had moved in the background more than a century ago. Although outstanding achievements have already been made in the valorization of biomass as a chemical feedstock, the full substitution of petrochemicals is still a distant dream.

\section{Natural product syntheses using renewable feedstocks}

The main intention of the present review is the appreciation of syntheses that were performed based on renewable carbon sources and that follow some of the concepts of sustainable chemistry. The potential of those approaches is highlighted to provide inspiration to fellow researchers. In contrast to the synthesis of polymers ${ }^{89-91}$ or other functional materials, ${ }^{92-96}$ the concept of total synthesis using renewable carbon sources is not widespread. Total synthesis is already operating under very stringent conditions and the way of accomplishing the ultimate goal is often subordinated, with the application of any suitable method and effort being justified, at least in an academic setting. To compare several functioning approaches to the same target molecule, aspects like step count and overall yield are commonly applied, yet softer or less well-defined aspects such as "elegance" also play a role.

The following syntheses demonstrate that the challenge of avoiding fossil resources can be tackled at the same time. The key criterion for the inclusion of total syntheses in this review is the origin of carbon atoms and the renewability of the starting materials used. Other aspects of sustainable chemistry such as the use of benign solvents, of catalytic methods instead of stoichiometric transformations, the avoidance of protecting 
groups and critical reagents or the step efficiency will be addressed and discussed where relevant. Furthermore, we primarily selected examples where starting materials were used in a so-called "class-transcendent" fashion (i.e. the product belongs to a different class of compounds than the starting material) to demonstrate the full potential of the starting materials and the capability of combining different sources. We pay tribute to the fact that a synthesis of a saccharide from a terpene is more challenging and remarkable than a synthesis from another saccharide. In fact, (oligo)peptide, (oligo)saccharide and (oligo)nucleotide natural products will not be covered, as the transcendence criterion is not fulfilled in these cases and the natural origin of the starting materials is rather obvious. For a better visualization, we use a color coding for the carbon atoms of each moiety derived from the respective biomass resources presented herein.

Wood- (or lignin-) derived carbons are colored in blue, (hemi)cellulose-as well as carbohydrate-based moieties are shown in green, compounds obtainable from fats and oils are colored in orange, purple was chosen for chitin- and chitosanderived groups, and terpene and terpenoids are shown in red.

Heteroatoms are also colored in this code if they are introduced from the respective bio-based material. Otherwise, inserted heteroatoms will be black. These five classes of renewable starting materials were selected as they represent the most intensely investigated and used sources for starting materials to date. Starting materials of natural origin not covered by the above list specified in this review (e.g. amino acids) are also colored black. Petrochemistry-derived carbon atoms that remain in the final product will not occur in this review, but for the sake of simplicity, carbons of this kind introduced transiently will also be depicted in black.

\subsection{Wood/lignin}

A major component of lignocellulose is lignin, the largest source of aromatics on earth, as wood-derived biomass consists of up to $35 \%$ of lignin. ${ }^{97}$ Lignin is an amorphous cross-linked biopolymer that, in combination with cellulose and hemicelluloses, confers structural stability to plants. ${ }^{98}$ The complexity of its structure and its chemical stability make this biopolymer difficult to break down into useful building blocks. ${ }^{99,100}$ Nevertheless, the benefits of its use would be its carbon-neutrality and the lack of competition with food production (not considering the competition for potentially arable land). ${ }^{\mathbf{1 0 1}}$ Therefore, it is a promising alternative to petroleum resources. ${ }^{102,103}$ Lignin can be derived from wood pulp and is a waste product of paper production. It is biosynthetically derived from three phenylpropanoid monolignol monomers, differing only in their oxygenation pattern (Scheme 5).

2.1.1. Valorization of wood/lignin. Various approaches for lignin depolymerization have been developed (oxidative, reductive, pyrolysis, hydrogenolysis, deoxygenation $)^{\mathbf{9 9 , 1 0 4 - 1 0 8}}$ and these can deliver several platform chemicals such as vanillin (4) which proved useful for the synthesis of natural products (Scheme 5). ${ }^{\mathbf{1 0 9 , 1 1 0}}$

More advanced strategies for lignin valorization are the focus of ongoing research and promise to convert wood-derived

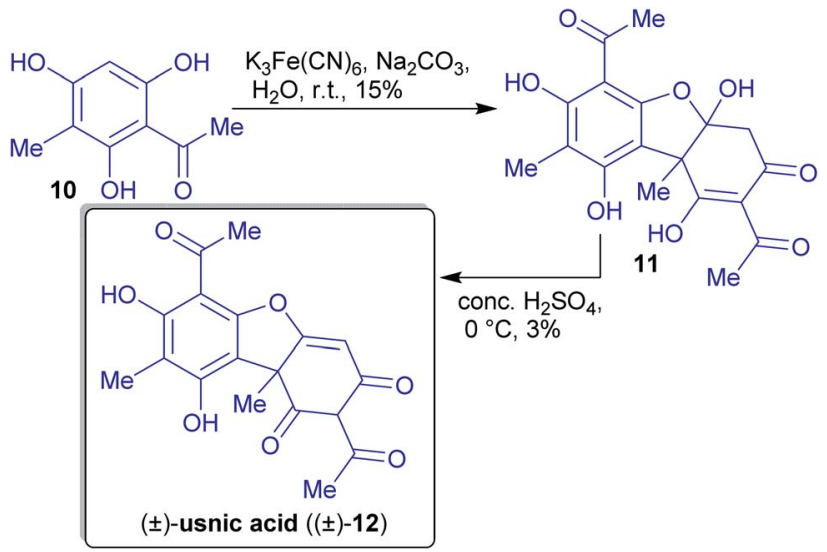

Scheme 6 Synthesis of $( \pm)$-usnic acid $(( \pm)$-12) via oxidative coupling of acetophenone moieties 10 .

industrial waste or residues from agriculture into carbonneutral, renewable building blocks. However, numerous issues such as lignin repolymerisation, low overall efficiency, structural variability and problems with product separation and purification need to be addressed. ${ }^{\mathbf{1 0 0}}$ The reader may be referred to further references on utilizing wood or lignin as the source of platform chemicals and their acquisition. ${ }^{99,100,108,111-113}$ Arduengo and Opatz have coined the term "xylochemistry" for the synthesis of organic compound exclusively from wood-derived building blocks (vide infra). ${ }^{\mathbf{1 1 0 , 1 1 4 - 1 1 6}}$

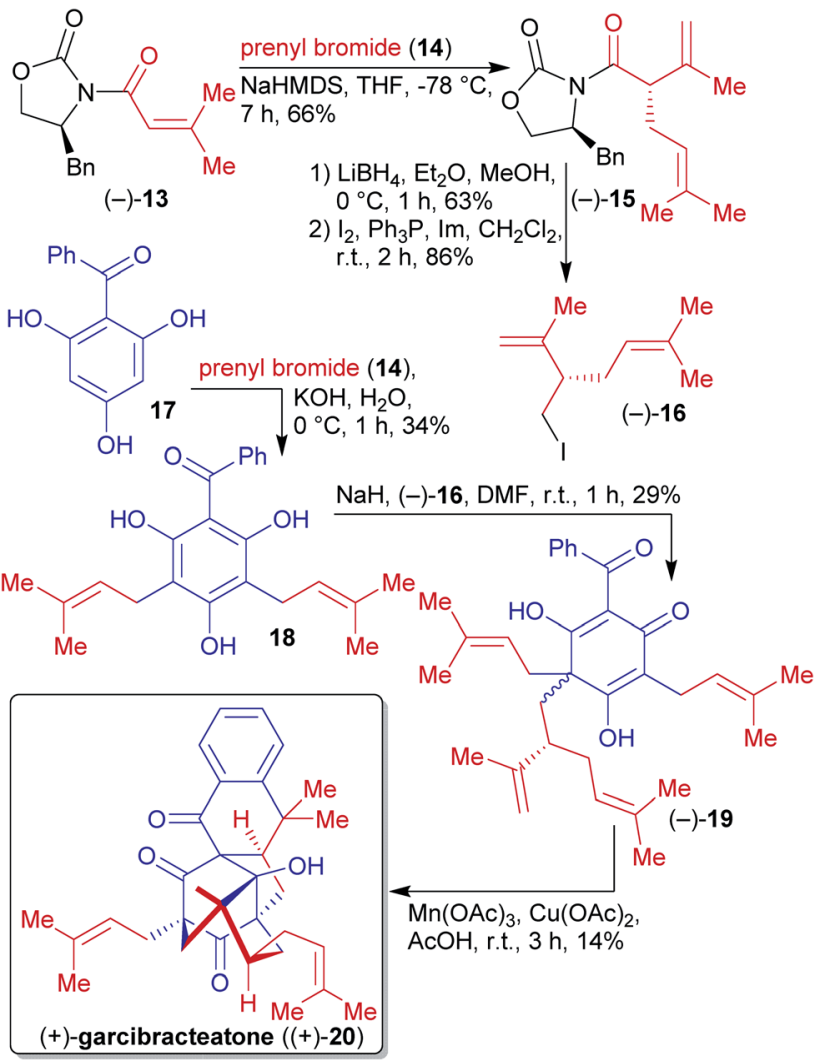

Scheme 7 Enantioselective synthesis of (+)-garcibracteatone ((+)-20) mimicking biosynthesis. 


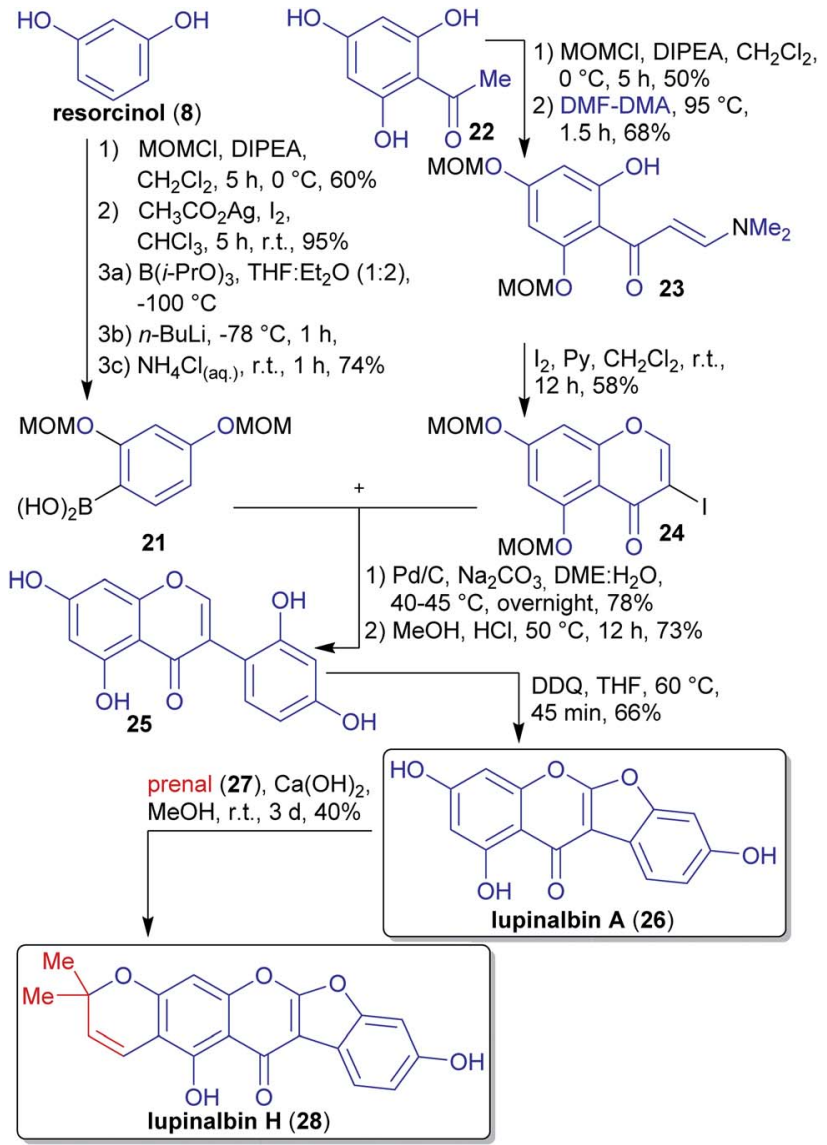

Scheme 8 Synthesis of lupinalbin $\mathrm{H}$ (28) from fragments 21 and 24 via Suzuki-Miyaura coupling.

2.1.2. Natural product syntheses using wood/lignin derived starting materials

2.1.2.1. ( \pm -Usnic acid. Barton et al. published a two-step synthesis of $( \pm)$-usnic acid $(( \pm)-12)$ by oxidative coupling of acetylated phloroglucinol 10 using potassium ferricyanide and subsequent acid-catalyzed dehydration (Scheme 6). Acetophenone 10 can be synthesized in two steps from natural phloroglucinol (5) ${ }^{\mathbf{1 1 7}}$ through Vilsmeier-Haack reaction followed by aldehyde reduction and subsequent acetylation with acetic anhydride. ${ }^{118,119}$

An advantage of this synthesis is the use of the environmentally benign solvents. Ferricyanide is a green oxidant and no carbon atom is "lost" during the synthesis (high atom economy). The reported yields are unfortunately low.

2.1.2.2. (+)-Garcibracteatone. George et al. reported the first enantioselective synthesis of the non-natural (+)-garcibracteatone $((+)-20)$ in 2014, which also allowed the determination of the absolute configuration of the naturally occuring enantiomer (Scheme 7). ${ }^{\mathbf{1 2 0 , 1 2 1}}$ Benzoylphloroglucinol (17) can be derived from natural phloroglucinol (5) and benzoic acid via Friedel-Crafts acylation. ${ }^{117,122-125}$ Phloroglucinol derivative 17 was first reacted with prenyl bromide (14), accessible from the natural product prenol, and subsequent C-alkylation with iodide (-)-16 affording the dearomatized phloroglucinol
19. ${ }^{126-128}$ Oxidative radical cyclization completed the synthesis of (+)-garcibracteatone $((+)-20)$.

$\mathrm{N}$-Acyloxazolidinone $\mathbf{1 3}$ could be prepared from biomassderived 3-methylcrotonic $\operatorname{acid}^{\mathbf{1 2 9}}$ and the phenylalaninederived Evans auxiliary. ${ }^{130}$ Subsequent $\alpha$-alkylation with prenyl bromide (14) and reduction followed by iodination delivered the enantioenriched fragment (-)-16.

The avoidance of protecting groups and the construction of a complex molecular scaffold from simple starting materials in a short route are the highlights of this sequence.

2.1.2.3. Lupinalbin $H$. The flavonoid lupinalbin $\mathrm{H}(\mathbf{2 8})$ was first isolated by Tahara et al. from the methanolic extract of the roots of yellow lupin (Lupinus luteus cv Topaz). ${ }^{131}$ Its first synthesis in 2011 by van Heerden et al. used a Suzuki-Miyaura reaction, followed by an oxidative cyclohydrogenation and a final $6 \pi$-electrocyclization (Scheme 8). ${ }^{132}$

Boronic acid 21 was prepared from resorcinol (8), which can be isolated from various plant species. ${ }^{\mathbf{1 3 3 - 1 3 5}}$ The hydroxy groups were protected and the arene regioselectively iodinated at C-5 to select the site of borylation.

The synthesis of fragment $\mathbf{2 4}$ was reported in 2010 by the same group starting from trihydroxyacetophenone $22 .{ }^{136}$ The isolation of the latter from plants has been reported. ${ }^{137,138}$ Reaction with DMF-dimethyl acetal, theoretically accessible from the wood-derived renewables $\mathrm{DMF}^{139}$ and $(\mathrm{MeO})_{2} \mathrm{SO}_{2}$ (prepared by reaction of $\mathrm{MeOH}$ with $\left.\mathrm{SO}_{3}\right),{ }^{\mathbf{1 4 0}}$ and subsequent iodination led to fragment $\mathbf{2 4 .}{ }^{\mathbf{1 4 1}}$

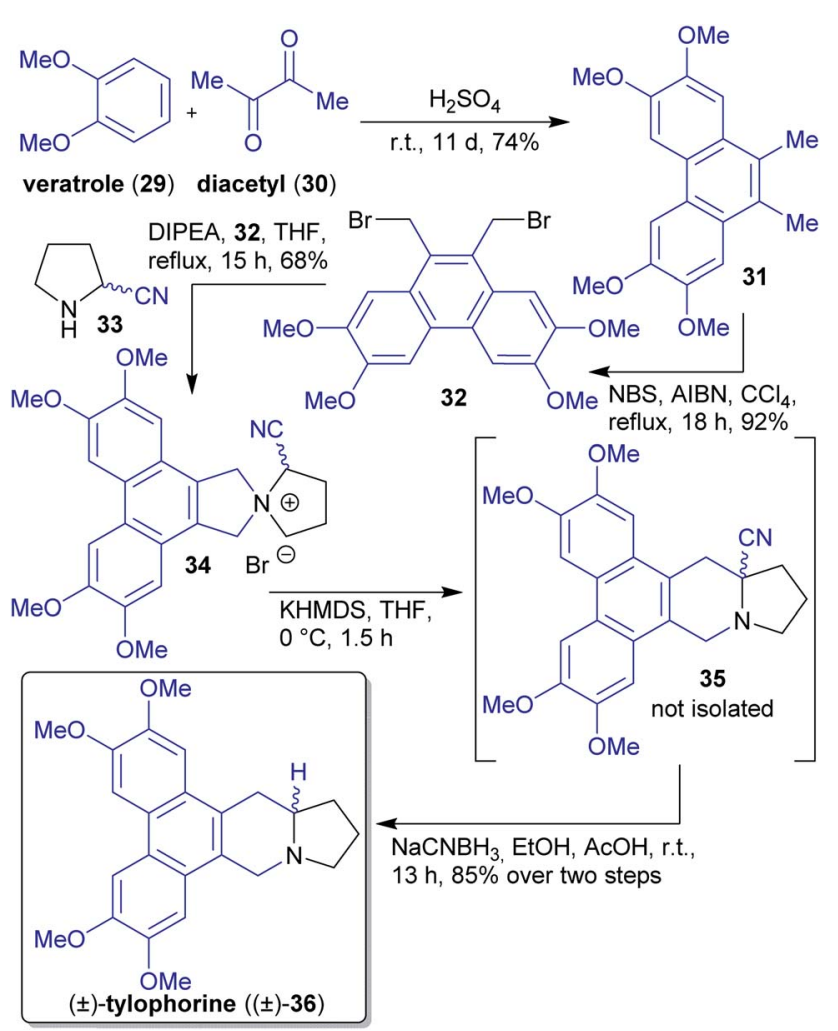

Scheme 9 Synthesis of $( \pm)$-tylophorine $(( \pm)-36)$ following xylochemical principles. 
By coupling of both precursors in the presence of a palladium catalyst, isoflavone 25 was obtained, and after deprotection, oxidation furnished lupinalbin A (26). This naturallyoccurring phytoestrogen was condensed with prenal (27) (accesible via catalytic aerobic oxidation of prenol) ${ }^{\mathbf{1 2 8 , 1 4 2}}$ to complete the synthesis of $28{ }^{\mathbf{1 4 3}}$ The authors were able to formally derive all carbon- and heteroatoms from renewable sources. The choice of solvents and reagents (e.g. DDQ) was however traditional and less compatible with the principles of green chemistry.

2.1.2.4. ( \pm -Tylophorine. Opatz et al. reported a short synthesis of the phenanthroindolizine alkaloid $( \pm)$-tylophorine $(( \pm)-36)^{\mathbf{1 4 4}}$ with a Stevens rearrangement as the key step and devoid of any protecting group manipulations (Scheme 9). ${ }^{\mathbf{1 4 5}}$ Three of five overall steps can be performed in a one-pot procedure and no chromatographic purification was required, which is in accordance with "green" principles of pollution prevention. $^{24}$

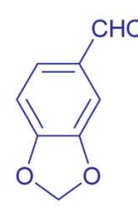

piperonal (6)
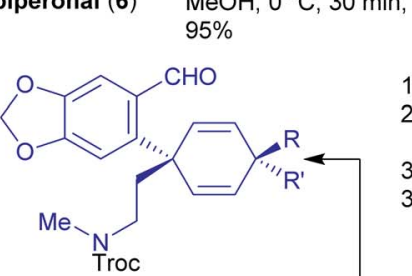

40a: $\mathrm{R}=$ OTBDPS, $\mathrm{R}^{\prime}=\mathrm{H}$ 40b: $\mathrm{R}=\mathrm{H}, \mathrm{R}^{\prime}=$ OTBDPS

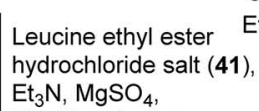
hydrochloride salt (41) $\mathrm{Et}_{3} \mathrm{~N}, \mathrm{MgSO}_{4}$ $\mathrm{CH}_{2} \mathrm{Cl}_{2}$, r.t., $3 \mathrm{~d}$

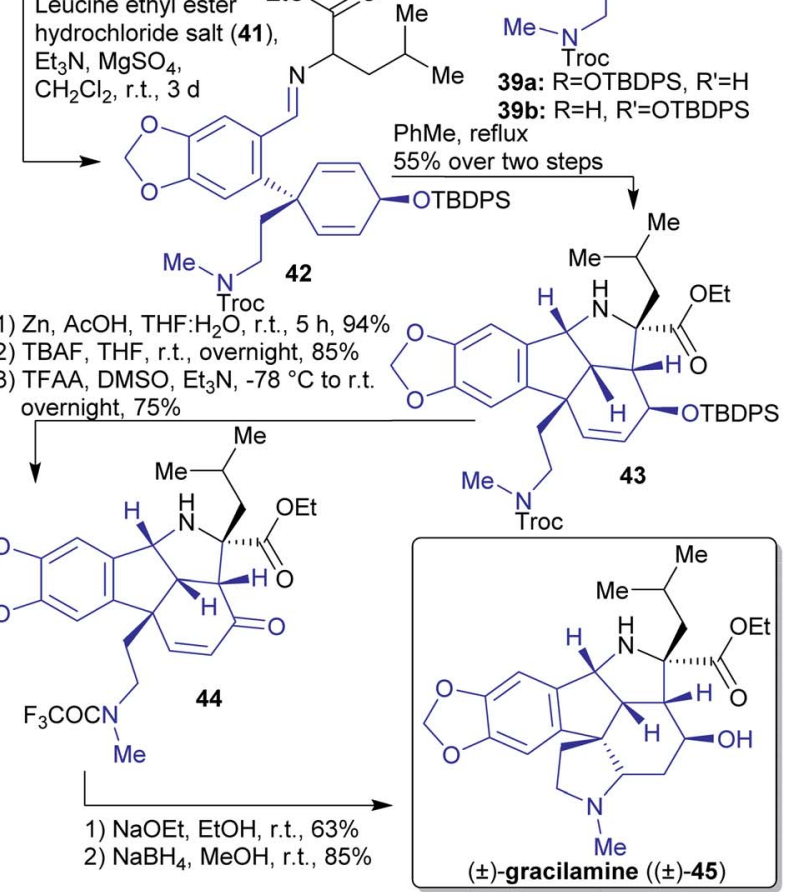
MP, $\mathrm{CH}_{2} \mathrm{Cl}_{2}$, $30 \mathrm{~min}, 95 \%$ tO 1b) $\mathrm{HCO}_{2} \mathrm{Et}$, reflux, $2 \mathrm{~d}$ quant. PIFA, TFE, 0
$30 \mathrm{~min}, 91 \%$

$\mathrm{NaBH}_{4}, \mathrm{CeCl}_{3} \cdot 7 \mathrm{H}_{2} \mathrm{O}$ $\mathrm{MeOH}, 0^{\circ} \mathrm{C}, 30 \mathrm{~min}$

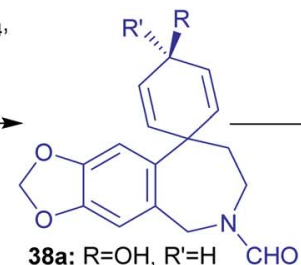

38a: $\mathrm{R}=\mathrm{OH}, \mathrm{R}^{\prime}=\mathrm{H}$ 1) $\mathrm{LiAlH}_{4}, \mathrm{THF}, 0^{\circ} \mathrm{C}, 8 \mathrm{~h}, 94 \%$

2) TBDPSCI, Im, DMAP, $\mathrm{CH}_{2} \mathrm{Cl}_{2}$, r.t., 48 h, $98 \%$

3a) $\mathrm{TrocCl}_{2} \mathrm{Et}_{3} \mathrm{~N}, \mathrm{CH}_{2} \mathrm{Cl}_{2}$, r.t. 3b) $\mathrm{AgNO}_{3}, \mathrm{Me}_{2} \mathrm{CO}: \mathrm{H}_{2} \mathrm{O}$, r.t. $66 \%$

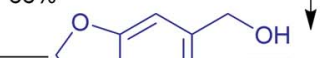

Scheme 10 Synthesis of $( \pm)$-gracilamine $(( \pm)-45)$ from piperonal (6).
Starting materials veratrole (29) and diacetyl (30) can be obtained from biomass ${ }^{\mathbf{1 4 6 , 1 4 7}}$ and were subjected to an acid catalyzed reaction furnishing phenanthrene derivative 31, which was brominated under free radical conditions. Reaction with $\alpha$-amino nitrile 33 afforded spirocyclic compound 34, which underwent a Stevens rearrangement to furnish natural $( \pm)$-tylophorine $(( \pm)-36)$ after reduction with $\mathrm{NaCNBH}_{3} \cdot{ }^{145}$

The $\alpha$-amino nitrile 33 was synthesized from pyrrolidine and sodium cyanide, the former can be derived from proline e.g. via a Pd-catalyzed decarboxylation reaction. ${ }^{\mathbf{1 4 5 , 1 4 8}}$

Drawbacks of the route are the use of toxic solvents and reagents, which are to be avoided according to "green" principles. It should be noted that natural tylophorine is almost racemic. ${ }^{149}$

2.1.2.5. ( \pm )-Gracilamine. The natural product $( \pm)$-gracilamine $(( \pm)-\mathbf{4 5})$ was isolated in $2005^{\mathbf{1 5 0}}$ and its first synthesis was reported in 2012 by $\mathrm{Ma}$ et al. $^{\mathbf{1 5 1}}$

The key step in the formation of spirocyclic intermediates 38a and 38b was an intramolecular oxidative phenol coupling (Scheme 10). ${ }^{152}$ The starting materials for this reaction, piperonal (6) and tyramine (37), can be obtained from renewable sources. ${ }^{153-155}$ Reduction of spirocyclic compound 38a and 38b with $\mathrm{LiAlH}_{4}$ followed by protection with TBDPSCl, ring opening using TrocCl gave benzyl alcohols 39a and 39b after treating with $\mathrm{AgNO}_{3}$ in the presence of $\mathrm{H}_{2} \mathrm{O}$.

Alcohols 39a and 39b were oxidized to aldehydes 40a and 40b. Through the condensation reaction of aldehyde 40a and leucine ethyl ester (41), imine 42 was formed, which reacted in a [3+2]cycloaddition with the corresponding azomethine ylide under formation of the natural product scaffold $\mathbf{4 3}$ containing all of the carbon atoms required. The final product 45 was obtained by deprotection, cyclization and reduction using $\mathrm{NaBH}_{4} \cdot{ }^{151}$

In this synthesis, all carbon- and hetero atoms can be obtained from renewable sources.

2.1.2.6. Cochinchinenone. The first total synthesis of the natural product cochinchinenone $(\mathbf{4 8})^{156}$ in only five steps and $58 \%$ overall yield was reported from Carreño et al. ${ }^{157}$ The synthesis

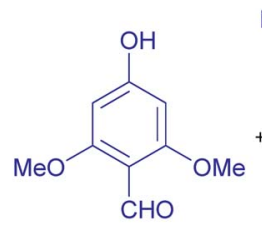

syringaldehyde (7)

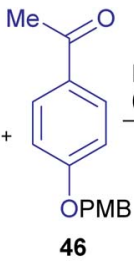

DIPEA, TMSOTf, $\mathrm{CH}_{2} \mathrm{Cl}_{2}$ $0{ }^{\circ} \mathrm{C}$ to r.t., overnight, $78 \%$

6

1) $\mathrm{H}_{2}, \mathrm{Pd} / \mathrm{C}, \mathrm{THF}$, r.t., $20 \mathrm{~h}$, quant 2a) oxone, $\mathrm{KOH}, \mathrm{H}_{2} \mathrm{O}: \mathrm{MeCN}$, r.t., $30 \mathrm{~min}$ 2b) $\mathrm{Na}_{2} \mathrm{~S}_{2} \mathrm{O}_{3}, 15 \mathrm{~min}, 96 \%$

3) TFA, anisole, $\mathrm{CH}_{2} \mathrm{Cl}_{2}$, r.t., $1 \mathrm{~h}, 78 \%$

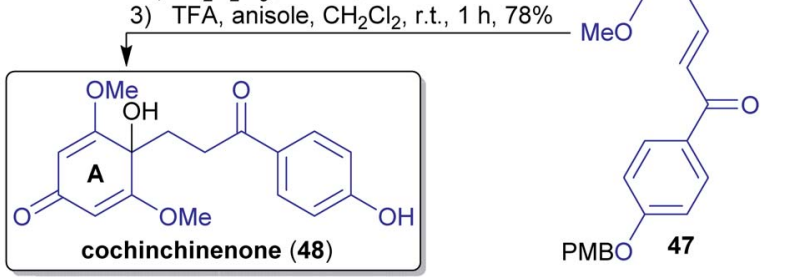

Scheme 11 Concise and first synthesis of cochinchinenone (48) based on lignin derived starting materials. 
commenced with the Mukaiyama aldol condensation of syringaldehyde (7) with PMB-protected 4-hydroxy-acetophenone (46), both derivable from lignin (Scheme 11). ${ }^{158,159}$ To obtain chalcone 48 with a $p$-quinol moiety in ring A, the corresponding ketone 47 was dearomatized oxidatively. To this end, the choice of the right protective group was crucial since derivatives such as OMOM, OTBDMS, OTBDPS, OTHP, and OBn led to negative results during the synthesis. Furthermore, the dearomatization did not proceed with a free $\mathrm{OH}$-group because of a competing Baeyer-Villiger reaction taking place instead. ${ }^{157}$ Only a single protective group is required and there is no loss of carbon atoms throughout the synthesis.

2.1.2.7. Taiwaniaquinones and taiwaniaquinols. The total synthesis of the racemic taiwaniaquinoids was reported by $\mathrm{Li}$ et al. in $2013 .^{160}$

The synthesis commenced with the preparation of common intermediate $\mathbf{5 4}$ with a an trans $\mathrm{A} / \mathrm{B}$ ring junction on a gram scale (Scheme 12). 1,2,4-Trimethoxybenzene is available from renewable resources and can be transformed into benzaldehyde 49 in several steps. ${ }^{161,162}$ This was then subjected to a Wittig olefination, followed by a Pd-catalyzed Suzuki-Miyaura coupling with iododiene $\mathbf{5 1}$ to afford diene 52. Through a $\mathrm{Bi}(\mathrm{OTf})_{3}$-catalyzed cationic cyclization and a Wolff-type ring contraction as the key steps, intermediate $\mathbf{5 4}$ was obtained. From there on, the natural products taiwaniaquinones A (57)

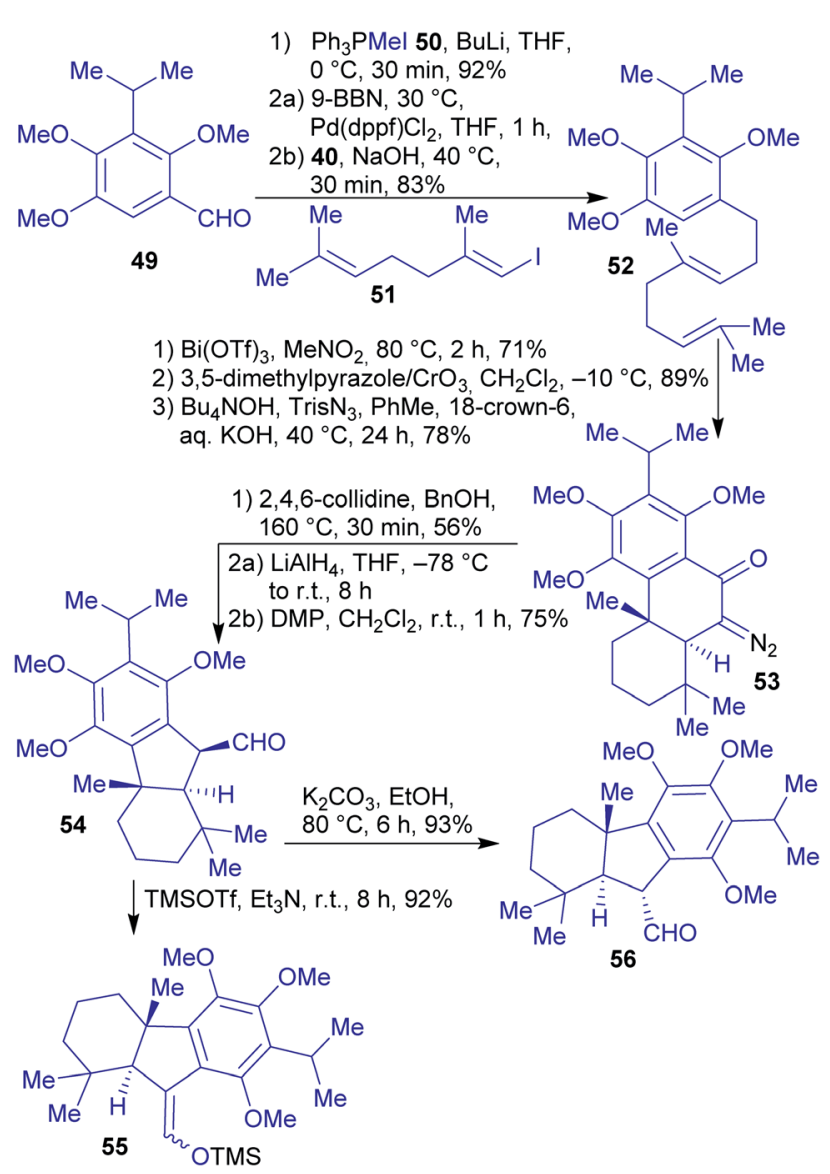

Scheme 12 Synthesis of intermediate 54 and subsequent intermediates for the synthesis of taiwaniaquinones and taiwaniaquinols, accessible via a Wolff-type ring contraction.

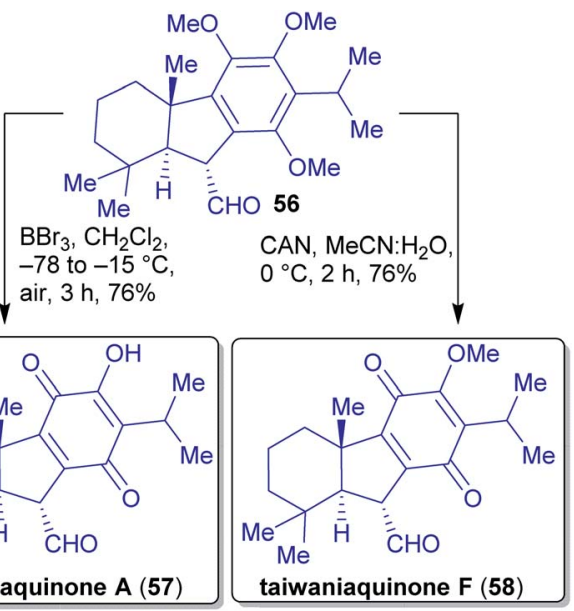

Scheme 13 Closing synthesis of taiwaniaquinone A (57) and $F(58)$.

and $\mathrm{F}$ (58), and taiwaniaquinols B (59) and D (60) were prepared in 2-3 steps in racemic form. ${ }^{\mathbf{1 6 0}}$

Quinones A 57 and F 58 were accessed by epimerization of aldehyde 54 followed by oxidation (taiwaniaquinone $\mathrm{F}(\mathbf{5 8})$ ) or by oxidation and $O$-demethylation (taiwaniaquinone A (57), Scheme 13).

Quinols B 59 and D 60 were obtained from the silyl enol ether derived from intermediate 54. Via a sequence of Saegusa-Ito oxidation, demethylation and oxidation, quinol D 60 was furnished. Subjecting the silyl enol ether of $\mathbf{5 4}$ to dihydroxylation conditions, a demethylation and an oxidation reaction led to quinol B 59 (Scheme 14).

All four natural products synthesized occur in the same plant species. ${ }^{163}$

Methylenetriphenylphosphorane (50) was prepared from triphenylphosphine and iodomethane, ${ }^{\mathbf{1 6 4}}$ available from methanol (wood spirit) and HI. ${ }^{165}$

Iododiene $\mathbf{5 1}$ can be prepared in three steps from 6methylhept-5-en-2-one, which can be isolated from several plant species. ${ }^{166,167}$

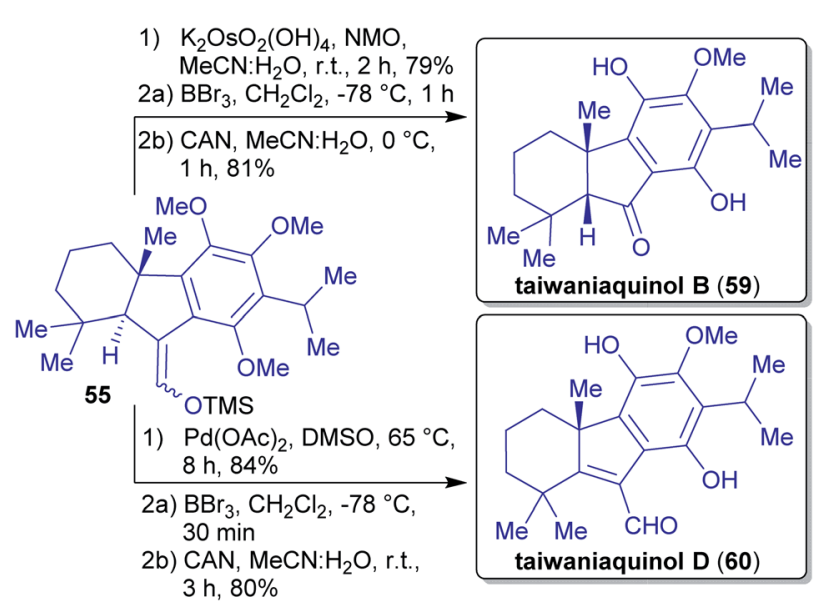

Scheme 14 Closing synthesis of taiwaniaquinol B (59) and D (60). 


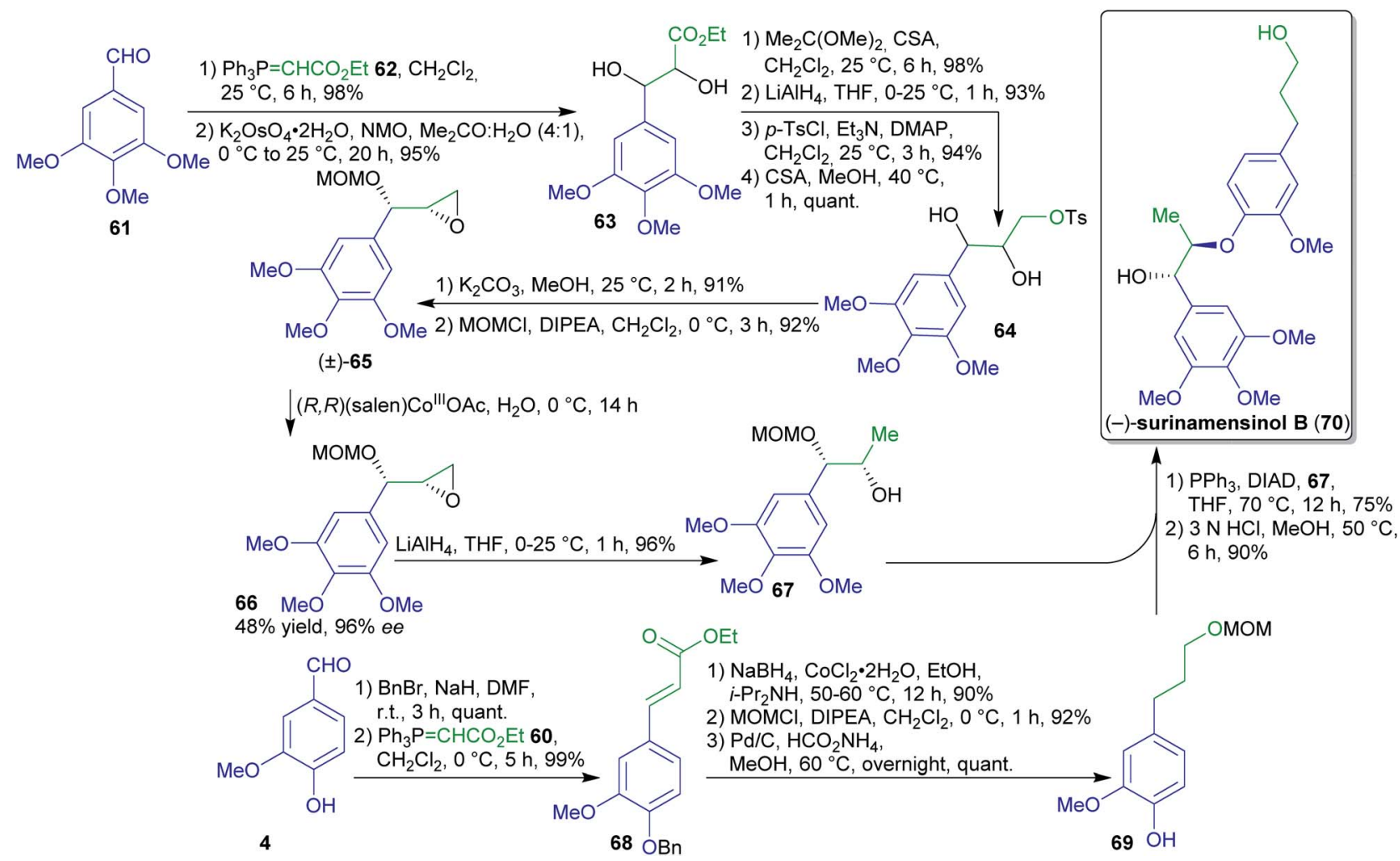

Scheme 15 First enantioselective synthesis of surinamensinol B (70). CSA = camphor-10-sulfonic acid.

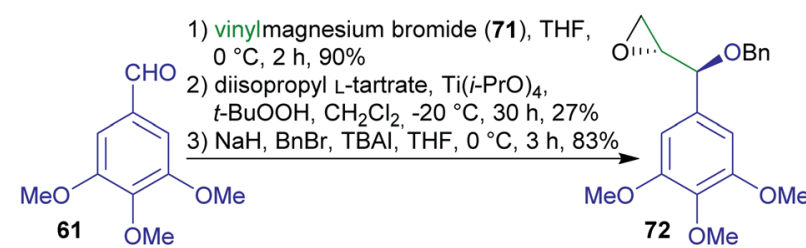

1) 2-propyl-1,3-dithiane (73), t-BuLi, HF/HMPA, $-20{ }^{\circ} \mathrm{C}$ to r.t., $1 \mathrm{~h}, 76 \%$

2) $\mathrm{I}_{2}, \mathrm{CaCO}_{3}, \mathrm{THF}: \mathrm{H}_{2} \mathrm{O}, 0^{\circ} \mathrm{C}, 30 \mathrm{~min}, 80 \%$

3) $\mathrm{Me}_{4} \mathrm{NBH}(\mathrm{OAc})_{3}, \mathrm{MeCN}: \mathrm{AcOH}$,

$-30^{\circ} \mathrm{C}, 12 \mathrm{~h}, 91 \%$

4) $\mathrm{Pd} / \mathrm{C}, \mathrm{H}_{2}$ (1 atm), $\mathrm{MeOH}$, r.t., $8 \mathrm{~h}, 95 \%$

1a) $\mathrm{H}_{3} \mathrm{CCH}(\mathrm{OMe})_{3}$, PPTS, $\mathrm{CH}_{2} \mathrm{Cl}_{2}$, r.t., 15 min $\mathrm{MeO}$

1b) $\mathrm{BF}_{3} \cdot \mathrm{OEt}_{2}, 0^{\circ} \mathrm{C}, 85 \%$

2) $\mathrm{K}_{2} \mathrm{CO}_{3}, \mathrm{MeOH}$, r.t., $1 \mathrm{~h}, 100 \%$

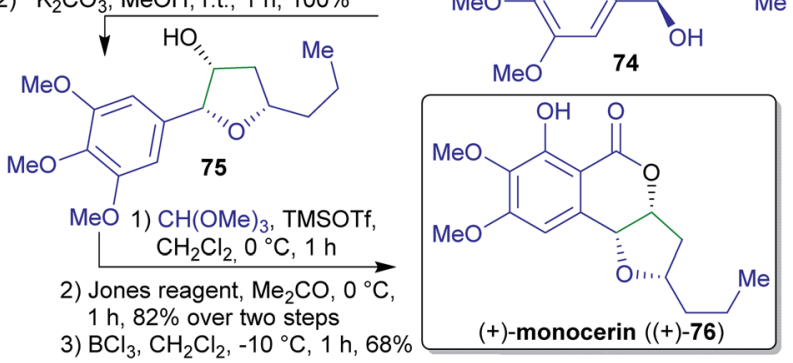

Scheme 16 Synthesis of $(+)$-monocerin ((+)-76) from the renewable starting material trimethoxybenzaldehyde 61 .

2.1.2.8. (-)-Surinamensinol $B$. The first enantioselective synthesis of (-)-surinamensinol B ((-)-70) was achieved by Sudalai et al. in 2015. ${ }^{184}$
Enantiopure fragment $\mathbf{6 7}$ could be prepared in several steps from 61 (Scheme 15). ${ }^{173}$ Diol 63 was obtained by Wittig olefination, dihydroxylation, reduction and subsequent tosylation afforded compound 64. After epoxidation and O-protection, compound $( \pm)$-65 was subjected to a hydrolytic kinetic resolution using a cobalt catalyst to obtain enantiopure syn-epoxide $\mathbf{6 6}$ in $96 \%$ ee. A regioselective reductive ring-opening led to fragment 67.

The synthesis of the natural product surinamensinol $\mathrm{B}$ (70) $)^{\mathbf{1 8 5}}$ commenced with $O$-benzylation of vanillin (4) followed by Wittig olefination and reduction to arylpropanol 69 . The latter was coupled with fragment 67 and the natural product 70 was obtained after acid-catalyzed deprotection. ${ }^{\mathbf{1 8 4}}$

The Wittig phosphonium ylide 62 employed twice in this sequence can be prepared from $\mathrm{PPh}_{3}$ and ethyl bromoacetate accessible from acetic acid or malonic acid via bromination ${ }^{\mathbf{1 8 6}}$ and subsequent esterification. ${ }^{187}$ While the synthesis of $\mathrm{PPh}_{3}$ from biomass should be feasible but likely is lengthier than the classical petrochemical approach, the recycling from the oxide through the dichloride is well-known. ${ }^{188}$

While "green" solvents are employed in several places, the extensive use of protecting groups and the hydrolytic kinetic resolution step with a maximum yield of $50 \%$ are less favorable.

2.1.2.9. (+)-Monocerin. A concise asymmetric total synthesis of (+)-monocerin ((+)-76) was achieved by the group of She et al. via a Lewis acid-mediated stereoselective cyclization reaction (Scheme 16). ${ }^{168}$ The synthesis commenced with the conversion of 3,4,5-trimethoxybenzaldehyde (61) into an allylic alcohol. Enantioselective epoxidation followed by O-protection afforded 
compound 72. ${ }^{169}$ This was reacted with lithiated dithiane 73, followed by reduction and deprotection to furnish triol $\mathbf{7 4}$.

2-Propyl-1,3-dithiane (73) is accessible via a condensation between potentially renewable butyraldehyde (1-butanol is a common fermentation product), ${ }^{170}$ and 1,3-propanedithiol. ${ }^{171}$ The synthesis was concluded by a Lewis acid-mediated cyclization reaction, followed by an oxa-Pictet-Spengler reaction, Jones oxidation and chelate-controlled regioselective $O$-demethylation affording the natural product $(+)$-monocerin $((+)-76) .{ }^{172}$

3,4,5-Trimethoxybenzaldehyde (61) is accesible from a renewable source. ${ }^{173}$ Vinylmagnesium bromide (71) can be synthesized in two steps from acrylic acid, ${ }^{174-176}$ derivable from lactic acid. ${ }^{177-181}$ Reaction of sodium methanolate with $\mathrm{CHCl}_{3}$ in the presence of DMF leads to trimethyl orthoformate. ${ }^{\mathbf{1 8 2}}$ The

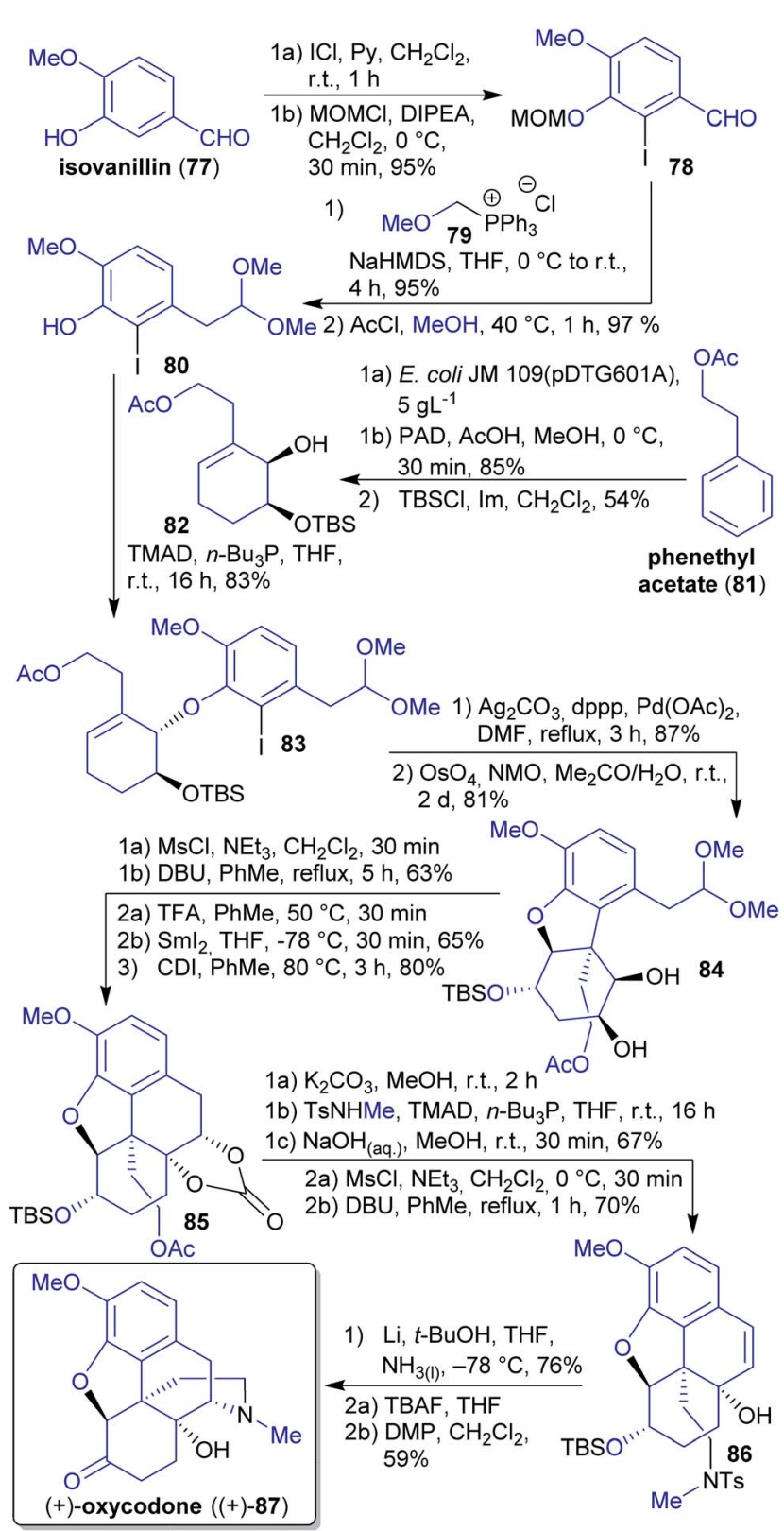

Scheme 17 Synthesis of (+)-oxycodone ((+)-87) from phenethyl acetate (81) and isovanillin (77). PAD = potassium azodicarboxylate. required chloroform can e.g. be prepared by chlorination of biogenic methane or via reaction of methanol with $\mathrm{FeCl}_{3}$ but its general avoidance would be desirable. ${ }^{183}$ Considering "green" chemistry, particularly the use of toxic reagents (Jones reagent, $\mathrm{HF} / \mathrm{HMPA}, \mathrm{BCl}_{3}$ ) appears problematic.

2.1.2.10. (+)-Oxycodone. In 2019, Hudlicky et al. reported a synthesis of (+)-oxycodone ((+)-87), the non-natural enantiomer of this opioid. ${ }^{189}$ Its natural antipode ${ }^{190}$ is widely applied in pain management. ${ }^{191}$ The synthesis commenced with the microbial dihydroxylation of phenethyl acetate (81) (available through fermentation of corn, barley and sweet molasses), ${ }^{192}$ selective hydrogenation of the less hindered $\mathrm{C}=\mathrm{C}$-double bond and a Mitsunobu reaction with iodophenol 80 (Scheme 17). The latter compound can be derived from natural isovanillin (77) via iodination, ${ }^{193}$ Wittig olefination with (methoxymethyl)triphenylphosphonium chloride (79) and reaction with methanolic HCl. ${ }^{194}$ Wittig salt 79 is theoretically accessible from the reaction of formaldehyde with $\mathrm{MeOH}$ and $\mathrm{HCl}$, affording

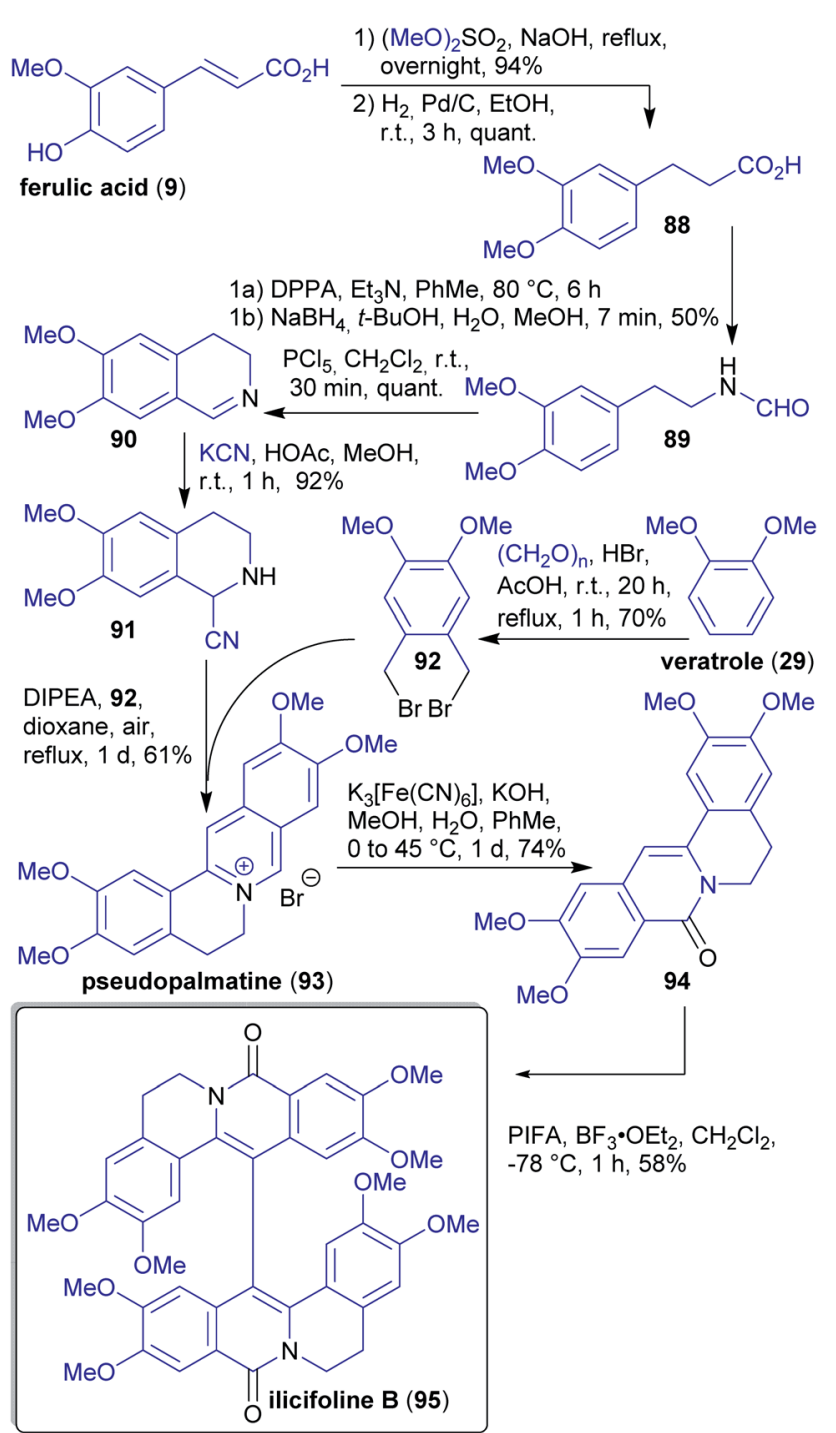

Scheme 18 Synthesis of ilicifoline B (95) from wood derived starting materials 9 and 29 . 

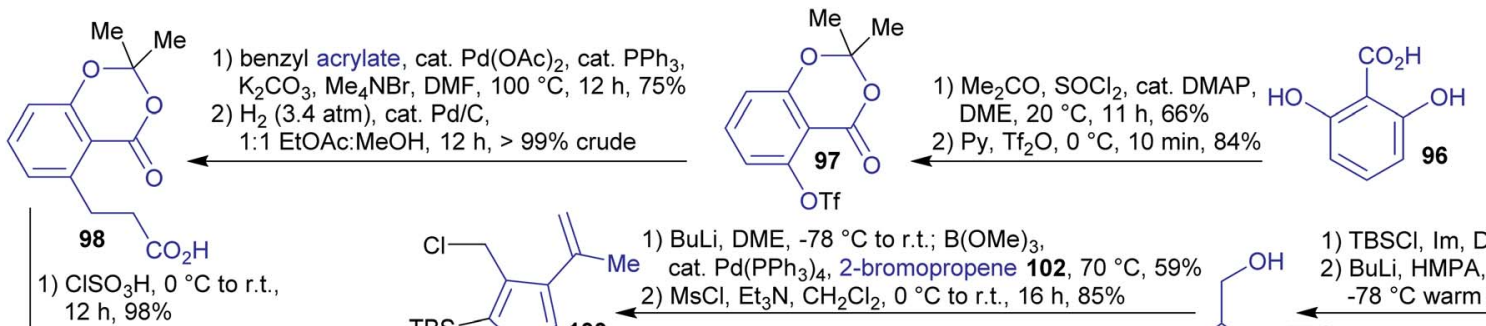

2) $(\mathrm{PhS})_{2}, \mathrm{Bu}_{3} \mathrm{P}, \mathrm{CH}_{2} \mathrm{Cl}_{2}$

$1.5 \mathrm{~h}, 81 \%$

$\begin{array}{ll}\text { 3) } \mathrm{Py}, \mathrm{Tf}_{2} \mathrm{O}, \mathrm{CH}_{2} \mathrm{Cl}_{2}, & \text { 1) allylMgCl } 104, \mathrm{THF} \text {, reflux, } 14 \mathrm{~h}, 98 \% \\ 0{ }^{\circ} \mathrm{C} \text { to r.t., } 2 \mathrm{~h}, 84 \% & \text { 2) }\end{array}$

2) cat. Grubbs II, $\mathrm{CH}_{2} \mathrm{Cl}_{2}$, reflux, $6 \mathrm{~h}, 99 \%$

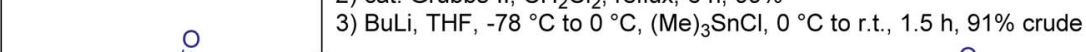<smiles>CCOc1ccc2c(c1C(=O)S)CCC2=O</smiles>

$\checkmark$

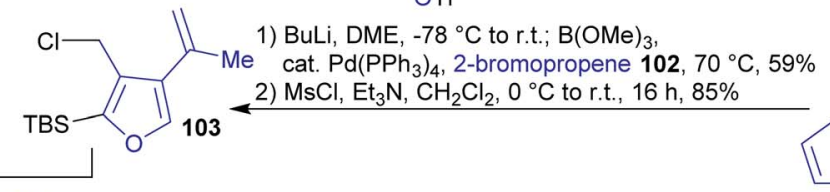

1) $\mathrm{TBSCl}, \mathrm{Im}, \mathrm{DMF}$, r.t., $95 \%$

2) BuLi, HMPA, THF

$-78^{\circ} \mathrm{C}$ warm to r.t., $87 \%$
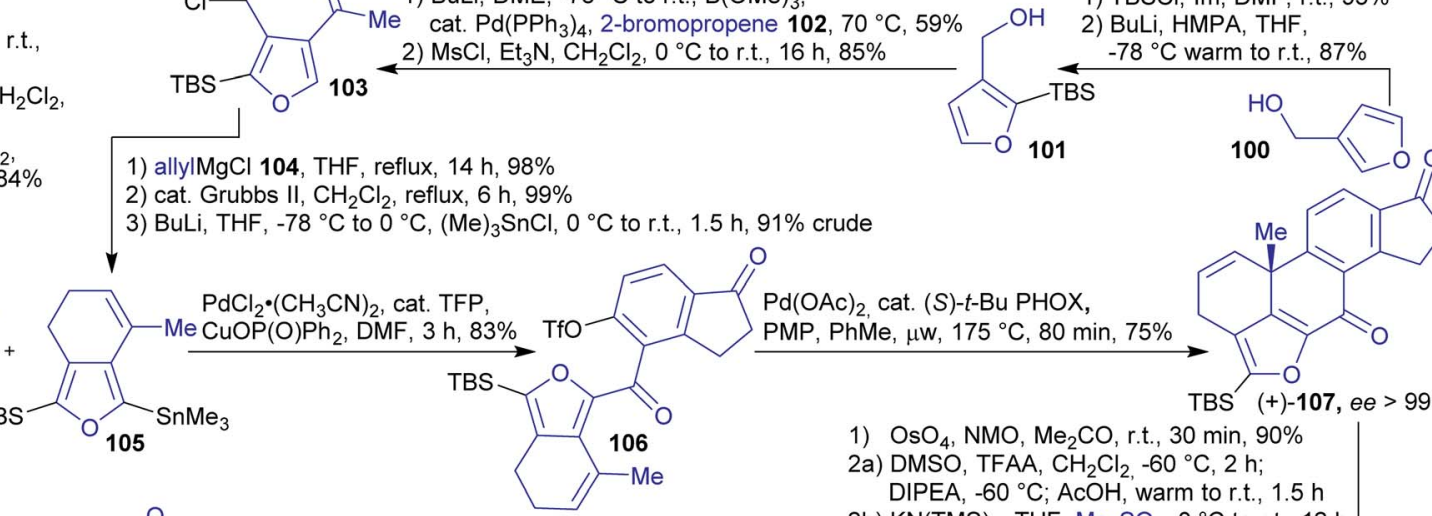

$\mathrm{Pd}$

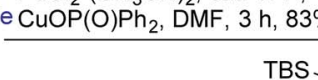

$\mathrm{Pd}(\mathrm{OAc})_{2}$, cat. (S)-t-Bu PHOX, PMP, PhMe, $\mu \mathrm{w}, 175^{\circ} \mathrm{C}, 80 \mathrm{~min}, 75 \%$<smiles>CSc1ccc([AsH2])o1</smiles>

TBS Me, $\mu \mathrm{w}, 175^{\circ} \mathrm{C}, 80 \mathrm{~min}, 75 \%$

TBS $(+)-107$

1) $\mathrm{OsO}_{4}, \mathrm{NMO}, \mathrm{Me}_{2} \mathrm{CO}$, r.t., $30 \mathrm{~min}, 90 \%$

2a) DMSO, TFAA, $\mathrm{CH}_{2} \mathrm{Cl}_{2},-60^{\circ} \mathrm{C}, 2 \mathrm{~h}$; DIPEA, $-60^{\circ} \mathrm{C} ; \mathrm{AcOH}$, warm to r.t., $1.5 \mathrm{~h}$<smiles></smiles>

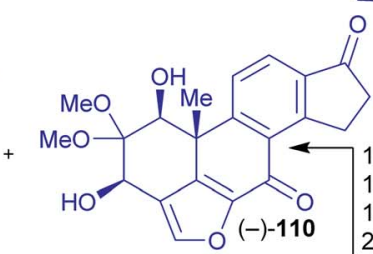
il 2b) $\mathrm{KN}(\mathrm{TMS})_{2}, \mathrm{THF} ; \mathrm{Me}_{2} \mathrm{SO}_{4}, 0{ }^{\circ} \mathrm{C}$ to r.t., $12 \mathrm{~h}$, $64 \%$

3) TFA: $\mathrm{MeNO}_{2}$, r.t., $36 \mathrm{~h}, 91 \%$

1a) TBSOTf, 2,6-lutidine, $\mathrm{CH}_{2} \mathrm{Cl}_{2},-30{ }^{\circ} \mathrm{C}, 20 \mathrm{~min}$ 1b) $\mathrm{BH}_{3} \cdot \mathrm{THF},-30^{\circ} \mathrm{C}, 4 \mathrm{~h}$

1) $\mathrm{TMSOTf}, \mathrm{Et}_{3} \mathrm{SiH}$

A $\mathrm{CH}_{2} \mathrm{Cl}_{2},-30^{\circ} \mathrm{C}, 15 \mathrm{~min}$ $43 \%$

2) $\mathrm{AcOOH}, \mathrm{CH}_{3} \mathrm{OH}, 53 \%, 9 \mathrm{~h}, \mathrm{dr}=1: 2(-)-110:(+)-109$

2) TEMPO, PIDA,

$\mathrm{CH}_{2} \mathrm{Cl}_{2}$, r.t., $10 \mathrm{~h}, 48 \%$

1a) TMSOTf, $\mathrm{BH}_{3} \cdot \mathrm{SMe}_{2}$, $\mathrm{CH}_{2} \mathrm{Cl}_{2},-35^{\circ} \mathrm{C}, 20 \mathrm{~min}$

1b) $\mathrm{Py}, \mathrm{AcOH},-35^{\circ} \mathrm{C}, 10 \mathrm{~min}$

1c) $\mathrm{Et}_{3} \mathrm{~N} \cdot 3 \mathrm{HF}$, r.t., $70 \mathrm{~min}, 49 \%$<smiles>CO[C@H]1C(=O)c2coc3c2[C@@](C)(c2ccc4c(c2C3=O)CCC4=O)[C@@H](O)[C@@H]1I</smiles>
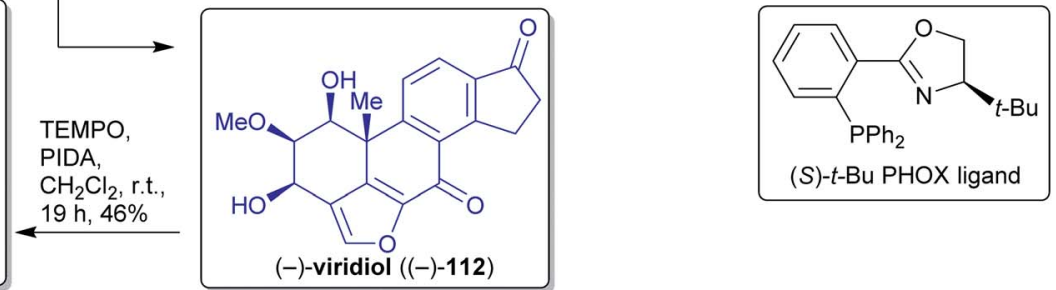

Scheme 19 First enantioselective synthesis of $(-)$-viridin $((-)-111)$ and $(-)$-viridiol $((-)-112)$.

chloromethyl methyl ether, ${ }^{195}$ and subsequent reaction with $\mathrm{PPh}_{3}{ }^{196}$ Intramolecular Heck reaction of ether 83 followed by dihydroxylation furnished diol 84. Through mesylation and DBU-catalyzed elimination, a ketone was obtained. Subsequent pinacol-type coupling with deprotected aldehyde and protection yielded carbonate 85. Methanolysis of the acetate followed by Mitsunobu coupling, carbonate hydrolysis and two-step dehydration led to tosylamide 86. The synthesis was completed via Parker radical amination and oxidation of deprotected alcohol yielding (+)-oxycodone $((+)-87) .{ }^{189}$ Tosylmethylamine can be prepared from methanol and tosylamide ${ }^{197}$ (product of toluenederived $\mathrm{TsCl}$ with sodium cyanate or ammonia). ${ }^{198,199}$

The authors could have derived all carbon atoms in the product from renewable resources. The use of a highly stereoselective microbial dihydroxylation and of several "green" solvents $\left(\mathrm{MeOH}, \mathrm{Me}_{2} \mathrm{CO}, \mathrm{H}_{2} \mathrm{O}\right)$ are an advantage, yet toxic reagents and the use of non-green protecting groups had to be included.
2.1.2.11. Ilicifoline B. Opatz et al. reported the first total synthesis of the dimeric protoberberine-type alkaloid ilicifoline B (95) in 2015. ${ }^{114}$

The synthesis of $\mathbf{9 5}{ }^{\mathbf{2 0 0}}$ commenced with methylation and hydrogenation of the wood-derivable natural product ferulic acid (9), ${ }^{201}$ followed by a Bischler-Napieralski cyclization and addition of in situ generated $\mathrm{HCN}^{202}$ to furnish $\alpha$-amino nitrile 91 (Scheme 18). In a cascade reaction with dibromide 92, berberine alkaloid pseudopalmatine (93) is formed, subsequent oxidation and dimerization furnished alkaloid ilicifoline B (95). ${ }^{114}$ Dibromide 92 is accessible from veratrole (29), a pyrolysis product of wood. ${ }^{203}$ Formaldehyde and dimethyl sulfate can be obtained from methanol. ${ }^{140,204}$

The authors used entirely wood-derivable building blocks, so-called xylochemicals, instead of conventional petrochemicals for the construction of the natural product carbon scaffold. In the light of "green" chemistry, the use of a non-toxic cyanide source and solvents like toluene, $\mathrm{MeOH}, \mathrm{H}_{2} \mathrm{O}$ or EtOH is 


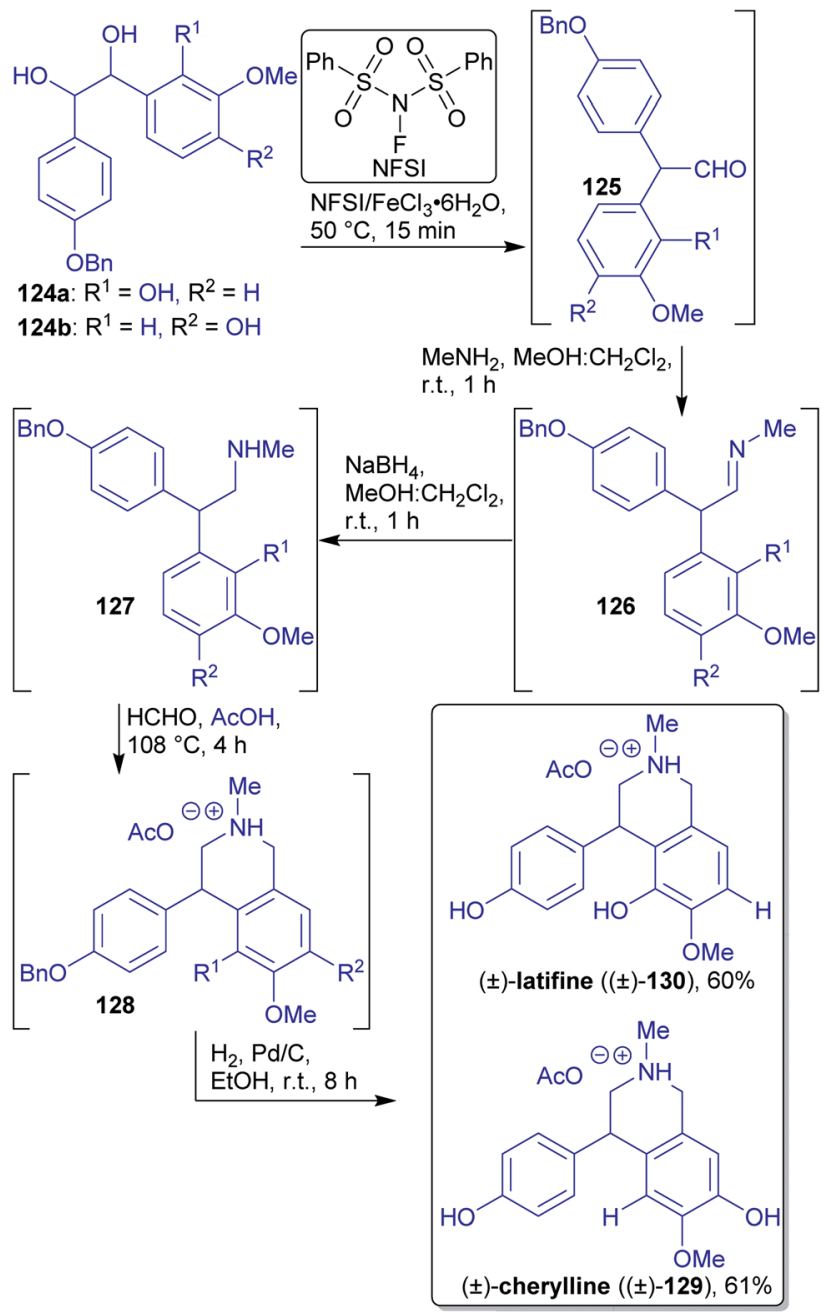

Scheme 20 One-pot synthesis of $( \pm)$-latifine $(( \pm)-130)$ and $( \pm)$-cherylline $(( \pm)-129)$ utilizing a catalyzed, solvent free pinacol rearrangement.

positive, yet undesired solvents like dioxane, $\mathrm{CH}_{2} \mathrm{Cl}_{2}$ should generally be avoided.

2.1.2.12. (-)-Viridin and (-)-viridiol. In 2017, Guerrero et al. reported the first enantioselective synthesis of the natural products (-)-viridin ((-)-111) and (-)-viridiol ((-)-112). ${ }^{\mathbf{2 0 5 - 2 0 7}}$

The authors pursued the convergent approach of coupling two achiral fragments and employing an enantioselective intramolecular Heck reaction to set the absolute stereochemical configuration of an all-carbon quaternary stereocenter in the synthesis of 111 and 112..$^{205-207}$ Indanone 99 was synthesized starting from plant-derivable 2,6-dihydroxybenzoic acid (96) ${ }^{208}$ by protection of all hydroxy groups, ${ }^{209,210}$ Heck alkenylation and subsequent hydrogenation furnishing dihydrocinnamic acid 98 (Scheme 19). This intermediate is converted into indanone 99 in three steps.

The starting material 3-hydroxymethylfuran (100) for the synthesis of the second fragment can be obtained by reduction of naturally occurring 3-furoic acid. ${ }^{211,212}$ Subsequent silylation, reaction with 2-bromopropene (102) and chlorination led to compound 103. 2-Bromopropene (87) is accessible from wood-

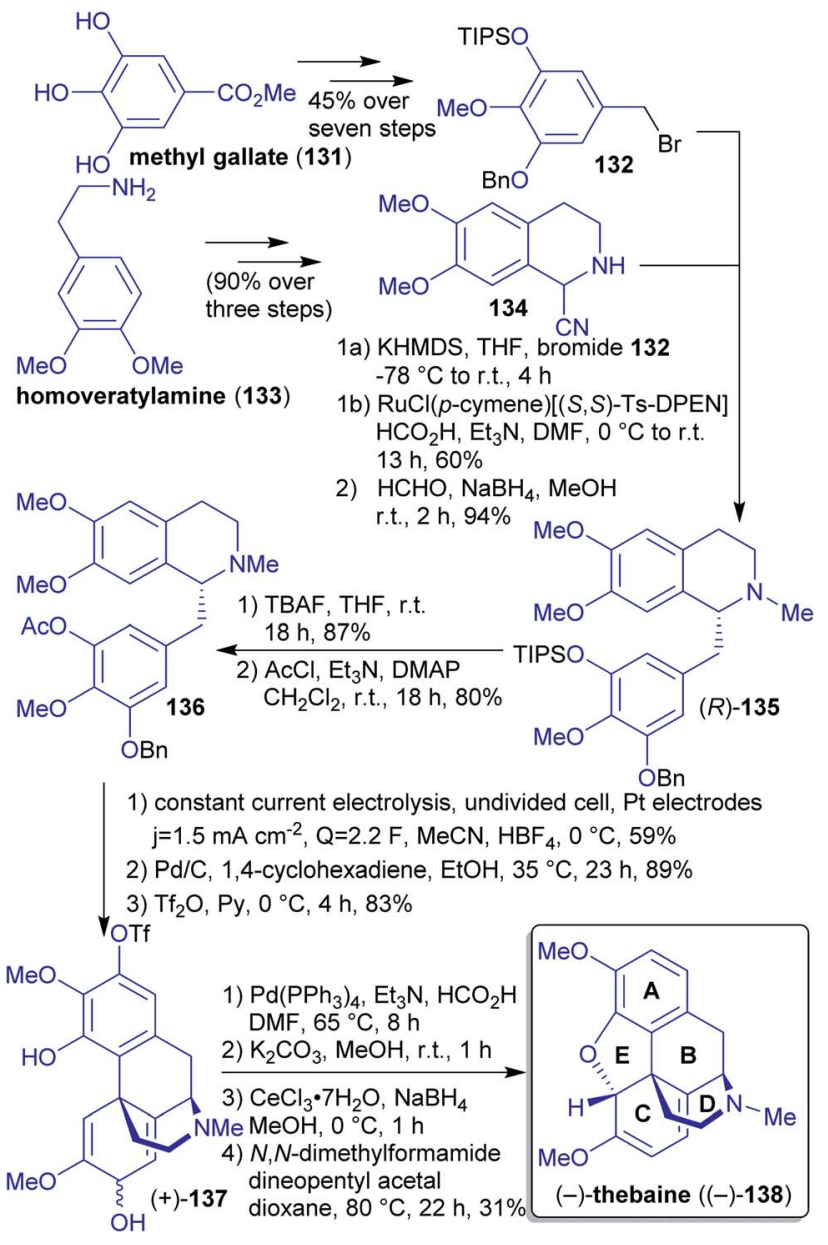

Scheme 21 Synthesis of (-)-thebaine ((-)-138) from renewable starting materials.

derived acetone ${ }^{\mathbf{2 1 3}}$ in two steps via reaction with hydrazine and subsequent bromination. ${ }^{\mathbf{2 1 4 2 1 5}}$ Compound 103 was reacted with allylmagnesium chloride 104, followed by ring closing metathesis and stannylation reaction affording second fragment 105. Allylmagnesium chloride (104) can be obtained from allylic alcohol (available from biomass) ${ }^{\mathbf{2 1 6}, 217}$ via chlorination and reaction with magnesium. ${ }^{\mathbf{2 1 8 , 2 1 9}}$

Enantiopure compound (+)-107 already bears the complete carbon skeleton of viridin (111) and was obtained from fragments 99 and 105 via Liebeskind coupling and Heck cyclization. Upjohn dihydroxylation, double Swern oxidation and $O$-methylation yielded methoxy enone 108. Site- and diastereoselective reduction followed by treatment with $\mathrm{AcOOH}$ and $\mathrm{MeOH}$ delivered a mixture of hydroxy ketal diastereomers (+)-109 and (-)-110.

Reduction of ketal (+)-109 with $\mathrm{Et}_{3} \mathrm{SiH}$ and TEMPO-catalyzed oxidation led to viridin (-)-111. Alternatively, ketal (-)-110 was reduced with dimethyl borane to afford natural product viridiol $(-)-112$ and via same oxidative conditions as before viridin $(-)-111$.

Unfortunately, numerous highly toxic or otherwise problematic reagents had to be used (e.g. HMPA, $\mathrm{OsO}_{4}$, TFA, TFAA). 
2.1.2.13. ( \pm )-Latifine and ( \pm )-cherylline. The hydrobenzoin substrates 124a and 124b were synthesized via a Wittig epoxidation/ring-opening one-pot protocol from substituted benzaldehydes accessible from biomass. ${ }^{109,201,220,221}$ The authors prepared 2,2-diarylacetaldehyde 125a and 125b via a pinacol rearrangement using an eco-friendly catalyst and microwave irradiation under solvent-free conditions (Scheme 20). This key step was followed by one-pot reductive amination, PictetSpengler and hydrogenation reactions and only one chromatographic purification to afford the desired isoquinoline alkaloids 129 and 130. $^{220}( \pm)$-Cherylline (129) and $( \pm)$-latifine (130) are both secondary metabolites of Crinum latifolium $\mathrm{L}$ (Amaryllidaceae). ${ }^{222}$

The authors provided an efficient and solvent-economical route in which half of the reactions operate at ambient temperature so that no additional heating is required. In general, one-pot approach are also favorable in the light of "green" chemistry.

2.1.2.14. (-)-Thebaine. So far, all synthetic approaches towards (-)-thebaine ((-)-138) using stoichiometric oxidants to mimic the biosynthetic oxidative phenol coupling delivered only low yields. The group of Opatz et al. reported the first electrochemical access to natural (-)-thebaine $((-)-138)$ via regio- and diastereoselective anodic coupling (Scheme 22). ${ }^{223,224}$

Homoveratrylamine (133) and methyl gallate (131) are both accessible from biomass ${ }^{225,226}$ and were reacted in several steps to furnish compounds $\mathbf{1 3 4}$ and 132. Via a deprotonation/ alkylation/reduction sequence, tetrahydroisoquinoline 135 was formed. The anodic coupling was performed after a less favorable but inevitable switch of protecting groups, yielding intermediate 137. Subsequent deacetylation, Luche reduction and closure of the E-ring through conjugate nucleophilic substitution afforded (-)-thebaine ((-)-138).

Based on this procedure, the authors were also able to synthesize the natural opioid (-)-oxycodone ((-)-87), wheras the synthesis of its optical antipode was achieved by Hudlicky et al. along a different synthetic route (vide supra). ${ }^{\mathbf{1 8 9 , 2 2 7}}$

Under "green" aspects, switching of protecting groups is not ideal. Furthermore, several of undesired solvents (DMF, THF, $\mathrm{CH}_{2} \mathrm{Cl}_{2}$ ) as well as toxic or hazardous reagents (1,4-cyclohexadiene, DMAP, $\mathrm{HCO}_{2} \mathrm{H}, \mathrm{Et}_{3} \mathrm{~N}$ ) had to be used.

\subsection{Cellulose}

Cellulose (113) and hemicelluloses account for up to $80 \%$ of the dry biomass of plants in which they form the cell walls. While the chemical structures of hemicelluloses are very heterogeneous, cellulose consists exclusively of $\beta(1 \rightarrow 4)$ linked poly-Dglucose, making it a non-edible carbohydrate source for most animals including humans. It is a very abundant and promising sustainable feedstock for chemical raw materials.

2.2.1. Valorization of cellulose. In view of the large body of research regarding the valorization of cellulose and considering the amount of literature and reviews available, we restricted the presented chemical starting materials to the molecules relevant for the syntheses covered in this review (Scheme 21). For detailed information on the utilization of cellulose for fuel ${ }^{228-230}$ and chemical raw material production ${ }^{231-233}$ as well as for macromolecular chemistry, ${ }^{228}$ we refer the reader to the references given.

One of the most important small molecules obtainable from cellulose (as well as of hexoses in general) in high yields is 5hydroxymethylfurfural (5-HMF, 119 $)^{234-236}$ and related compounds that can either be obtained from 5-HMF (119) or directly from cellulose. Those are 5-(chloromethyl)furfural (5CMF, 120), ${ }^{237,238}$ 2,5-diformylfuran (DFF, 123), ${ }^{239,240}$ 2,5-dimethylfuran (DMF, 121, not to be confused with dimethylformamide commonly abbreviated in the same way) ${ }^{\mathbf{2 4 1 , 2 4 2}}$ and levulinic acid (LA, 122). ${ }^{\mathbf{2 4 3 - 2 4 6}}$ Another interesting raw material is levoglucosenone (LGO, 115), which bears several useful

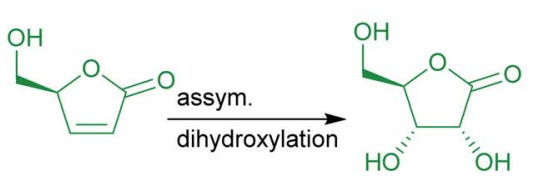

(S)-HBO (116) D-(+)-ribonolactone (117) Baeyer-Villige

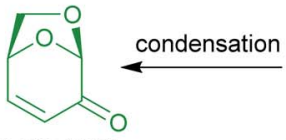

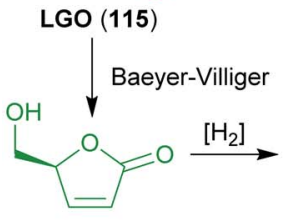

(S)-HBO (116)
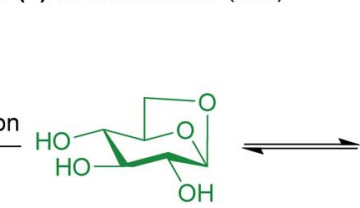

levoglucosan (114)

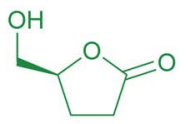

(S)-2H-HBO (118)
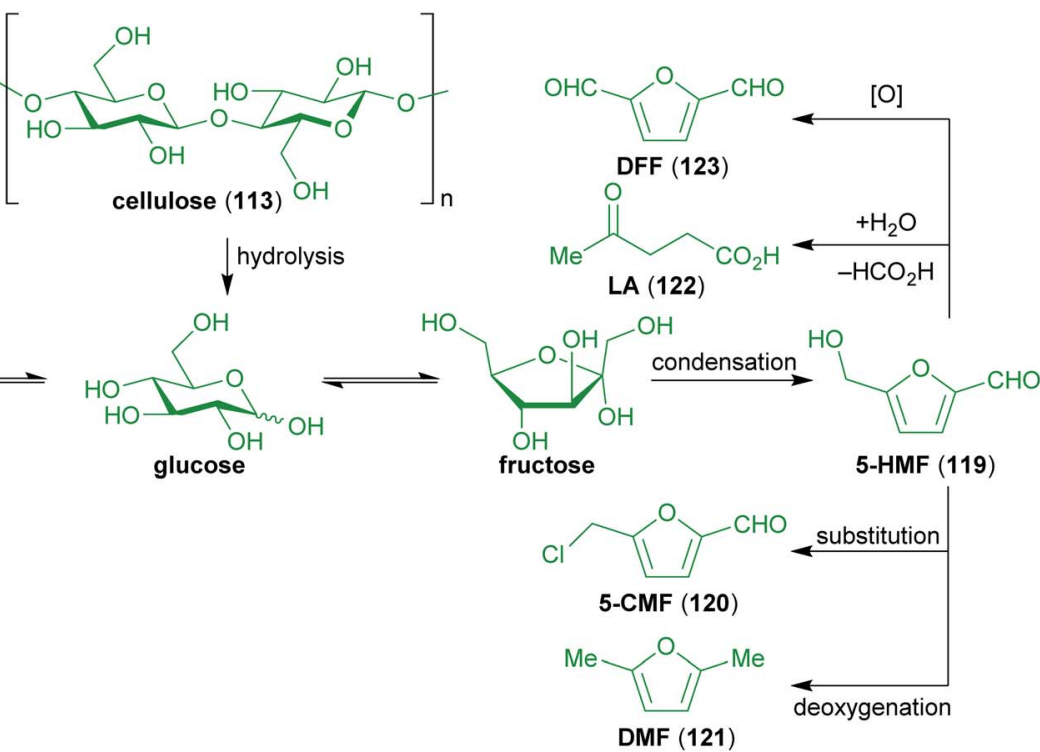

Scheme 22 Valorization of cellulose for selected platform chemicals. 
functional groups in the form of an enone and an acetal moiety in its chiral bicyclic skeleton. ${ }^{247-250}$ It is derived from levoglucosan (114), a product of the pyrolysis of cellulose. ${ }^{251-253}$ Furthermore, it can be transformed to other useful compounds like $(S)$ - $\gamma$-hydroxymethyl- $\alpha, \beta$-butenolide (HBO, 116) via BaeyerVilliger oxidation, ${ }^{254,255}$ the respective saturated derivative $(2 \mathrm{H}$ HBO, 118), ${ }^{255}$ and D-(+)-ribono-1,4-lactone (117). ${ }^{256}$

Although glucose is an important compound obtainable from cellulose that has elaborately been used for the natural product synthesis, those syntheses are only cursory covered in this review due to the wealth of literature already available. ${ }^{257-262}$

2.2.2. Natural product syntheses using cellulose derived starting materials

2.2.2.1. (-)-Hongconin. The cardioprotective agent hongconin ((-)-145) $)^{\mathbf{2 6 3 - 2 6 5}}$ was synthesized from (-)-levoglucosenone $((-)-115)$ via Hauser-Kraus-annulation with cyanophthalide 141 by Swenton et al. (Scheme 23). ${ }^{266}$ The latter can be synthesized from the xylochemical 3-methoxybenzoic acid (139). ${ }^{267}$ Acetal reduction, Appel reaction, radical reduction and methylation furnished naphthopyran 144. Deprotonation and treatment with iodomethane in the presence of DMPU (avoiding the more common but highly toxic and carcinogenic HMPA) gave a $4: 1$ mixture in favor of the desired trans-product which was converted to the respective quinone with $\mathrm{AgO}$ and subsequently treated with sodium dithionite to obtain (-)-hongconin $((-)-145)$.

This very straightforward approach provides access to enantiopure (-)-hongconin (145) in a short sequence utilizing

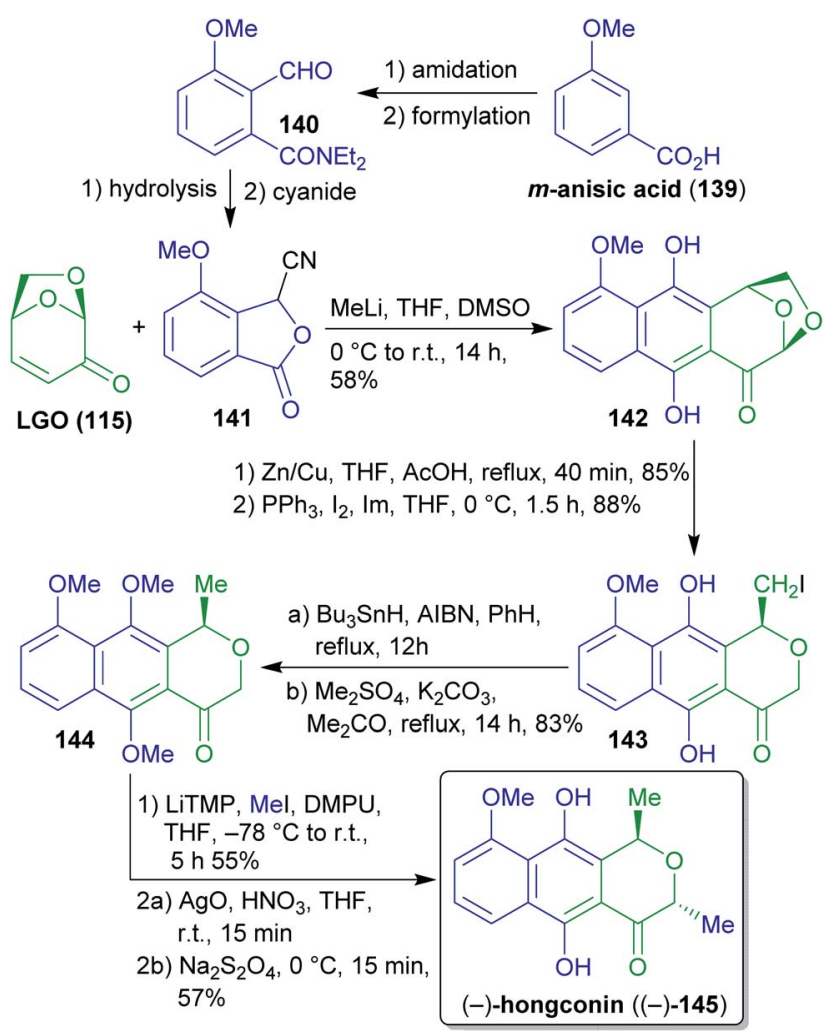

Scheme 23 Synthesis of (-)-hongconin ((-)-145) from levoglucosenone (139). cellulose-derived $\mathbf{1 1 5}$ as a chiral synthon and wood-derived 139 as an aromatic building block. Although the procedures used are based on less green methods, only one protecting group transformation had to be performed.

2.2.2.2. (+)-Dairy lactone. A concise synthesis of the flavoring compound dairy lactone (149), named after its natural occurrence in cow milk as well as its dairy-like odor and flavor, ${ }^{268,269}$ was presented in 2016 using the levoglucosenonederived $\gamma$-lactone $2 \mathrm{H}$-HBO (118). ${ }^{270}$ To create an electrophilic species from alcohol 118, it was converted to epoxide 146 via the respective tosylate and alkaline transesterification (Scheme 24). Reaction with lithiated 1-heptyne (147) and acidic transesterification furnished lactone 148, which was hydrogenated to (+)-149 using a Lindlar catalyst. Alkyne 147 can be produced from any $\omega-6$ fatty acid derivative (e.g. linoleic acid) by cross metathesis with ethylene, ${ }^{271}$ bromination and dehydrobromination. ${ }^{272}$

2.2.2.3. (+)-Herbarumins. Another levoglucosenone-derived starting material, $\delta$-ribonolactone (117), was used as its acetonide protected derivative $\mathbf{1 5 0}$ by Fürstner et $a .^{273}$ for the synthesis of phytotoxic herbarumins I and II (158 and 159, Scheme 25). ${ }^{274}$ Similar to the synthesis of 149 , the lactone was converted to an epoxide through ring transformation, which was then transformed into lactol 152 by nucleophilic attack of ethylmagnesium bromide and reduction. The hemiacetal was subjected to a Steglich esterification with hexenoic acids 155ab to furnish 156a-b. 5-Hexenoic acid (155a) as well as the 2methoxymethyl derivative $\mathbf{1 5 5 b}$, which was synthesized from 155a using Evans aldol methodology, are available from eicos-5enoic acid (153) via cross metathesis with ethylene. ${ }^{275}$ Esters 156a-b were subjected to olefin metathesis using catalyst 157 to ensure $E$-selectivity. Final deprotection furnished enantiopure $(+)-158$ and $(+)-159$.

Although the solvents used during these syntheses are ecologically less favorable, the number of protecting group manipulations is minimal and makes this route a straightforward approach to two natural products from bio-based starting materials.

2.2.2.4. (-)-Jiadifenolide. Jiadifenolide (168), a neurotrophic sesquiterpenoid, ${ }^{\mathbf{2 8 4 , 2 8 5}}$ was synthesized by Theodorakis et al. ${ }^{\mathbf{2 8 6}}$ from cyclopentadienone (161) which is available from methyl levulinate (160) in a single step (Scheme 26). ${ }^{287}$ Allylation with

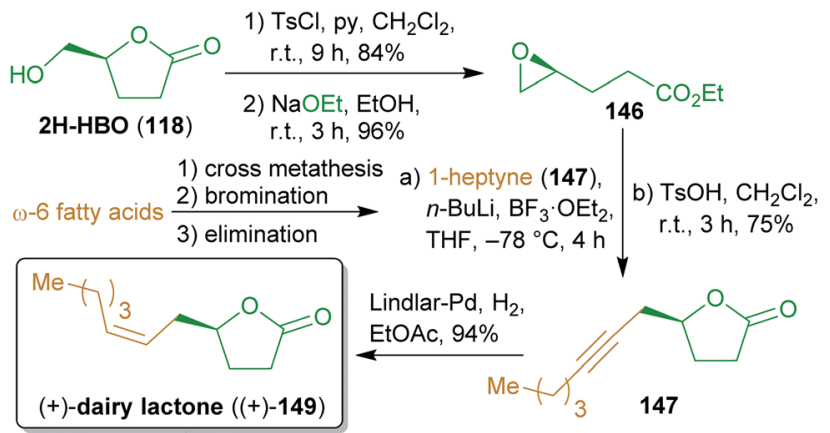

Scheme 24 Synthesis of (+)-dairy lactone $((+)-149)$ from $2 \mathrm{H}-\mathrm{HBO}$ (118). 


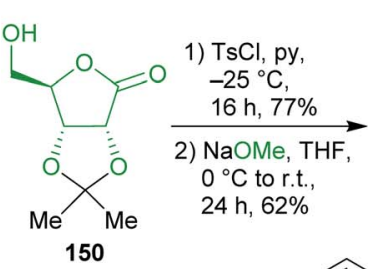<smiles>O=[Sn](c1ccccc1)N1OC1c1ccccc1</smiles>

Davis' oxaziridine (154)

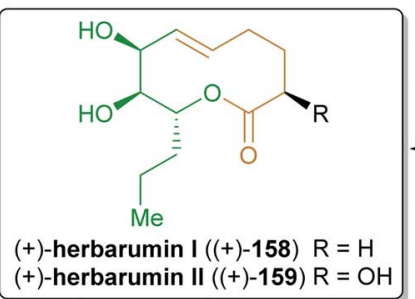

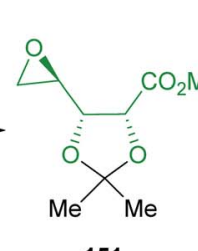

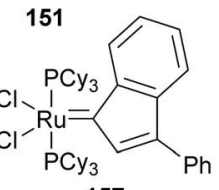

157
1) $\mathrm{EtMgBr}, \mathrm{CuBr} \cdot \mathrm{SMe}_{2}$,

THF, $-78{ }^{\circ} \mathrm{C}$, 28 h, $60 \%$ $-78{ }^{\circ} \mathrm{C}, 3 \mathrm{~h}, 97 \%$

$-78^{\circ} \mathrm{C}, 3 \mathrm{~h}, 97 \%$
2) DIBAL-H, $\mathrm{CH}_{2} \mathrm{Cl}_{2}$

1) $\mathrm{Ph}_{3} \mathrm{P}=\mathrm{CH}_{2}$ quinuclidine, THF, r.t. $30 \mathrm{~min}, 62-77 \%$

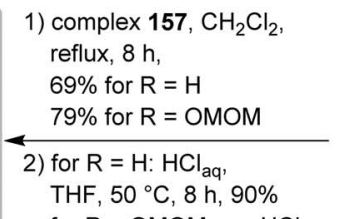

for $\mathrm{R}=\mathrm{OMOM}$, aq. $\mathrm{HCl}$, $\mathrm{MeOH}, \mathrm{H}_{2} \mathrm{O}, 60^{\circ} \mathrm{C}, 3 \mathrm{~h}, 84 \%$
<smiles>CC(C)(C)OC1C(CCN)OC(O)C1O</smiles>
$\mathrm{Me}$
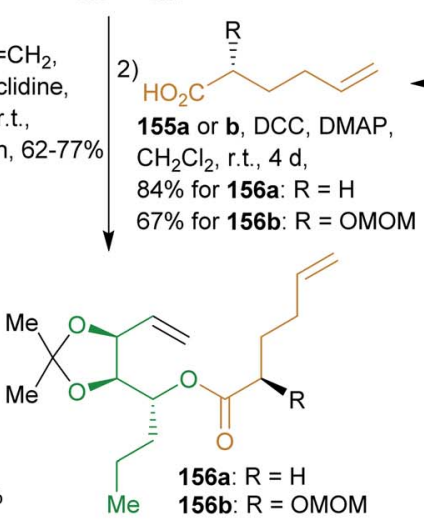

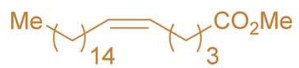

eicos-5-enoic acid (153)

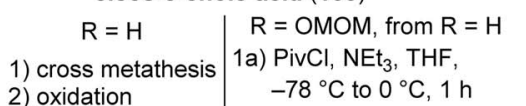

1b) $n$-BuLi, Evans auxiliary, THF, $-78^{\circ} \mathrm{C}$ to r.t., $4 \mathrm{~h}, 90 \%$

2) NaHMDS, THF, 154, CSA

$-78{ }^{\circ} \mathrm{C}, 1.5 \mathrm{~h}, 89 \%$

$2 \mathrm{~h}, 78 \%$

4) $\mathrm{LiOH}, \mathrm{H}_{2} \mathrm{O}_{2}$, THF,

$\mathrm{H}_{2} \mathrm{O}, \mathrm{O}^{\circ} \mathrm{C}, 1 \mathrm{~h}, 89 \%$

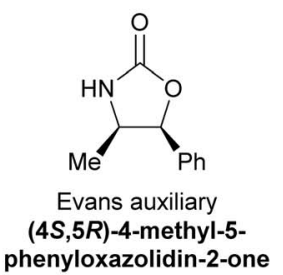

Scheme 25 Synthesis of herbarumins from ribonolactone (117) and eicos-5-enoic acid (153).

allyl acetate and Michael addition to methyl vinyl ketone (MVK) furnished intermediate $162,{ }^{288,289}$ which was converted to enantioenriched diketone 163 via organocatalysis with D-prolinamide in high enantiopurity. Allyl acetate as an ester of allyl alcohol is available from glycerol ${ }^{217}$ while MVK is produced from acetone (available from wood by pyrolysis) ${ }^{290,291}$ and formaldehyde (available from methanol) via aldol condensation or
Mannich reaction. ${ }^{292,293}$ Regio- and stereoselective reduction, silyl protection, carboxylation with methyl magnesium carbonate (MMC) and trapping with Meerwein's salt as well as methylation via the TMS-enolate gave intermediate 164 as a single isomer. MMC is made from magnesium methanolate and carbon dioxide and can therefore be considered to be renewable. ${ }^{294}$ Global reduction, TBS protection of the primary

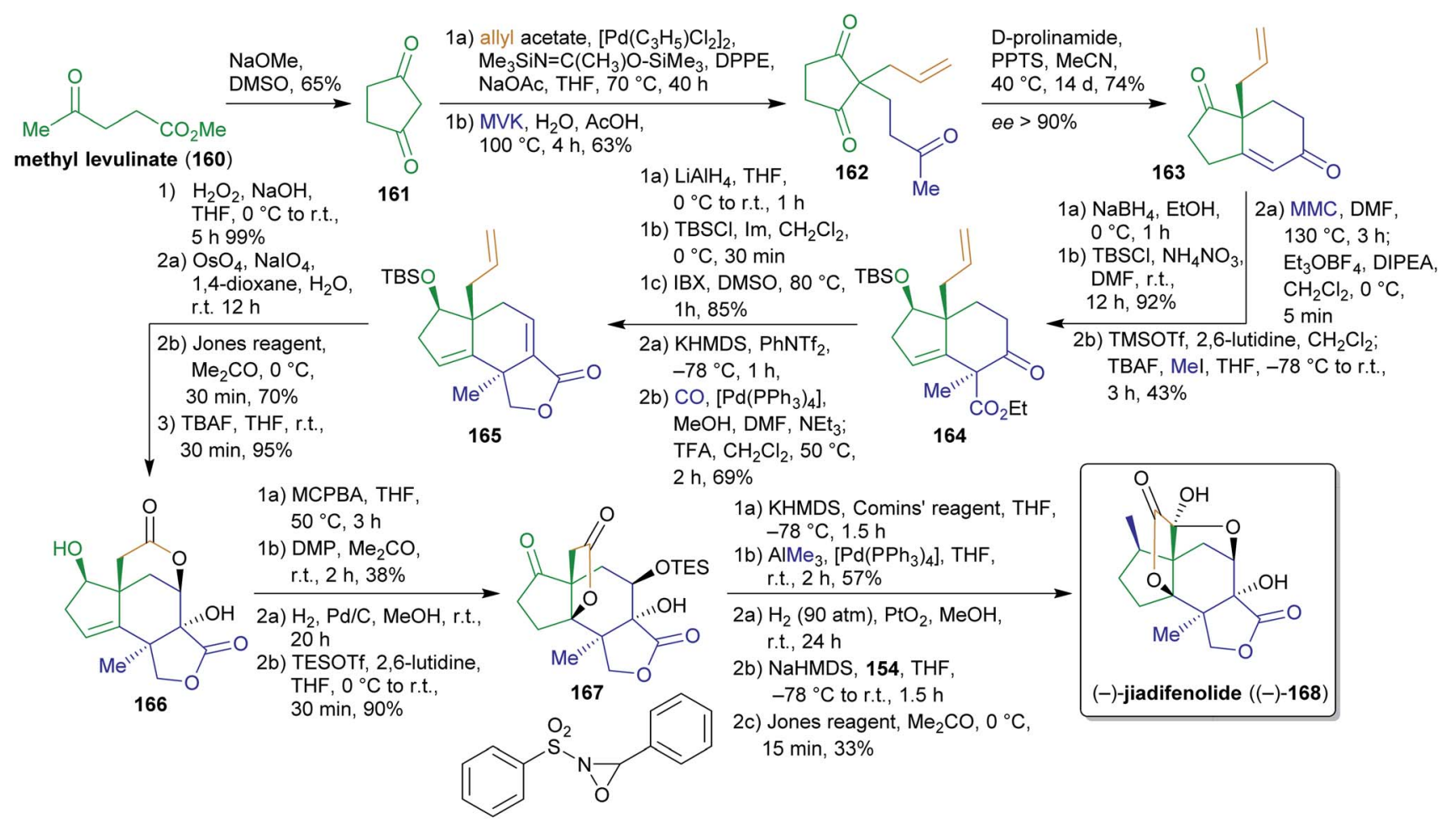

Davis' oxaziridine (154)

Scheme 26 Synthesis of (-)-jiadifenolide ((-)-168) by Theodorakis et al. 
alcohol and oxidation of the secondary alcohol restored the carbonyl group, which was converted to the respective vinyl triflate to perform carbomethoxylation. After desilylation, spontaneous lactonization occurred to form 165, which was oxidized to the respective epoxide. Oxidative cleavage of the terminal olefin and oxidation of the resulting aldehyde triggered "6-exo-tet" epoxide opening to form the desired lactone 166 after TBS-deprotection. For this sequence, a direct $\mathrm{Ru}^{\mathrm{III}}$ based oxidation of the terminal alkene to the carboxylic acid was investigated but was unsuccessful and led to decomposition. Therefore, the more circumstantial two-step sequence had to be used. Directed epoxidation and direct treatment of the acidic solution with DMP led to the $\alpha, \beta$-unsaturated ketone, acid-catalyzed epoxide opening and transesterification to the thermodynamically favored 5-membered lactone. After hydrogenation of the double bond and TES protection, intermediate 167 was obtained. Next, the remaining carbonyl group should be transformed into a methyl group. This seemingly simple transformation proved challenging and the conventional methylenation approaches (Wittig reaction, Ti- and Zn-based) failed. Therefore, the vinyl triflate was prepared with Comins' reagent and $\mathrm{Pd}^{0}$-catalyzed cross coupling with $\mathrm{AlMe}_{3}$ (accessible from $\mathrm{Al}$ and iodomethane $)^{295}$ gave the desired product. A final three-step one-pot sequence of hydrogenation, hydroxylation via the enolate and oxaziridine $\mathbf{1 5 4}$ as well as Jones oxidation gave (-)-jiadifenolide $((-)-\mathbf{1 6 8})$ in $1.5 \%$ overall yield over 25

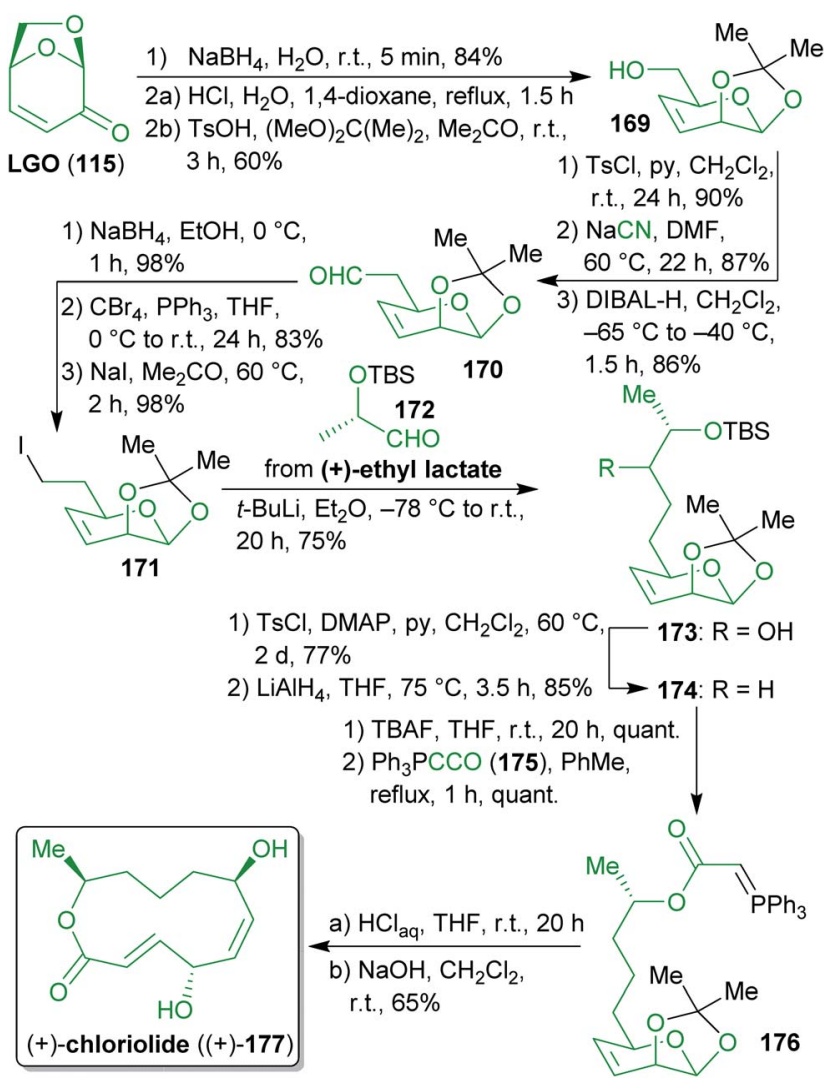

Scheme 27 Synthesis of $(+)$-chloriolide $((+)-177)$ from levoglucosenone (115). steps, representing the first total synthesis of this natural product.

The foregoing synthesis is an excellent example of constructing a fairly complex and stereochemically demanding natural product from simple and bio-derivable building blocks. Inevitable detours had to be taken, which unfortunately decreased the eco-friendliness of the approach, yet the entire carbon backbone was constructed from renewable starting materials.

2.2.2.5. (+)-Chloriolide. In 2014, Schobert et al. synthesized the fungal 12-membered macrolide chloriolide $(\mathbf{1 7 7})^{276}$ from levoglucosenone (115) and (+)-lactic acid via a Wittig-type macrocyclization (Scheme 27). ${ }^{277}$ Starting from 115, ketone reduction, acetal hydrolysis and acetonide protection led to alcohol 169, which was converted to the $\mathrm{C}_{1}$-homologated aldehyde 170 via transformation into a leaving group, nucleophilic substitution with cyanide and reduction. Sodium cyanide is currently produced by the Andrussow process from methane and ammonia and subsequent reaction with lye. ${ }^{278,279}$ Considering that synthetic natural gas and methane derived from agricultural waste and manure are widely established concepts, ${ }^{280}$ even methane-derived NaCN could be produced on the basis of renewables. Another route to biomass-based HCN has been mentioned earlier. ${ }^{281}$ The cumulated ylide 175 which is prepared from the respective alkoxycarbonylmethylenephosphorane and therefore from an $\alpha$-haloacetic acid derivative ${ }^{\mathbf{2 8 2 , 2 8 3}}$ was used to synthesize ylide ester 176 after TBS deprotection. Acetonide cleavage and Wittig-cyclization gave enantiopure $(+)-\mathbf{1 7 7}$. The presented work makes use of simple chiral bio-based starting materials to build a fairly complex natural product.

2.2.2.6. (-)-Aspergillides. For a formal synthesis of the cytotoxic aspergillides A and B (186 and 187) ${ }^{296-298}$ Loh and Koh selected 5-HMF (119) and levulinic acid (122) as biomassderived starting materials (Scheme 29). ${ }^{299}$ The tetrahydropyran moiety was synthesized from 119 which was benzyl protected and subjected to an aldol reaction. Oxidation of the racemic product and asymmetric transfer hydrogenation furnished $\beta$ hydroxyester 180. Although the non-stereoselective aldol reaction/oxidation/asymmetric reduction sequence does not look very eco-friendly at first glance, it turned out to be the only suitable way to access enantiopure 180. Asymmetric Mukaiyama aldol reactions as well as dynamic enzymatic kinetic resolutions of racemic 180 were attempted but neither of them provided the desired outcome in terms of yield and enantiomeric excess.

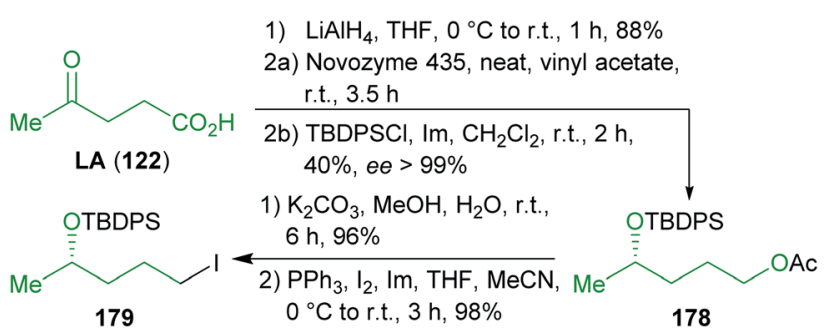

Scheme 28 Synthesis of levulinic acid (122) derived intermediate 179 for the synthesis of aspergillides A (187) and B (186). 


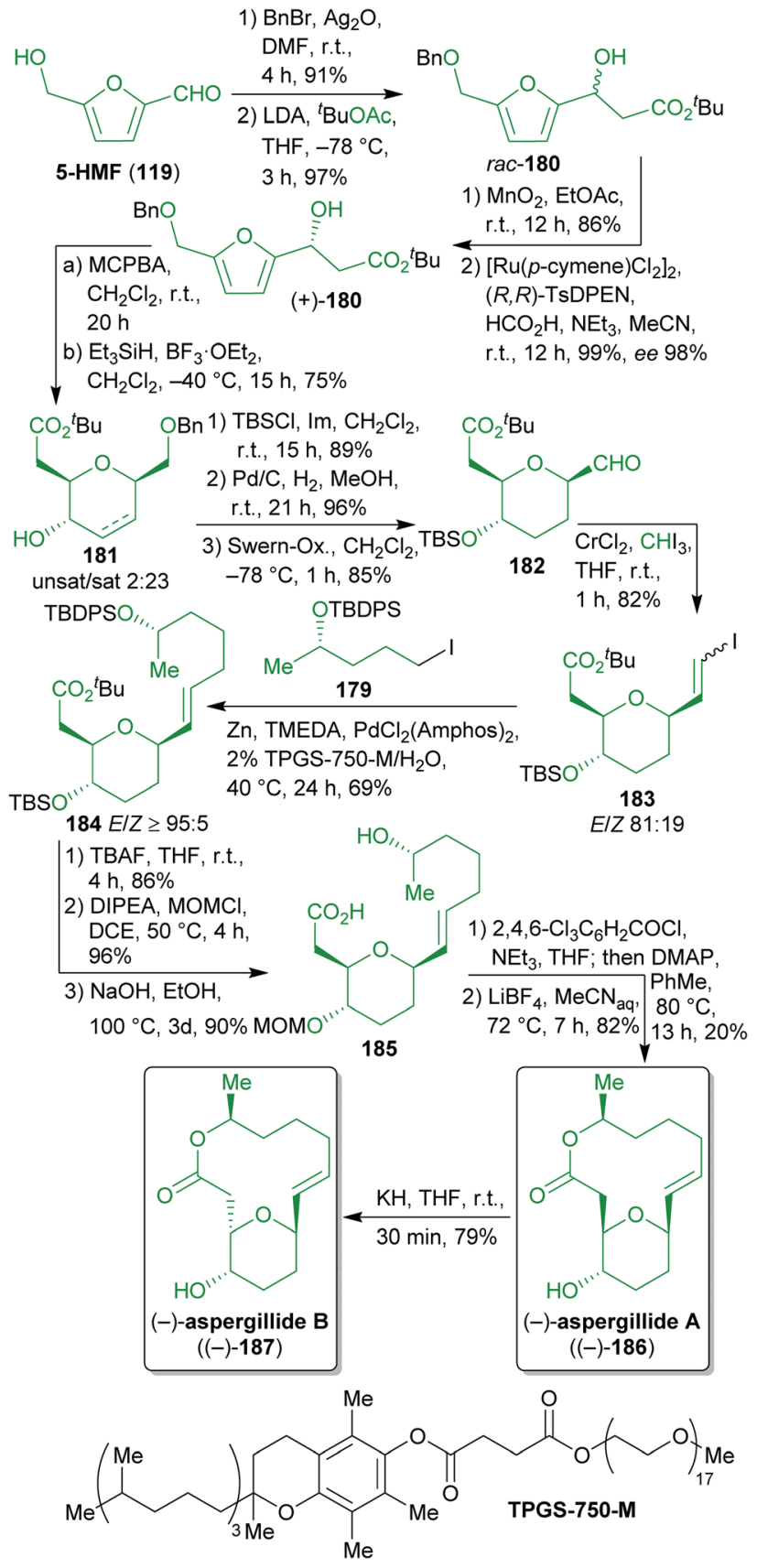

Scheme 29 Synthesis of aspergillides A ((-)-187) and B ((-)-186) from 5-HMF (119) and LA (122).

Achmatowicz rearrangement and reductive deoxygenation gave a mixture of dihydro- and tetrahydropyran 181. After O-protection, hydrogenation removed the double bond and the benzyl group. The resulting primary alcohol was subjected to Swern oxidation and the following Takai iodoolefination (iodoform is e.g. available from the reaction of ethanol with $\mathrm{I}_{2}$ in alkaline medium ${ }^{300}$ furnished the first 5-HMF-derived building block 183.

On the other hand, levulinic acid (122) was reduced to the respective racemic diol, which was subjected to dynamic enzymatic kinetic resolution and the desired enantioenriched alcohol was TBDPS protected to obtain 184. Ester hydrolysis and iodination furnished the second building block 179 in excellent yield and ee (Scheme 28). Both building blocks were coupled by means of a Neigishi reaction with high selectivity in favor of the desired $E$-isomer. An eco-friendly micelle-based variant using the commercially available amphiphile TPGS-750 $\mathrm{M}^{301}$ in water and in situ-generation of the organozinc reagent was employed..$^{\text {302-304 }}$ After cleavage of the silyl protecting groups, a MOM group was installed and the ester was saponified to yield seco-acid 185 which was already used by Fuwa et al. as an intermediate and was converted to (-)-186 by Yamaguchi esterification. $^{305}$ Epimerization with potassium hydride gave $(-)-187 .{ }^{306}$

Throughout this remarkable sequence, a number of steps were intentionally conducted in accordance with the principles of "green" chemistry. As already pointed out, the Neigishi coupling of 183 and 179 is an example of "greener" chemistry and the dynamic enzymatic kinetic resolution also ensures a high overall yield.

2.2.2.7. (-)-Bissetone and (-)-palythazine. For the first total syntheses of the marine natural products bissetone $(\mathbf{1 9 0})^{\mathbf{3 0 7}}$ and palythazine $(193)^{308}$ Lichtenthaler and coworkers ${ }^{309-311}$ used glucose as a biomass-derivable starting material in a classtranscendent fashion (Scheme 30). Both sequences proceed via the dihydropyranone $\mathbf{1 8 9}$, which can be prepared from $\mathrm{D}^{-}$ glucose on a molar scale in six steps via the hydroxyglucal ester 188. ${ }^{312-314}$ Addition of the lithium enolate of (potentially xylochemical) acetone and subsequent protecting group cleavage furnished enantiopure (-)-bissetone $((-)-190)$. The nucleophilic attack is favored from the axial side and therefore leads to the product with the desired relative configuration.

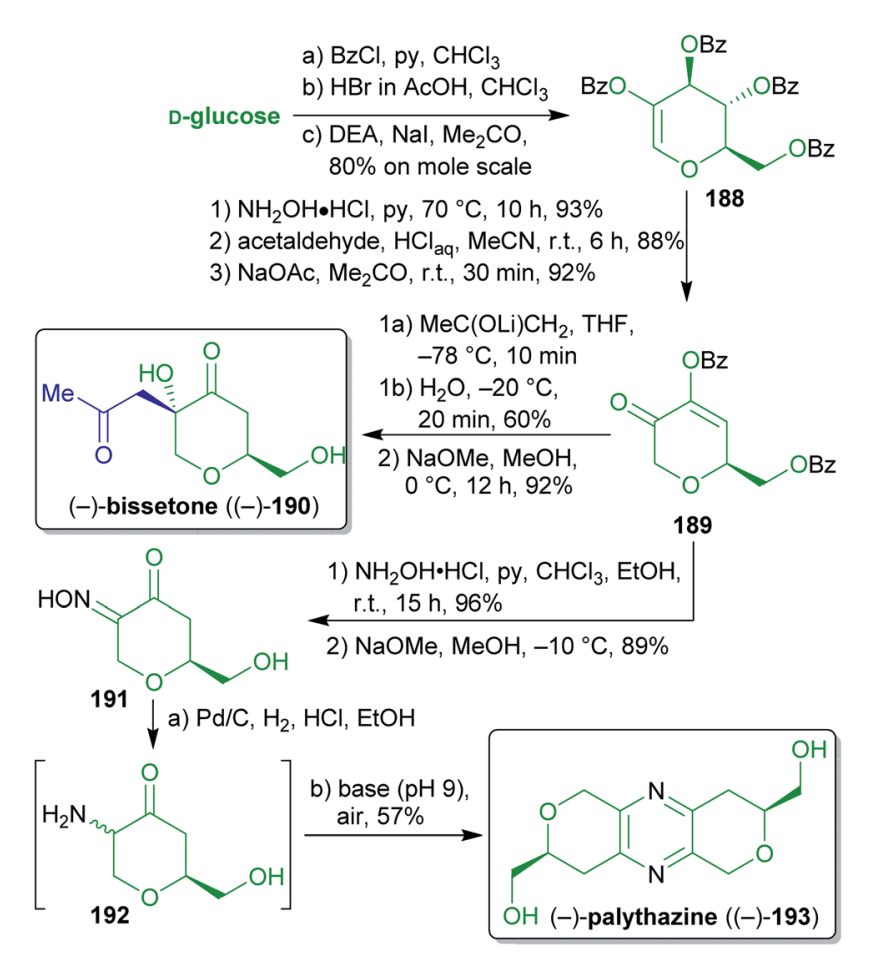

Scheme 30 First total syntheses of (-)-bissetone ((-)-190) and $(-)$-palythazine $((-)-193)$ from glucose. 
For the synthesis of $(-)-193$, the carbonyl group of 189 was converted into the oxime 191 which spontaneously underwent oxidative dimerization into enantiopure (-)-palythazine $((-)-193)$ upon exposure to air after global deprotection and oxime reduction. The absolute configuration of $(-)$-palythazine $((-)$-193) was proven through this stereospecific synthesis. These concise and straightforward syntheses make excellent use of biomass-based D-glucose as an enantiopure starting material (ex-chiral pool strategy) to prepare non-carbohydrate natural products. Acetone ${ }^{290,291}$ was used as a potentially renewable $\mathrm{C}_{3}$-synthon. Additionally, in contrast to classic carbohydrate chemistry, only a single protecting group transformation was performed throughout the entire sequence.

2.2.2.8. (+)-Castanospermine. Mootoo and coworkers ${ }^{315,316}$ utilized the hydroxyl substitution pattern of D-glucose for the synthesis of polyhydroxyindolizidine alkaloid (+)-castanospermine $((+)-198) \cdot{ }^{317}$ The synthesis of this plant-derived natural product commenced with the allylation of aldehyde 194 which is readily available from glucose (Scheme 31$).{ }^{318-320}$ The desired threo-epimer was the major product ( $9: 1$ selectivity) and could be separated by chromatography. After benzylation, treatment with iodonium dicollidine perchlorate (IDCP), reductive elimination and Swern-oxidation furnished ketone 196. Ozonolysis and acetal hydrolysis gave key tricarbonyl intermediate 197a in the lactol form $\mathbf{1 9 7 b}$, which was subjected to triple reductive amination. During this reaction only $5 \%$ of the undesired C8aepimer was formed. Global deprotection furnished enantiopure $(+)$-castanospermine $((+)-\mathbf{1 9 8})$ with a high yield of $22 \%$ over nine steps starting from 194.

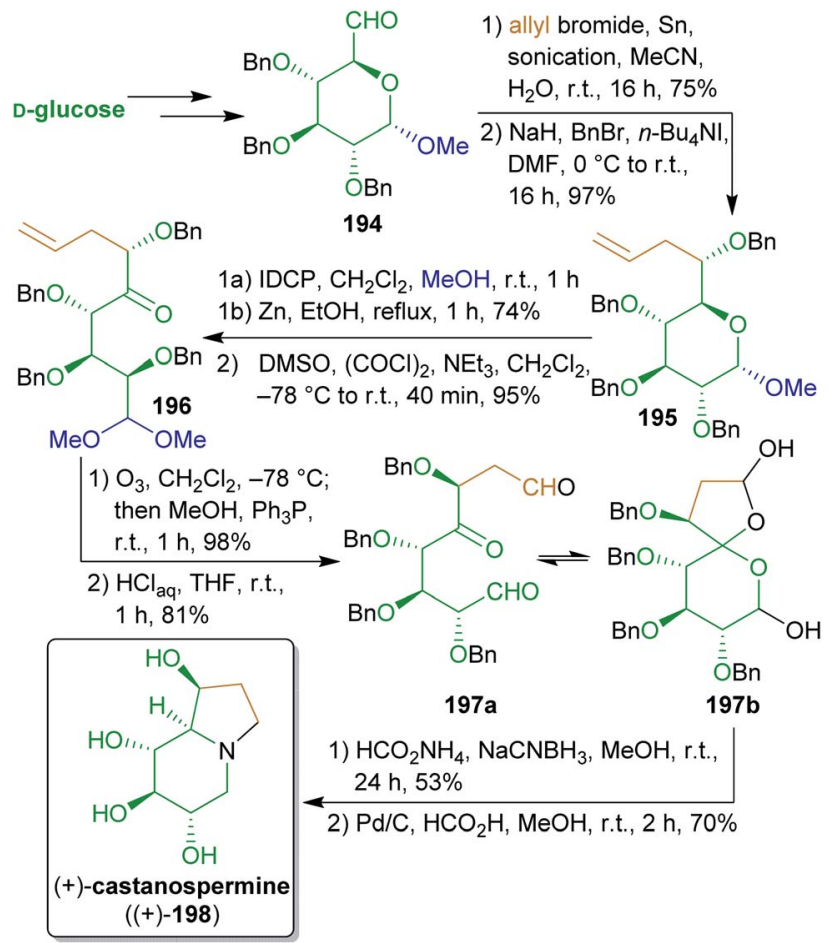

Scheme 31 Synthesis of polyhydroxindolizidine alkaloid castanospermine (198).

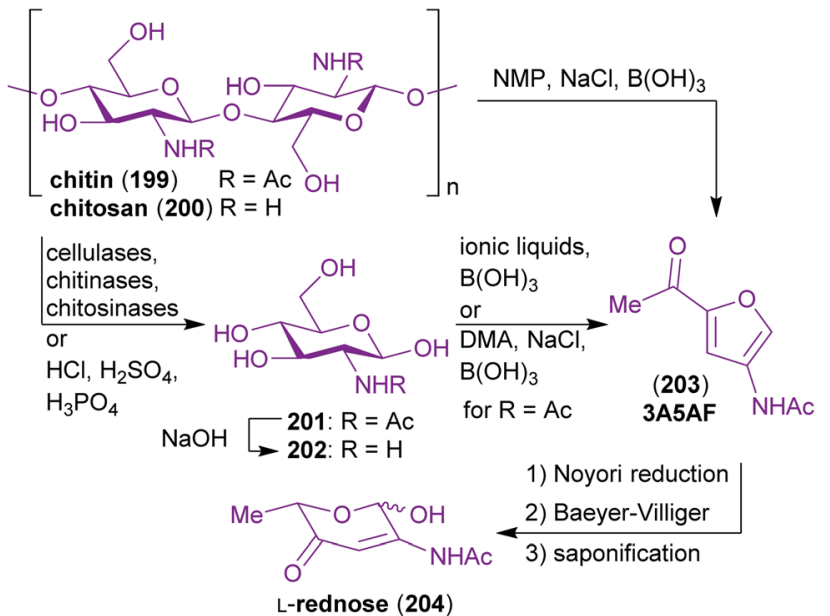

Scheme 32 The chemical structure of chitin/chitosan and examples of starting materials derived thereof.

This remarkable work makes formidable use of the innate stereoinformation of bio-based glucose to synthesize this stereochemically demanding natural product.

\subsection{Chitin and chitosan}

Chitin 199 and chitosan 200 are the chemical constituents of the exoskeleton of crustaceans and insects as well as of cell walls of molluscan organs and fungi. This makes it the second most abundant biopolymer (after cellulose) ${ }^{321}$ and the most abundant nitrogen containing biopolymer on earth. ${ }^{322}$ Similar to the structure of cellulose, chitin is a linear polysaccharide, but unlike cellulose it is composed of $\beta(1 \rightarrow 4)$-linked 2-acetamido-2-deoxyD-glucopyranose (N-acetylglucosamine, GlcNHAc 201) monomers (Scheme 32). As depicted in Scheme 32, the C-2-substituent of the sugar-derived monomer is either an acetamido- or a free amino group. The term chitin refers to the material with $>50 \%$ of acetylated amino groups while the material with a lower degree of $\mathrm{N}$ acetylation is called chitosan. ${ }^{323}$

2.3.1. Valorization of chitin and chitosan. The utilization of chitin and chitosan for the production of biofuel, chemical raw materials or functional materials with applications in chemistry and pharmaceutics has been called the "shell biorefinery"322,324 or - hence its predominantly marine origin - the "ocean-based biorefinery". ${ }^{325}$ Although this is a very promising feedstock due to its abundance, its availability as a waste

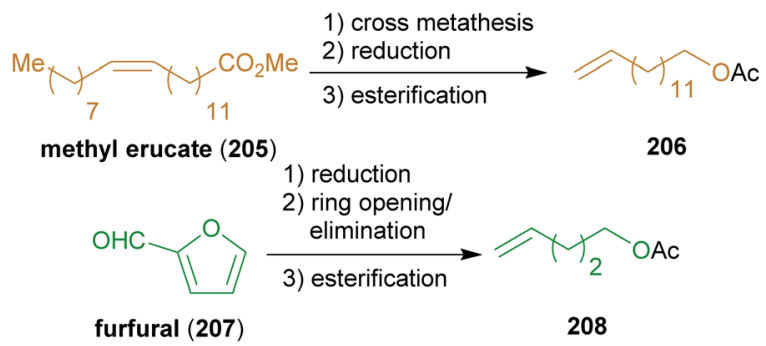

Scheme 33 Schematic synthesis of terminal olefins 206 and 208 for the synthesis of rhizochanilin C (217). 
product from food production and its unique potential as a source for nitrogen containing raw materials, the field of chitin valorization is just emerging. Extensive reviews and summaries about its structure and biosynthesis can be found elsewhere. ${ }^{326-328}$ For detailed information about the valorization of this promising feedstock we refer to existing literature. ${ }^{322-325,329-332}$ Therefore, we will focus on a small number of low molecular weight organic compounds obtainable from chitin or chitosan that are relevant for the synthesis of natural products within the scope if this review. As for other biopolymers, the compounds accessible from chitin and chitosan vary with the conditions used for depolymerization.

The natural material in the form of shrimp, crab or lobster shells has to be digested by grinding, deproteinization, demineralization, discoloration and drying prior to depolymerization. ${ }^{333}$ The prepared chitin and chitosan can be cleaved directly into the corresponding amino sugars N-Ac-glucosamine (GlcNHAc, 201) or 2-amino-2-deoxy-glucose $\left(\mathrm{GlcNH}_{2}, 202\right)$ either enzymatic or with inorganic acids (Scheme 32). ${ }^{\mathbf{3 2 4 3 3 4 - 3 3 7}}$ GlcNHAc can be deacetylated to yield $\mathrm{GlcNH}_{2}$ or be converted to two highly promising $\mathrm{N}$-containing starting materials that are challenging to make from other resources.

The furan derivative 3 -acetamido-5-acetylfuran (3A5AF, 203) can easily be prepared from 201 in a single step ${ }^{338-340}$ or directly from 199. ${ }^{338,341} 3 \mathrm{~A} 5 \mathrm{AF}(203)$ can in turn be converted to L-rednose (204), which contains a $\beta$-aminoenone moiety rarely seen in carbohydrates, in a three step sequence. ${ }^{342}$

2.3.2. Natural product syntheses using chitin/chitosan derived starting materials

2.3.2.1. (-)-Rhizochalinin C. Molinski's and Ko's synthesis of rhizochalinin $C(\mathbf{2 1 7})^{\mathbf{3 4 3 , 3 4 4}}$ is a good example for the potential of the combinatorial use of biomass derived starting materials. ${ }^{345}$ Their approach to construct this $\mathrm{L}$-threo, $\alpha, \omega$-bifunctionalized sphingoid base combines the use of D-glucosamine from chitin/chitosan as an element of the chiral pool for extracting the stereocenters and fats/oils as well as hemicellulose derived starting materials to build the largest part of the carbon backbone. The key achievement of this work is the conversion of $\mathbf{2 0 2}$ into the useful synthons for L-threo sphingoid bases 209 and 210 by a sequence starting with a Barbier reaction with allyl bromide, followed by $\mathrm{N}$-protection, glycol cleavage, reduction and diol protection (Scheme 34). The allyl bromide used for the Barbier reaction is derivable from glycerol which is produced on a megaton scale by hydrolysis of fats and oils ${ }^{346}$ through allyl alcohol as an intermediate. ${ }^{217,347}$

The respective threo-diastereomers were subjected to olefin metathesis and further functionalized to furnish the respective Western 214 and Eastern halves 215, which were coupled by a Horner reaction. Prior to the olefin metathesis, a switch of the protecting groups was conducted to prepare the required deoxygenation.

The reactant for cross-metathesis with threo-209, tetradec-13enyl acetate (206), can be easily obtained by cross metathesis of methyl erucate (205) with ethylene,$^{348,349}$ followed by reduction and esterification (Scheme 33). Likewise, the olefin 208 could be prepared from hemicellulose via furfural 207 which is hydrogenated to tetrahydrofurfuryl alcohol. ${ }^{350}$ A ring opening/

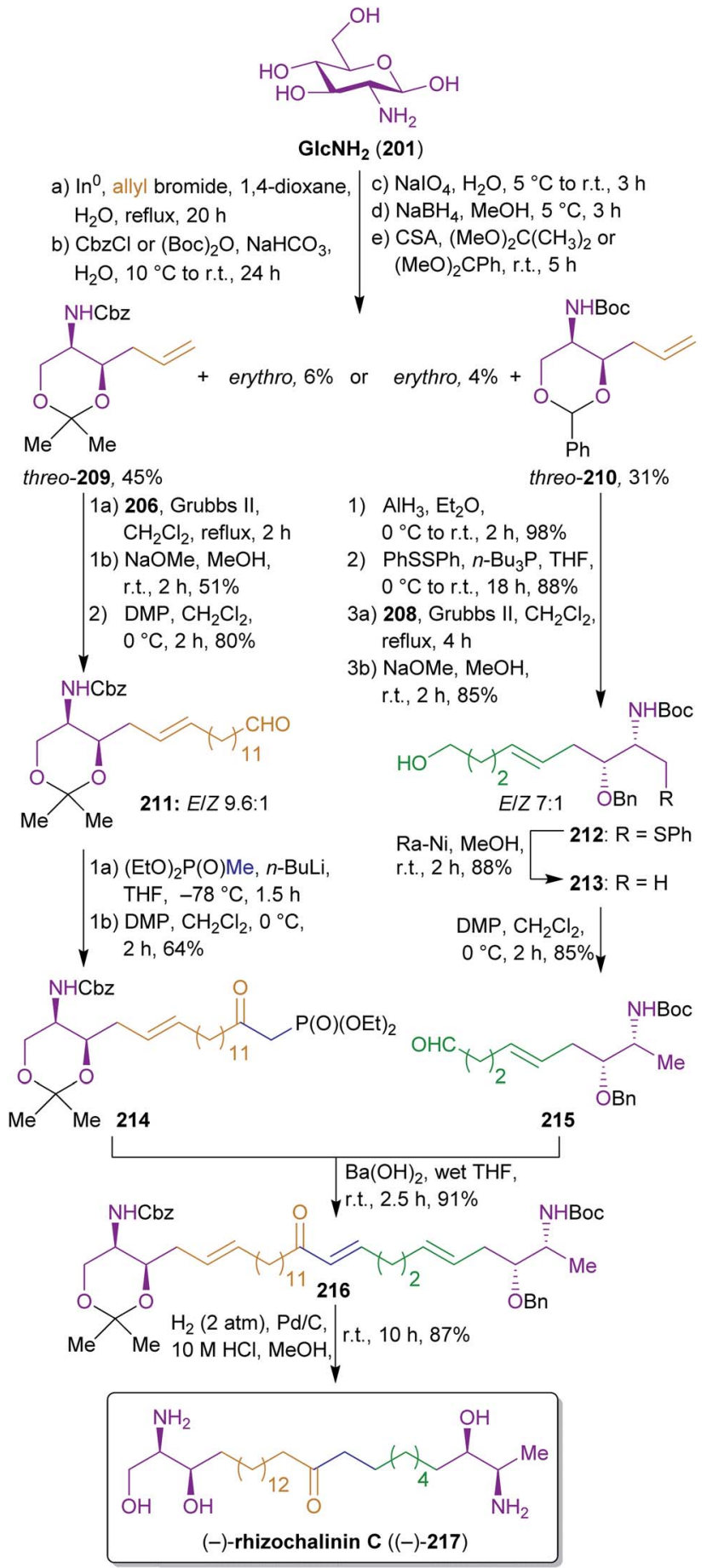

Scheme 34 Synthesis of sphingoid base synthons and (-)-rhizochanilin C ((-)-217) from 202.

elimination sequence gave pent-4-ene-1-ol ${ }^{351}$ which was esterified to 208. The synthesis of the phosphonate 214 is conducted with diethyl methylphosphonate which in turn can be synthesized from methanol and triethyl phosphite. ${ }^{352}$ Hydrogenation under strongly acidic conditions ensured global deprotection and saturation of the Horner product 216 in a single step to furnish stereopure (-)-rhizochanilin C ((-)-217). This synthesis 
makes excellent use of a variety of sustainable building blocks to construct a rather demanding natural product.

Unfortunately, frequently used methods such as glycol cleavage, cross metathesis or Horner reactions are not very atom economic.

2.3.2.2. (-)-Pochonicine. The total synthesis of fungal polyhydroxylated pyrrolizidine (-)-pochonicine hydrochloride $((-)-226 \cdot \mathrm{HCl})^{353}$ from GlcNHAc $(201)$ by Takahashi et al. ${ }^{354}$ is one of the numerous examples where the originally proposed absolute configuration of the natural product had to be revised based on synthetic work.

Starting from monothiolacetal 218, which was prepared from $201,{ }^{355}$ the configuration of the hydroxyl group at C-3 and the N-protecting group were switched (Scheme 35). Reductive acetal opening and nucleophilic attack of the nitrogen at C-5 led to pyrrolidine 221. After debenzylation and oxidation, a nucleophilic allylation was performed through attack of a Grignard reagent. Both diastereomers (threo- and erythro222) were formed in this step. The synthesis of (-)-pochonicine $((-)-226)$ was conducted with the erythro-isomer but the threo-isomer was also advanced to obtain the respective $\mathrm{C}-1$ and C-3 epimers of 226. The structure shown in Scheme 35 corresponds to the originally proposed configuration ${ }^{353}$ but comparison of the analytical data proved to be inconsistent with that of the natural product. Dihydroxylation of the terminal olefin again led to a mixture of diastereomers 224, whereas the 7- $(S)$-epimer led to $(-)-226$ and the 7- $(R)$-epimer to the respective C-3-epimer (not shown). After conversion to the hydrochloride, the observed optical rotation of the synthetic product proved to be opposite to the one of the isolated compound.

In this noteworthy work, four different diastereomers were synthesized from two common precursors to clarify the absolute configuration of this stereochemically demanding natural product. Unfortunately, the use of protecting group chemistry was inevitable due to the high degree of functionalization of the intermediates and final product.

2.3.2.3. (-)-Allosamizoline. As mentioned earlier, a major advantage of bio-based starting materials is the often high degree of functionalization, in particular with respect to stereogenic centers. Therefore, GlcNHAc and $\mathrm{GlcNH}_{2}$ are ideal templates for the synthesis of stereochemically demanding natural products. Several groups have utilized $\mathrm{GlcNH}_{2}(201)$ in this respect for the synthesis of (-)-allosamizoline $((-)-231),{ }^{356-361}$ a bacterial pseudo-aminosugar with chitinase inhibitory activity. ${ }^{362-365}$ For this potentially biomimetic approach, ${ }^{366}$ two main routes emerged for the crucial intramolecular ring closure to form the cyclopentane ring (Scheme 36). While Simpkins and Whittle used a radical ring closure of thiocarbamate 228 and an oxime ether 229,,$^{358,359}$ the Tatsuta and Kitahara groups opted for an oxidative cycloaddition to generate isoxazoline intermediate $\mathbf{2 3 5} .^{\mathbf{3 5 6 , 3 6 0}}$

All three ways converge into the same carbamate intermediate $\mathbf{2 3 0}$ and they rely on the same carbon sources to construct 231. This work highlights how simple biomass-based building blocks, namely $\mathrm{GlcNH}_{2}$ and dimethylamine (available from methanol and ammonia ${ }^{367}$ can be transformed into valuable natural products without the use of fossil carbon sources.

2.3.2.4. Proximicin A. The nitrogen-containing furan derivative 3A5AF (203) was utilized by Sperry and coworkers for a proof-of-concept synthesis of proximicin A (241), ${ }^{368}$ a potential chemotherapeutic compound. ${ }^{369,370}$ It is the first natural product synthesis that uses this unique bio-based starting material, which appears to be perfectly suited for the synthesis

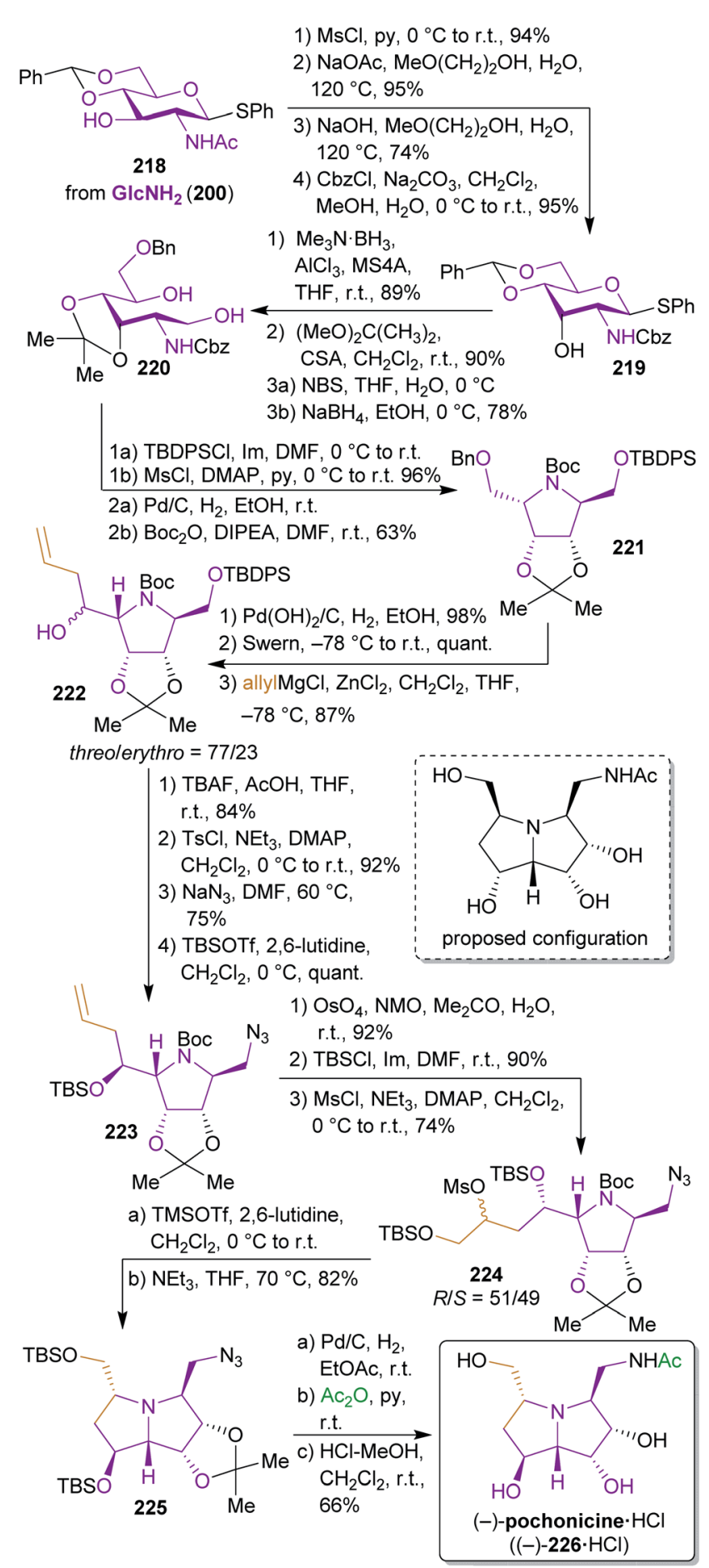

Scheme 35 Synthesis of (-)-pochonicine hydrochloride $((-)-226 \cdot \mathrm{HCl})$ from GlcNHAc. 


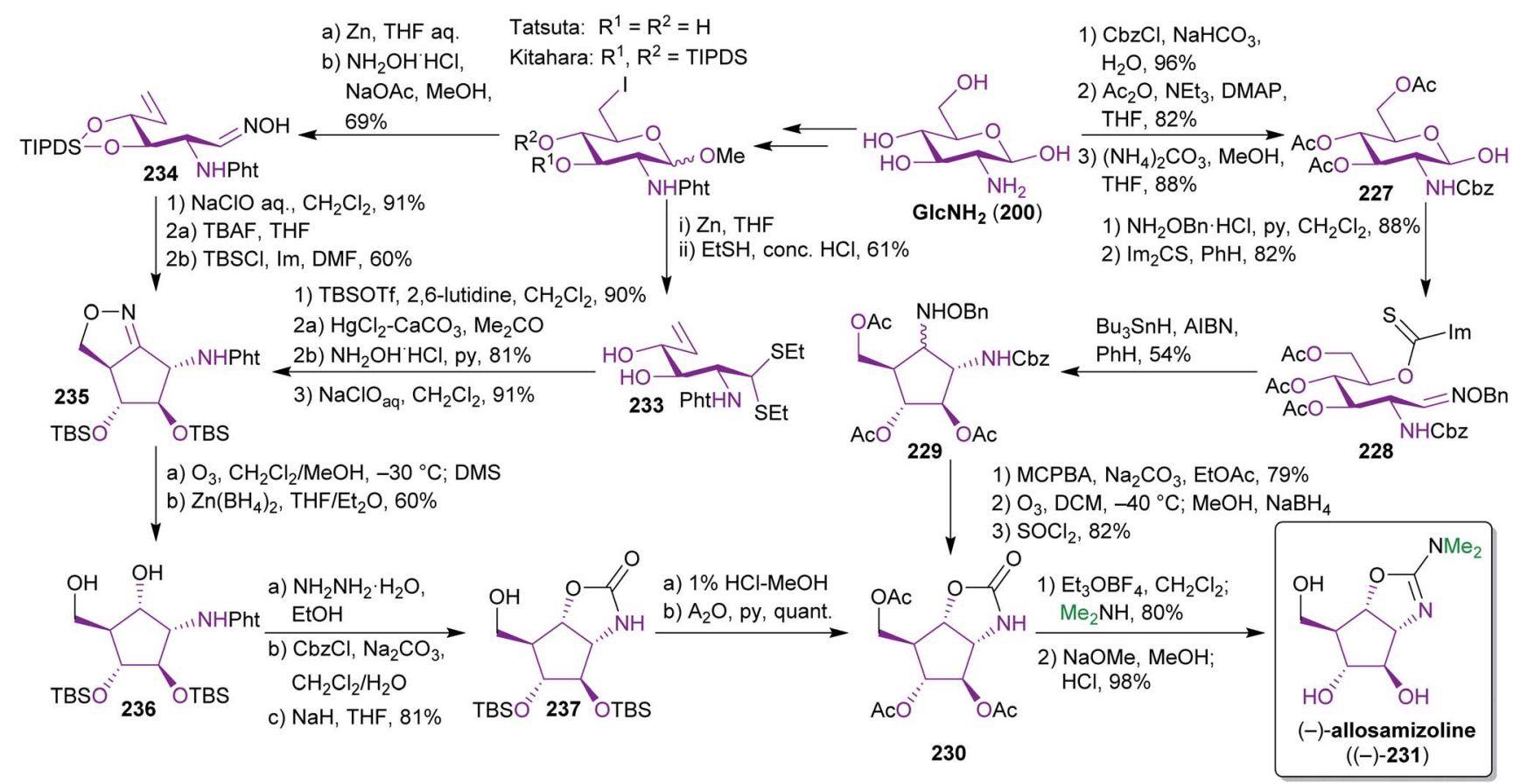

Scheme 36 Synthesis of (-)-allosamizoline ((-)-231) from $\mathrm{GlcNH}_{2}$.

of 241. Proximicin A was produced in a seven-step sequence from chitin via the key intermediates 238 and 239 (Scheme 37) simultaneously obeying the fundamentals of green chemistry (Scheme 38). In this remarkable work, only "green" solvents ([BMim]Cl - 1-butyl-3-methylimidazolium chloride, $\mathrm{MeOH}$, $\mathrm{H}_{2} \mathrm{O}, \mathrm{DMC}$ ) and procedures were used while it still compared well with former "non-green" syntheses of $\mathbf{2 4 1}$ in terms of step count and yields. ${ }^{369,370}$ The non-toxic dimethyl carbonate (DMC), which can be made directly from methanol and carbon monoxide in the presence of $\mathrm{CuCl}$ and oxygen, ${ }^{371-373}$ was used for the introduction of the carbamate moiety ${ }^{374}$ instead of the conventional methyl chloroformate. Furthermore, the amide coupling of the intermediates 238 and 239 was conducted with the uronium-based coupling reagent $\mathrm{COMU}^{375}((1-$ cyano-2ethoxy-2-oxoethylidenaminooxy)dimethylamino-morpholinocarbenium hexafluorophosphate) instead of the conventional, potentially explosive 1-hydroxybenzotriazole derivatives (e.g. TBTU, HATU, HBTU).

\subsection{Fats and oils}

Fats and oils, either of plant or animal origin, occur in the form of tri-, di- and monoglycerides with varying compositions of fatty acids depending on their origin. The annual production reaches almost $200 \mathrm{Mt}$ and has been increasing over the last decades. ${ }^{376,377}$ Although this figure indicates a very large industrial product class, one has to keep in mind that the largest fraction of this amount is used for food and feed. Furthermore, with the advent of biodiesel, the ratio of utilization of fats and oils for food/feed versus industry was slowly shifting from $86: 14$ to $80: 20$ over the past few decades. ${ }^{378}$ If this ethical dilemma could be solved, fats and oils would represent a structurally ideal renewable feedstock not only for the production of chemical raw materials and synthetic chemistry but also for fuel and polymer production.

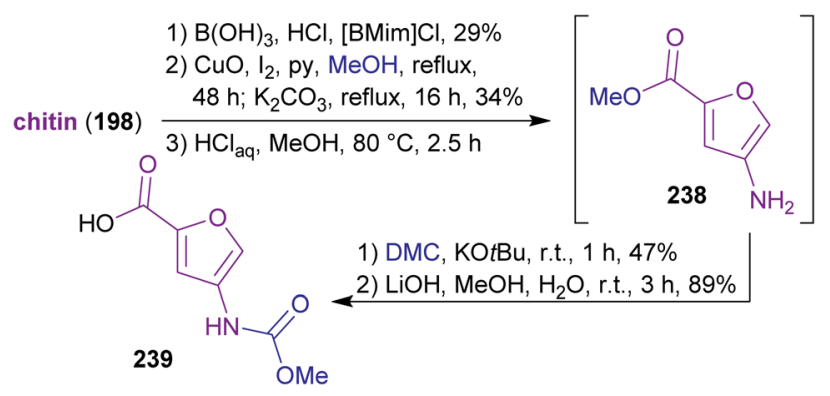

Scheme 37 Synthesis of key intermediates 238 and 239 for proximicin A (241) from chitin via 3A5AF (203).

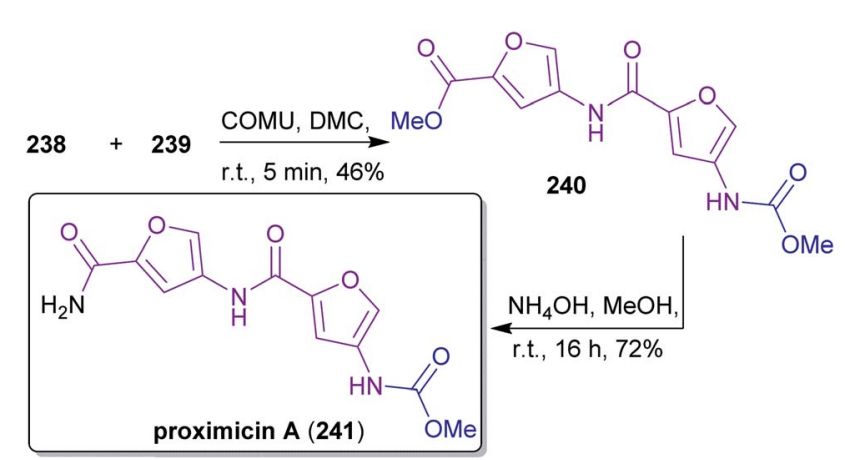

Scheme 38 Closing amide coupling and amide synthesis for proximicin A (241). 
2.4.1. Valorization of fats and oils. The main application of fats and oils is the production of bio-based fuels and especially the production of biodiesel. ${ }^{379-381}$ In terms of fine chemicals, plant oils have recently gained attention from surfactant and polymer science. ${ }^{349,382}$ The number of chemical raw materials that can be produced from fats and oils is very large and these have been reviewed in depth elsewhere. ${ }^{349,383-385}$

After saponification (the production of soap in this process is the origin of this word), the free fatty acids can be processed in various ways leading to different raw materials depending on the chain length, the degree of unsaturation and the position of the double bonds of the fatty acid. Glycerol is produced on a large scale through saponification of fats and oils ${ }^{346}$ and e.g. can serve for the production of glyceraldehyde,,$^{386,387}$ allylic alcohol,,$^{217}$ acrolein, ${ }^{388}$ and acrylic acid ${ }^{179}$ as well as of polymers of the latter. The main methods to valorize free fatty acids for chemical production are esterification, reduction, allylic oxidation, addition, dihydroxylation, epoxidation, cycloaddition, metathesis and ozonolysis. The latter two methods permit the simple variation of the length of the carbon chain. For example, erucic acid (docos13-enoic acid), which is very abundant in rapeseed and mustard oil, ${ }^{389}$ can be converted to brassylic acid (tridecanedioic acid) derivatives by ozonolysis ${ }^{390}$ or to 13 -tetradecenoic acid derivatives by olefin metathesis (see the synthesis of rhizochalinin, Scheme 34). ${ }^{348,349}$ Likewise, 9-decenoic acid is available from the abundant oleic acid $^{391,392}$ whereas meadowfoam seed oil, rich in eicos-5enoic acid (153), ${ }^{393,394}$ can be converted to 1-pentadecanal (276) by ozonolysis. ${ }^{395}$ In natural product synthesis, starting materials derived from fats and oils usually serve for the introduction of alkyl chains and generally have to be combined with other building blocks to introduce heteroatoms and stereoinformation.

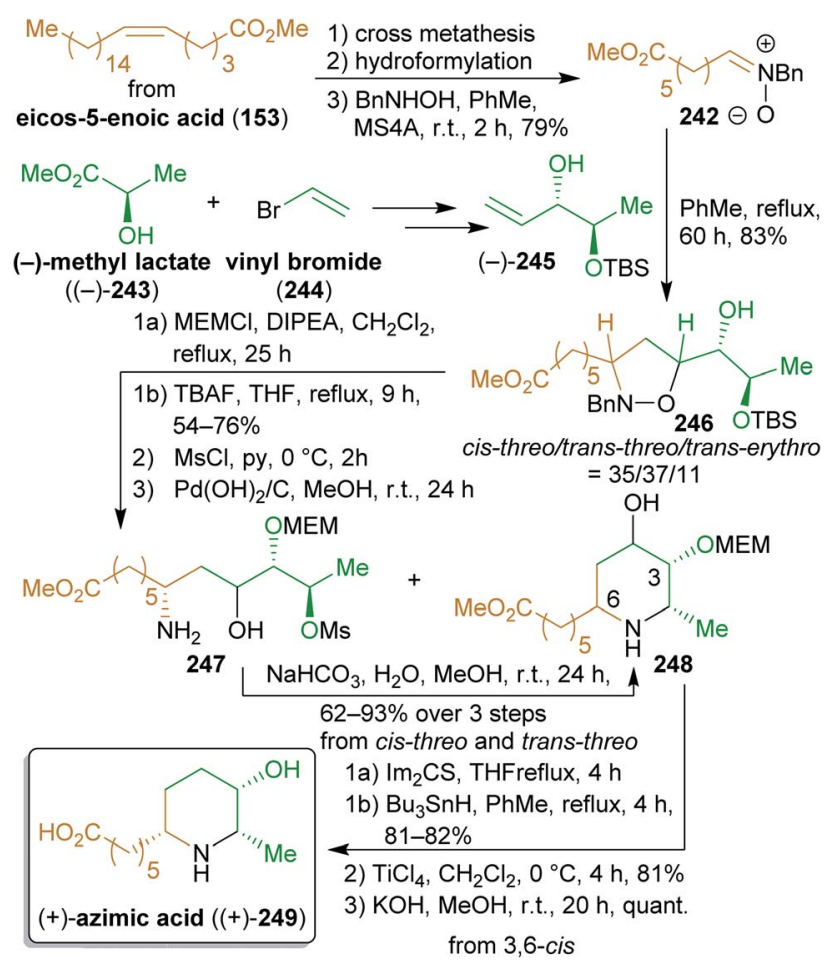

Scheme 39 Synthesis of (+)-azimic acid ((+)-249).
2.4.2. Natural product syntheses using fats and oils derived starting materials

2.4.2.1. (+)-Azimic acid and (+)-julifloridine. Following this approach, the Naito group has accomplished the total synthesis of two 3-piperidinol alkaloids, (+)-azimic acid ((+)-249) and $(+)$-julifloridine $((+)-253),{ }^{396,397}$ using methyl lactate $(243)$ as the chiral template and eicos-5-enoic acid (153) as well as erucic acid derived building blocks (Schemes 39 and 40). Both enantiomers of lactic acid are readily available by fermentation of almost any type of carbohydrate biomass, ${ }^{398}$ whereas vinyl bromide is accessible from ethanol via ethylene (the so-called bio-ethylene) and 1,1- or 1,2-dibromoethane.

Methyl esters (+)-321 and (-)-321 were converted to the respective enantiopure olefins $\left((+)-245\right.$ and (-)-245) ${ }^{399}$ which served as the dipolarophiles in a 1,3-dipolar cycloaddition with the nitrones $\mathbf{2 4 2}$ and $\mathbf{2 5 0}$. Both are accessible from fatty acid starting materials. The terminal olefin obtained from cross-metathesis of methyl ester of $\mathbf{1 5 3}$ with ethylene ${ }^{349}$ can be converted to $\mathbf{2 4 2}$ by hydroformylation ${ }^{\mathbf{4 0 0 , 4 0 1}}$ and reaction with N-benzylhydroxylamine. Ozonolysis of methyl erucate (205) and reduction of the product gives tridecan-1,13-diol, which was converted to nitrone 250. The cycloadditions produced three different diastereomers, of which the cisthreo- and the trans-erythro-form could be converted to (+)-249.

Because of the different configuration of julifloridine (253), only the trans-threo diastereomer (shown in Scheme 40) was converted to $(+)-253$. The foregoing work accomplished a very step-efficient synthesis of two stereochemically challenging natural products from simple building blocks.

2.4.2.2. (-)-Panclicin D. Romo's concise synthesis ${ }^{\mathbf{4 0 2 , 4 0 3}}$ of the $\beta$-lactone panclicin $\mathrm{D}$ (261) with pancreatic lipase inhibiting activity $^{\mathbf{4 0 4 , 4 0 5}}$ exclusively uses fat- and oil-derived starting

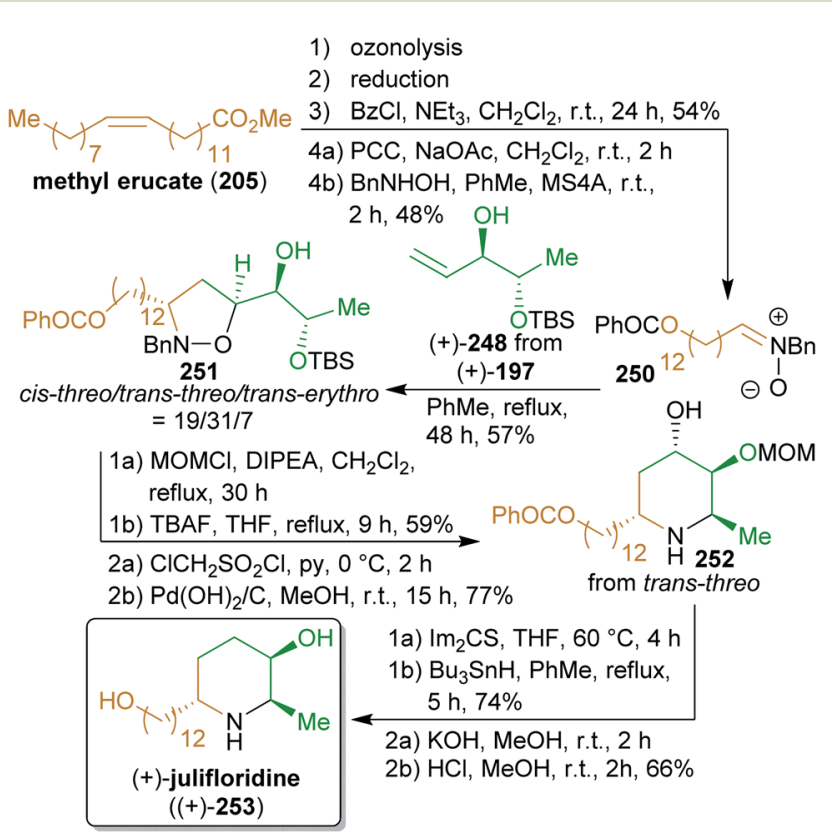

Scheme 40 Synthesis of (+)-julifloridine ((+)-253). 


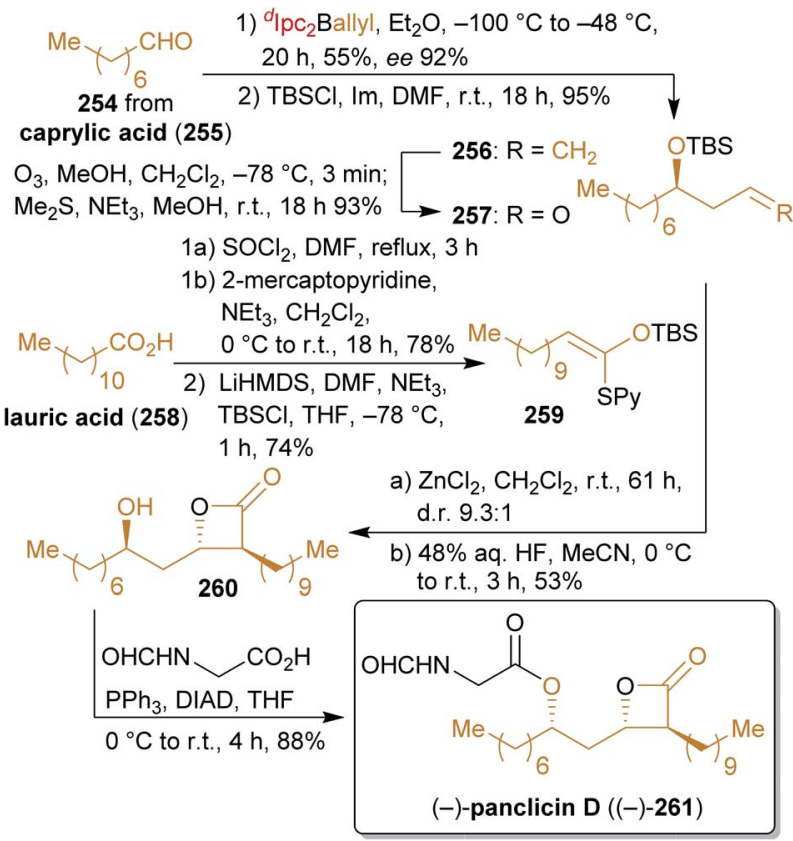

Scheme 41 Synthesis of (-)-panclicin D ((-)-261) by Romo et al.

materials in the form of lauric acid (258) and caprylic acid (255) as the main carbon sources as well as allyl diisopinocampheylborane as a terpene/glycerol-derivable chiral allylating agent (Scheme 41). While lauric acid is very abundant in laurel oil (hence the name), in coconut milk and oil as well as in palm kernel oil, caprylic acid can also be found in coconut oil, albeit in much lower concentration. ${ }^{406,407}$ Caprylic acid can be produced by de novo synthesis from bio-engineered yeast or $E$. coli strains ${ }^{408-410}$ or by anaerobic microbial fermentation from ethanol and acetate via chain elongation. ${ }^{411,412}$

Lauric acid is converted to the ketene thioacetal 259 which is subjected to a tandem Mukaiyama aldol-lactonization with aldehyde $\mathbf{2 5 7}$ to form the $\beta$-lactone ring. For the synthesis of 257 , methyl caprylate is converted to octanal $(\mathbf{2 5 4})^{413}$ followed by enantioselective addition of an allyl group, protection and ozonolysis. After desilylation, $\mathrm{N}$-formyl glycine was attached by a Mitsunobu reaction to furnish (-)-panclicin D ((-)-261). The use of little functionalized starting materials for the formation of this interesting natural product makes this synthesis remarkable.

2.4.2.3. (+)-Prosophylline and (+)-prospinine. The antibiotic piperidine alkaloids $(+)$-prosophylline $((+)-272)^{414}$ and $(+)$-prosopinine $((+)-273)^{415,416}$ were synthesized by Helmchen et al. via an iridium-catalyzed allylic substitution (Scheme 42). ${ }^{417,418}$ This key reaction was used twice during the synthesis to introduce and modify the required stereochemistry. The first application of this methodology was the conversion of the trityl-protected carbonate 262 available from dimethyl fumarate ${ }^{419}$ to allylic amine 264 . Dimethyl fumarate can be obtained from malic acid or furfural (207), ${ }^{420-422}$ both available from cellulose. After epoxidation,

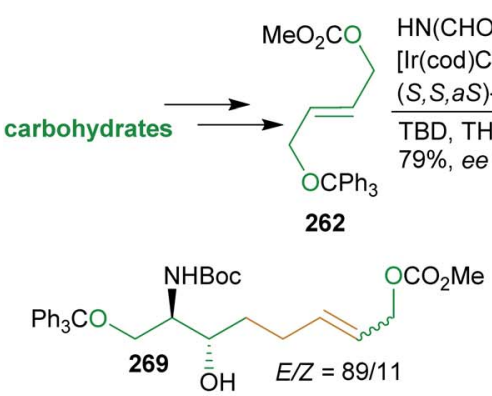

a) TFA, $\mathrm{CH}_{2} \mathrm{Cl}_{2}$, b) TBDMSCl, Im, $\mathrm{CH}_{2} \mathrm{Cl}_{2}$, \begin{tabular}{l|l} 
r.t., $1 \mathrm{~h}$ & $0{ }^{\circ} \mathrm{C}$ to r.t., $84 \%$
\end{tabular}
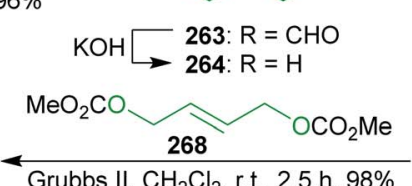

Grubbs II, $\mathrm{CH}_{2} \mathrm{Cl}_{2}$, r.t., 2.5 h, $98 \%$
MCPBA, $\mathrm{CH}_{2} \mathrm{Cl}_{2}$, $40{ }^{\circ} \mathrm{C}, 24 \mathrm{~h}, 78 \%$ anti/syn $=13 / 87$ ally $\mid \mathrm{MgCl}, \mathrm{Cul}, \mathrm{THF}$,
$-40^{\circ} \mathrm{C}$ to r.t., $18 \mathrm{~h}$,
$86 \%$, d.r. $33: 1$ $\mathrm{Ph}_{3} \mathrm{CO}$ NHBoc<smiles></smiles>

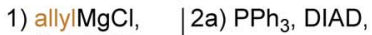
Cul, THF, $\quad \mathrm{AcOH}, \mathrm{PhMe}$, $-40{ }^{\circ} \mathrm{C}$ to r.t., $\quad 0^{\circ} \mathrm{C}$ to r.t., $29 \mathrm{~h}$ 22 h, d.r. $9: 1,2$ b) $\mathrm{K}_{2} \mathrm{CO}_{3}, \mathrm{MeOH}$, $87 \%$

$$
\text { Oे threo-267 }
$$

1) $\mathrm{CbzCl}, \mathrm{Na}_{2} \mathrm{CO}_{3}, \mathrm{CH}_{2} \mathrm{Cl}_{2}$ $0{ }^{\circ} \mathrm{C}$ to r.t., $2.5 \mathrm{~h}, 97 \%$

2) $\mathrm{HCl}_{\mathrm{aq}}, \mathrm{MeOH}$, r.t., $2.5 \mathrm{~h}, 99 \%$

3) Grubbs II-Hoveyda, $\mathrm{CH}_{2} \mathrm{Cl}_{2}$, reflux to r.t., $25 \mathrm{~h}, 58 \%$

4) $\mathrm{Pd}(\mathrm{OH})_{2} / \mathrm{C}, \mathrm{H}_{2}, \mathrm{MeOH}$, r.t., $1 \mathrm{~h}$, quant.

5) $\mathrm{NaOH}$, quant.

1) $\mathrm{CbzCl}, \mathrm{Na}_{2} \mathrm{CO}_{3}, \mathrm{CH}_{2} \mathrm{Cl}_{2}$ $0{ }^{\circ} \mathrm{C}$ to r.t., $15 \mathrm{~min}, 94 \%$ 2) $\mathrm{HCl}_{\mathrm{aq}}, \mathrm{MeOH}$, r.t., $2.5 \mathrm{~h}, 94 \%$

3) Grubbs II-Hoveyda, $\mathrm{CH}_{2} \mathrm{Cl}_{2}$, reflux to r.t., $24 \mathrm{~h}, 62 \%$

4) $\mathrm{Pd}(\mathrm{OH})_{2} / \mathrm{C}, \mathrm{H}_{2}$, $\mathrm{MeOH}$, r.t., 3 h, quant.<smiles>CC(C)N([C@@H](C)Br)p1oc2ccc3ccccc3c2c2c(ccc3ccccc32)o1</smiles>

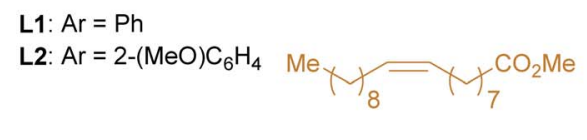

methyl oleate (274)

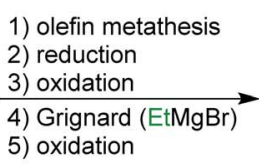

5) oxidation
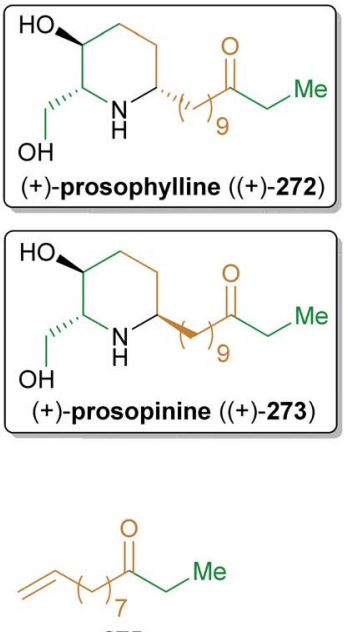

275

Scheme 42 Synthesis of (+)-prosophylline ((+)-272) and (+)-prospinine ((+)-273). TBD =1,5,7-triazabicyclo[4.4.0]dec-5-ene. 
Grignard reaction and cross metathesis with a biscarbonate likewise accessible from dimethyl fumarate, the nitrogen was deprotected to enable the ring closure, while the free hydroxy group was protected. Both diastereomers from the epoxidation reaction were convergently converted to the same threo-amino aclohol 267 with the desired configuration. Again, allylic substitution with both enantiomers of the chiral ligand (L2) led to the respective piperidine diastereomers $\mathbf{2 7 1 a}$, b with excellent ee and high $\mathrm{dr}$ which is the result of extensive optimization studies. Nprotection, olefin metathesis with dodec-1-en-10-one (275), hydrogenation and Cbz-removal led to the desired natural products $\mathbf{2 7 2}$ and 273 . Ketone $275^{423}$ is produced from the cross metathesis product of methyl oleate (274) with ethylene. ${ }^{275}$

This synthesis is characterized by the use of powerful methodology for the catalytic introduction of chiral information in combination with the utilization of various sustainable carbon sources to produce two alkaloids through a common precursor.

2.4.2.4. (+)-Jaspine B. The cytotoxic marine natural product jaspine $B$ (281) received great attention since its isolation and elucidation in $2002^{\mathbf{4 2 4 , 4 2 5}}$ and numerous synthetic approaches have been published in the past decade 226-436 $^{\text {due to its }}$ remarkably low $\mathrm{IC}_{50}$-values against a variety of tumor cell lines. ${ }^{\mathbf{4 2 4}}$ Among these syntheses, the concise procedure of Enders and coworkers stands out, which starts from protected dihydroxyacetone 277 and 1-pentanal (276). Dihydroxyacetone (278) is produced on a large scale from glycerol by fermentation. ${ }^{437}$ The acetonide 277 is subjected to an organocatalyzed aldol reaction with 276 (Scheme 43). After stereoselective reduction of the keto group, the generated hydroxy group was converted to an azide moiety under inversion of the configuration. The same sequence was used for the ring closure to furnish the tetrahydrofuran ring with the required configuration. After hydrogenation of the azide group, (+)-jaspine B $((+)-281)$ was obtained in high stereoselectivity.

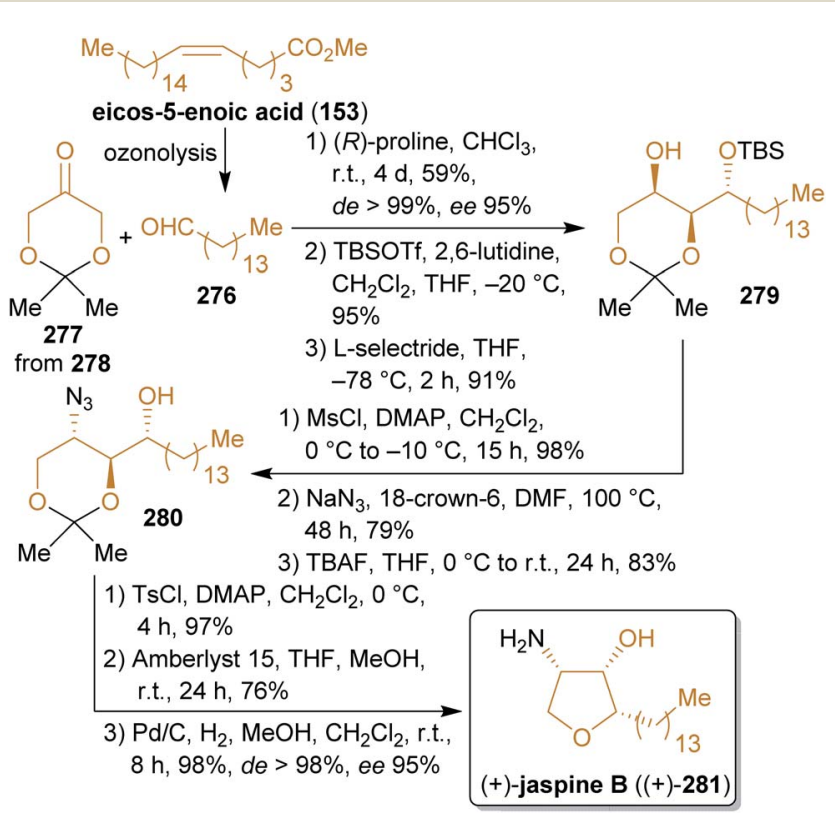

Scheme $43(+)$-Jaspine B ((+)-281) synthesis.
2.4.2.5. (+)-Pancratistatin. The antiproliferative isocarbostyril alkaloid pancratistatin $(\mathbf{2 8 8})^{\mathbf{4 3 8 , 4 3 9}}$ was synthesized by Alonso et al. ${ }^{\mathbf{4 4 0}}$ from 277 and the xylochemical vanillin (4). The correct stereochemistry is established by the organocatalyzed reaction of 277 with nitroenal $283^{441}$ during which five stereocenters are formed (Scheme 44). Nitro group reduction, carbamate formation and reduction of the keto group gave the precursor $\mathbf{2 8 6}$ for the Bischler-Napieralski reaction, after which global deprotection led to (+)-pancratistatin ((+)-288). 2-Nitroethanol can be considered a xylochemical since it is produced from nitromethane (itself available in a single operation from methanol $)^{\mathbf{4 2} 2}$ and formaldehyde. ${ }^{\mathbf{4 4 3}}$ The presented approach is very straightforward and uses renewable inexpensive starting materials as well as simple synthetic methods.

2.4.2.6. Ophiocerins and (-)-botryolide $E$. The following synthesis of the ophiocerins A-C (300, 292 and 295) and

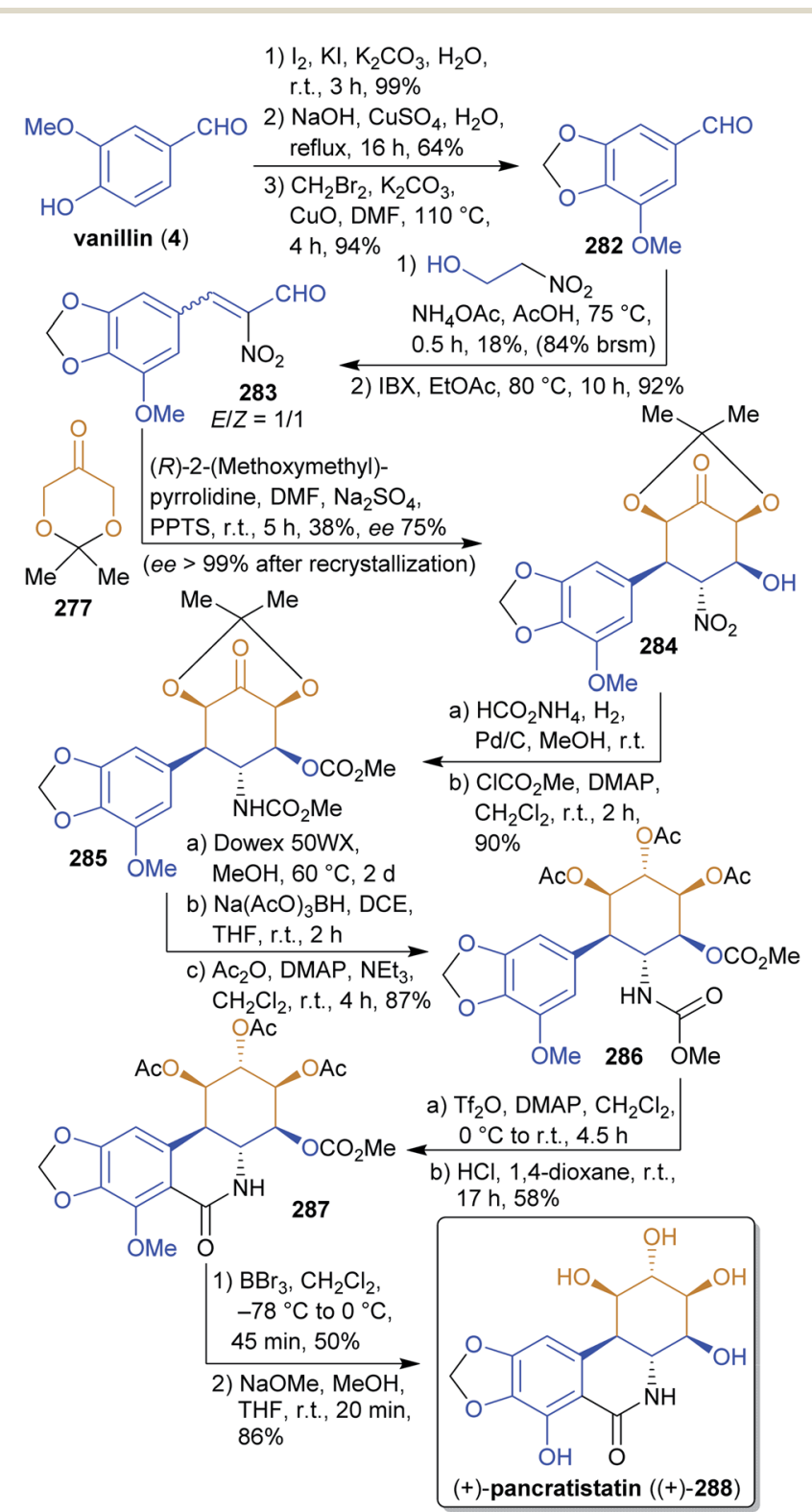

Scheme 44 Total synthesis of (+)-pancratitstatin ((+)-288) by Alonso et al. 

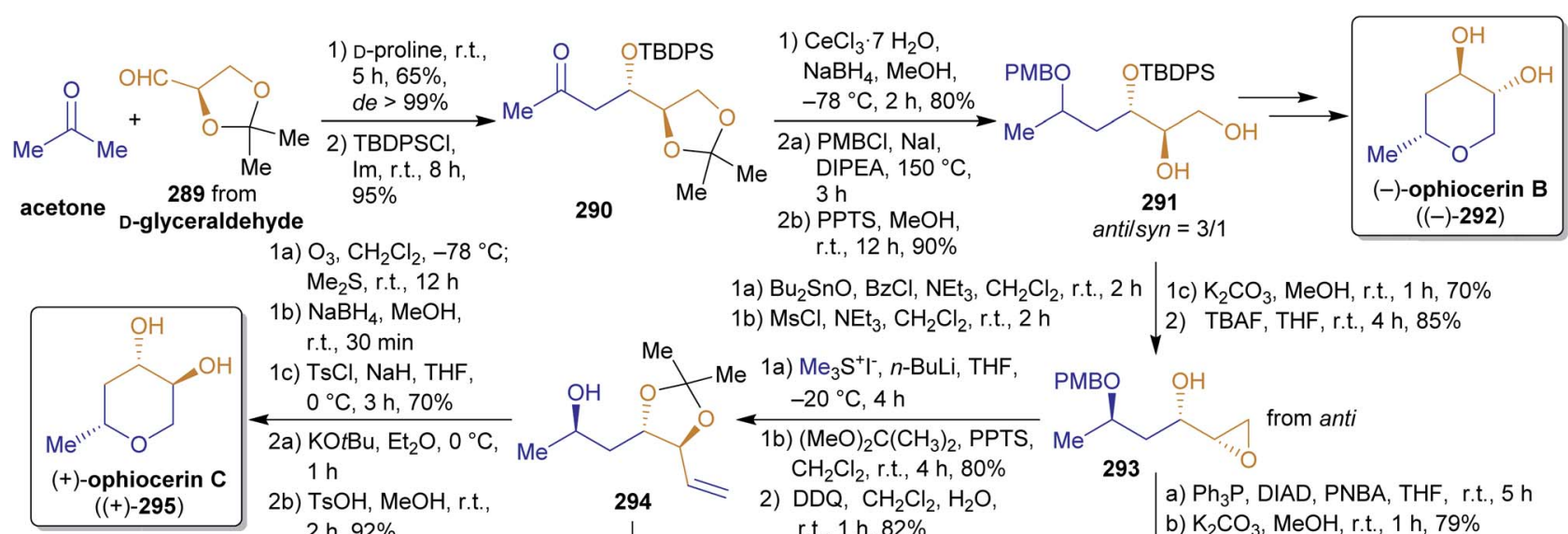

$$
\mathrm{Me}_{2} \mathrm{~S} \text {, r.t., } 12 \mathrm{~h}
$$

1b) $\mathrm{NaBH}_{4}, \mathrm{MeOH}$ r.t., $30 \mathrm{~min}$

1c) $\mathrm{TsCl}, \mathrm{NaH}, \mathrm{THF}$, $0^{\circ} \mathrm{C}, 3 \mathrm{~h}, 70 \%$ 2a) $\mathrm{KOtBu}, \mathrm{Et}_{2} \mathrm{O}, 0^{\circ} \mathrm{C}$ $1 \mathrm{~h}$
2b) $\mathrm{TsOH}, \mathrm{MeOH}$, r.t., 2 h, $92 \%$

1) $\mathrm{Ac}_{2} \mathrm{O}, \mathrm{DMAP}$, py, r.t., $4 \mathrm{~h}, 90 \%$ 2a) $\mathrm{O}_{3}, \mathrm{CH}_{2} \mathrm{Cl}_{2},-78^{\circ} \mathrm{C}$; $\mathrm{Me}_{2} \mathrm{~S}$, r.t., $12 \mathrm{~h}$
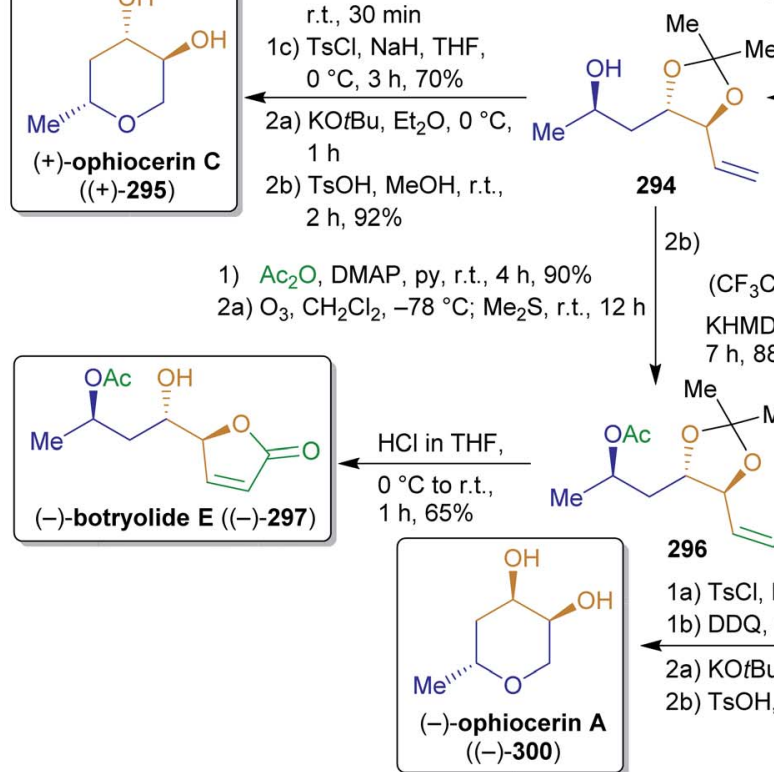

$\begin{array}{lll}\text { 1a) } \mathrm{Bu}_{2} \mathrm{SnO}, \mathrm{BzCl}, \mathrm{NEt}_{3}, \mathrm{CH}_{2} \mathrm{Cl}_{2} \text {, r.t., } 2 \mathrm{~h} & \text { 1c) } \mathrm{K}_{2} \mathrm{CO}_{3}, \mathrm{MeOH} \text {, r.t., } 1 \text { h, } 70 \%\end{array}$ 1b) $\mathrm{MsCl}, \mathrm{NEt}_{3}, \mathrm{CH}_{2} \mathrm{Cl}_{2}$, r.t., $2 \mathrm{~h}$

2) TBAF, THF, r.t., $4 \mathrm{~h}, 85 \%$

1a) $\mathrm{Me}_{3} \mathrm{~S}^{+} \mathrm{I}^{-}, n$-BuLi, THF,

$-20^{\circ} \mathrm{C}, 4 \mathrm{~h}$

1b) $(\mathrm{MeO})_{2} \mathrm{C}\left(\mathrm{CH}_{3}\right)_{2}$, PPTS, $\mathrm{M}$ $\mathrm{CH}_{2} \mathrm{Cl}_{2}$, r.t., $4 \mathrm{~h}, 80 \%$

2) $\mathrm{DDQ}, \mathrm{CH}_{2} \mathrm{Cl}_{2}, \mathrm{H}_{2} \mathrm{O}$, r.t., $1 \mathrm{~h}, 82 \%$

b) $\mathrm{O}$

$\left(\mathrm{CF}_{3} \mathrm{CH}_{2} \mathrm{O}\right)_{2} \stackrel{\text { II }}{P} \sim \mathrm{CO}_{2} \mathrm{Et}$ KHMDS, 18 -crown- $6,-78^{\circ} \mathrm{C}$, $7 \mathrm{~h}, 88 \%$

1a) $\mathrm{Me}_{3} \mathrm{~S}^{+} I^{-}, n$-BuLi, THF, $-20^{\circ} \mathrm{C}, 4 \mathrm{~h}$

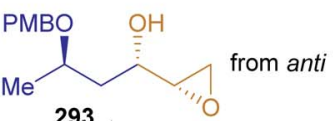

a) $\mathrm{Ph}_{3} \mathrm{P}, \mathrm{DIAD}, \mathrm{PNBA}, \mathrm{THF}$, r.t., $5 \mathrm{~h}$

b) $\mathrm{K}_{2} \mathrm{CO}_{3}, \mathrm{MeOH}$, r.t., $1 \mathrm{~h}, 79 \%$

$$
\checkmark
$$

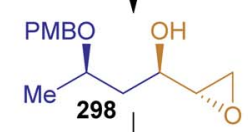

1b) $(\mathrm{MeO})_{2} \mathrm{C}\left(\mathrm{CH}_{3}\right)_{2}$, PPTS $\mathrm{CH}_{2} \mathrm{Cl}_{2}$, r.t., $4 \mathrm{~h}, 82 \%$

2a) $\mathrm{OsO}_{4}, \mathrm{NalO}_{4}$, 1,4-dioxane,

$\mathrm{H}_{2} \mathrm{O}, \mathrm{rt} ., 12 \mathrm{~h}$

2b) $\mathrm{NaBH}_{4}, \mathrm{MeOH}$, r.t., $30 \mathrm{~min}, 80 \%$

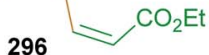

1a) $\mathrm{TsCl}, \mathrm{NEt}_{3}, \mathrm{CH}_{2} \mathrm{Cl}_{2}$, r.t., $3 \mathrm{~h}$ 1b) $\mathrm{DDQ}, \mathrm{CH}_{2} \mathrm{Cl}_{2}, \mathrm{H}_{2} \mathrm{O}$, r.t., $1 \mathrm{~h}, 83 \%$

2a) $\mathrm{KOtBu}, \mathrm{Et}_{2} \mathrm{O}, 0^{\circ} \mathrm{C}, 1 \mathrm{~h}$

2b) $\mathrm{TsOH}, \mathrm{MeOH}$, r.t., 2 h, $92 \%$

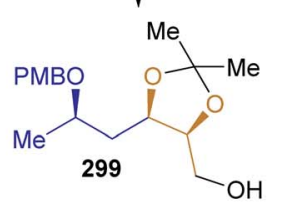

$((-)-300)$

Scheme 45 Synthesis of ophiocerins A-C (300, 292 and 295) and botryolide E (297).

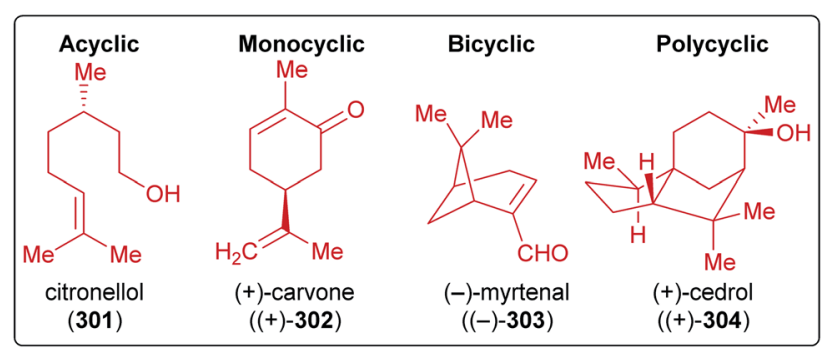

Scheme 46 Different classes of terpenes.

botryolide $\mathrm{E}(297)^{444}$ is an excellent example of the combination of a biomass-derived chiral precursor (isopropylideneglyceraldehyde (289)), other renewables-derived simple building blocks and organocatalysis for the formation of a variety of natural products (Scheme 45). Like dihydroxyacetone, glyceraldehyde can be generated from glycerol, e.g. by aerial oxidation over platinum catalysts, ${ }^{386}$ or directly by fermentation of carbohydrate biomass. ${ }^{45}$ Proline-catalyzed aldol reaction of acetonide-protected aldehyde 289 and acetone led to the respective $\beta$-hydroxy ketone $\mathbf{2 9 0}$ in excellent $d e$ which was protected with a TBDPS group. Before the cumene process was introduced, acetone was produced by Weizmann's acetone-butanol-ethanol (ABE) fermentation of carbohydrates through Clostridium acetobutylicum. ${ }^{446}$ Another source of

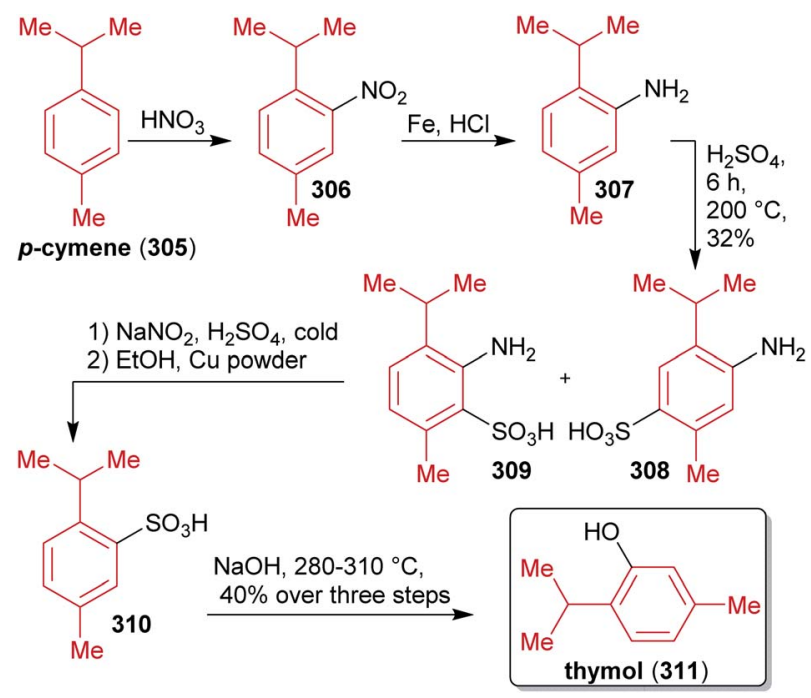

Scheme 47 Synthesis of thymol (311) from p-cymene (305).

acetone is the pyrolysis and dry distillation of wood and therefore it is considered a xylochemical. ${ }^{290,291}$ Reduction, PMBprotection and acetonide cleavage led to the pivotal intermediate 291 and all four natural products that were mentioned earlier were synthesized from this anti-diastereomer. For the synthesis of ophiocerins A and C (300 and 295), the secondary 


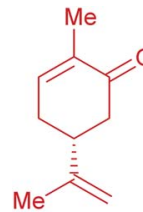

(-)-carvone $((-)-302)$

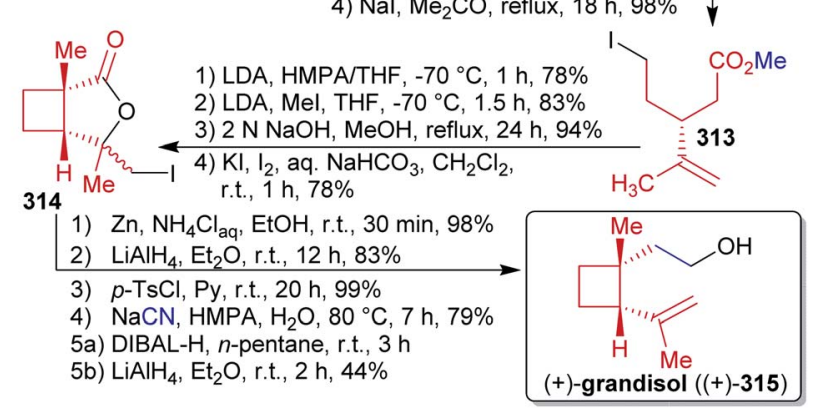

Scheme 48 Synthesis of $(+)$-grandisol $((+)-315)$ from (-)-carvone ((-)-302).

hydroxy group was converted into a leaving group and the synepoxy alcohol 293 was formed by nucleophilic substitution. For 300, the inversion of alcohol, epoxide opening, acetonide protection, Lemiuex-Johnson oxidation and reduction were performed. Trimethylsulfonium iodide was used for the olefin synthesis from epoxide $\mathbf{2 9 3}$ (available from dimethylsulfide and iodomethane, ${ }^{447}$ both methanol-derived). After PMB cleavage, the primary alcohol was converted into a leaving group and the tetrahydropyran ring was closed by nucleophilic substitution. Final acetonide cleavage furnished (-)-ophiocerin A ((-)-300). Ophiocerin C (295) was synthesized by essentially the same sequence except that no inversion was conducted and that PMB deprotection was performed prior to olefin cleavage by ozonolysis to obtain a suitable intermediate for the synthesis of botryolide E (297). Likewise, ophiocerin B (292) was prepared via the respective anti-epoxy alcohol (sequence not shown).

Starting from the olefin $\mathbf{2 9 4}$, botryolide $\mathrm{E}$ was synthesized by ester synthesis, ozonolysis and the Still-Gennari modification of the Horner reaction to obtain E-olefin 296. The required phosphonate can be produced from an $\alpha$-haloacetic acid derivative and is therefore accessible by fermentation of carbohydrates through acetic acid. ${ }^{347,448,449}$ Acid catalyzed acetonide cleavage and lactone formation produced (-)-297.

The use of simple bio-based starting materials and pivotal intermediates for the stereochemically flexible synthesis of natural products are notable key features of this work.

\subsection{Terpenes}

Terpenes represent abundant and renewable, inexpensive and versatile chiral starting materials and were employed in natural product synthesis ever since ${ }^{\mathbf{8 0 , 4 5 0}}$ Furthermore, terpenes are one of the largest and most diverse classes of plant produced organic compounds and do not directly compete with food production. ${ }^{451-454}$

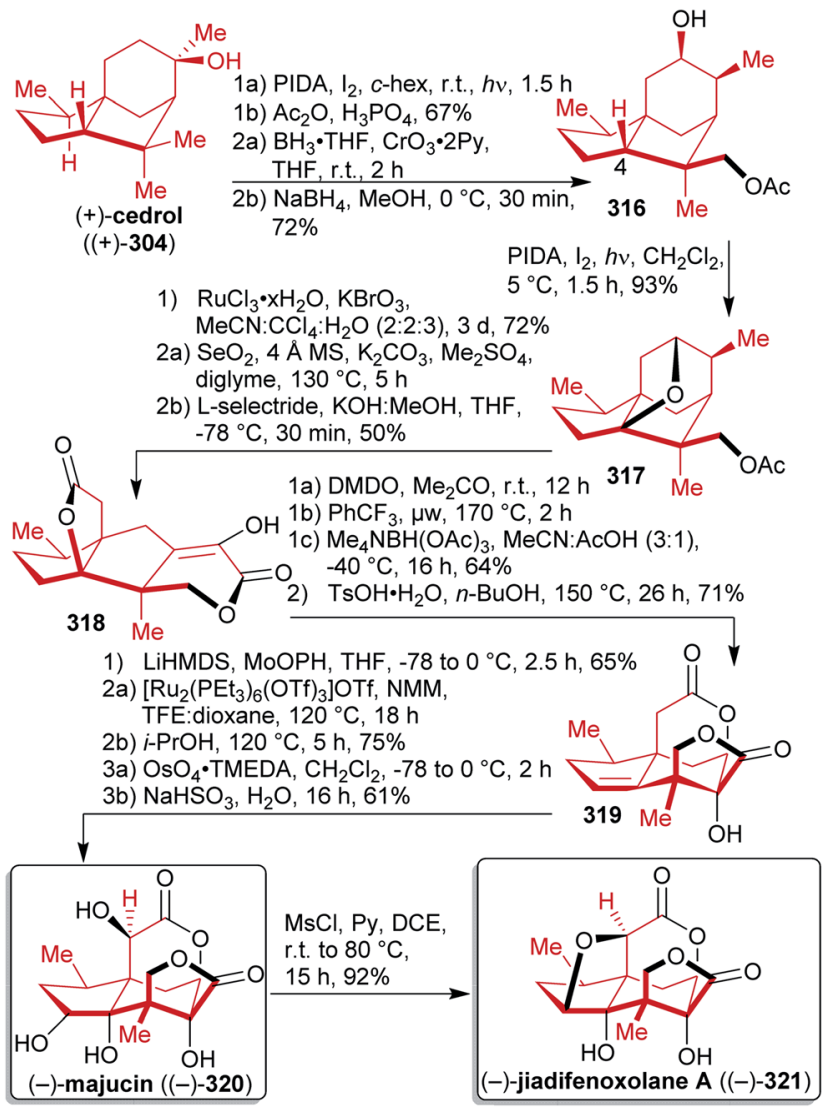

Scheme 49 Synthesis of (-)-majucin ((-)-320) and (-)-jiadifenoxolane A ((-)-321) from (+)-cedrol ((+)-304).

2.5.1. Valorization of terpene feedstock. Together with the amino acids and the carbohydrates, terpenes form the "chiral pool" (see the Introduction). ${ }^{455-457}$ Terpenes are hydrocarbon compounds usually containing one or more $\mathrm{C}=\mathrm{C}$-double bonds and having a limited degree of oxygenation. They can be divided into subgroups named after their carbon count, since isoprene units containing five $\mathrm{C}$-atoms are the biosynthetic precursors of all terpenes: ${ }^{452}$ the monoterpenes $\left(\mathrm{C}_{10}\right)$, the sesquiterpenes $\left(\mathrm{C}_{15}\right)$, the diterpenes $\left(\mathrm{C}_{20}\right)$, etc. They also differ in the arrangement of the isoprenoid units (acylic, mono- or polycyclic) and in their oxidation state (Scheme 46). Despite the enormous advances in asymmetric synthesis in the $20^{\text {th }}$ century, terpenes are still widely used as chiral starting materials. ${ }^{458}$ Furthermore, they can be useful as potential fuels, ${ }^{459}$ agents for the chemical communication of plants, flavor enhancement and pesticides, ${ }^{\mathbf{4 6 0 , 4 6 1}}$ or as a source of chirality in catalysts. ${ }^{81}$

The major sources of monoterpenes are turpentine oil (a waste product of paper pulp industry, contains mainly $\alpha$ - and $\beta$ pinene), ${ }^{462}$ and citrus oil (contains mainly (+)-limonene), ${ }^{463}$ a coproduct of citrus juice production. ${ }^{452}$ Terpenes can also be transformed and functionalized by biotechnological methods or biotransformations. ${ }^{452,464-466}$ For further information about sources of terpenes, their use in total synthesis and utilization as chiral building blocks, the reader may be referred to the literature. ${ }^{\mathbf{8 0 , 4 5 0 , 4 5 2}}$ 


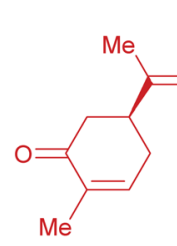

(+)-carvone $((+)-302)$

1a) $\mathrm{SO}_{2} \mathrm{Cl}_{2}, \mathrm{Na}_{2} \mathrm{CO}_{3}, \mathrm{CH}_{2} \mathrm{Cl}_{2}, \mathrm{O}^{\circ} \mathrm{C}, 2 \mathrm{~h}$

1b) $\mathrm{CeCl}_{3} \cdot 7 \mathrm{H}_{2} \mathrm{O}, \mathrm{NaBH}_{4}, \mathrm{MeOH}, 0{ }^{\circ} \mathrm{C}$ $1 \mathrm{~h}, 78 \%, 30 \mathrm{~g}$ scale

2) TBDPSCl, DMF, DMAP, r.t. overnight, $90 \%$, $20 \mathrm{~g}$ scale TBDPSO.

3a) $\mathrm{O}_{3}, \mathrm{Py}, \mathrm{CH}_{2} \mathrm{Cl}_{2},-78^{\circ} \mathrm{C}, 40 \mathrm{~min}$

3b) DMS, r.t., $8 \mathrm{~h}$

3c) $\mathrm{AcOH}$, piperidine, $40^{\circ} \mathrm{C}, 16 \mathrm{~h}$ $42 \%, 20 \mathrm{~g}$ scale

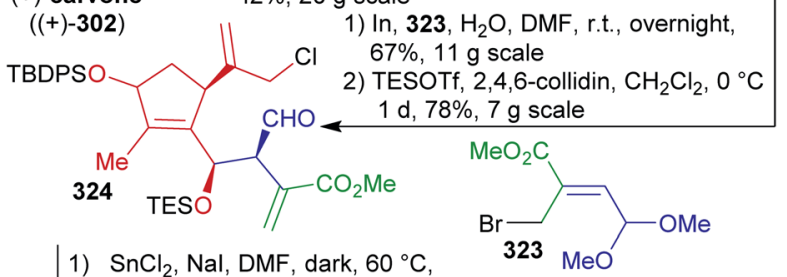

1) $\mathrm{SnCl}_{2}, \mathrm{Nal}, \mathrm{DMF}$, dark, $60^{\circ} \mathrm{C}$, $12 \mathrm{~h}, 90 \%, 7 \mathrm{~g}$ scale

2a) cat. $\mathrm{NaOMe}, \mathrm{MeOH}$, r.t., $16 \mathrm{~h}$

2b) $\mathrm{AcOH}, \mathrm{PtO}_{2}, \mathrm{H}_{2}$, r.t., $6 \mathrm{~h}$ a) TBAF, THF, DBU, r.t., overnight

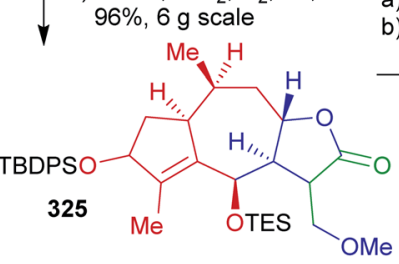

b) $\mathrm{MnO}_{2}, \mathrm{CH}_{2} \mathrm{Cl}_{2}$, r.t., $16 \mathrm{~h}$ $67 \%$, gram scale

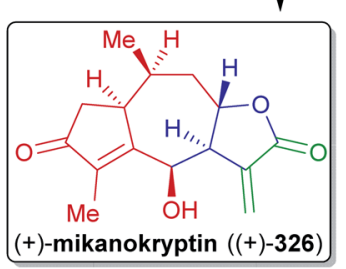

Scheme 50 Synthesis of (+)-mikanokryptin ((+)-326) using terpeneand wood-derived building blocks.

2.5.2. Natural product syntheses using terpene feedstock starting materials

2.5.2.1. Thymol. Phillips et al. published a five-step synthesis of natural thymol (311) in $1920 .{ }^{467}$ The synthesis commenced with nitration of natural $p$-cymene $(305)^{468}$ followed by Béchamp reduction. Sulfonation gave two isomeric products
309 and 308. Subsequent diazotation/reduction led to sulfonic acid 310. Fusion with $\mathrm{NaOH}$ finally produced thymol $(311)^{469}$ (Scheme 47). ${ }^{467}$

2.5.2.2. (+)-Grandisol. In 1992, Mori et al. reported a synthesis of the natural product (+)-grandisol ((+)-315) in eighteen steps and $\geq 98 \%$ ee (analyzed by GC). ${ }^{470}$

The synthesis commenced with epoxidation of (-)-carvone ((-)-302), accessible from biomass, ${ }^{\mathbf{4 7 1 , 4 7 2}}$ which is ring-opened oxidatively in a four-step sequence to yield acetal ester $\mathbf{3 1 2}$. The latter was reduced, tosylated, and subjected to a nucleophilic substitution by iodide furnishing iodoester 313. Subsequent cyclization, methylation and iodolactonization led to $\mathbf{3 1 4}$ (Scheme 48). The enantioselective synthesis was concluded by multiple reduction reactions, followed by tosylation, cyanation and further reductions affording the natural product (+)-grandisol $((+)-315) .^{470,473}$

Sodium cyanide is currently produced by the Andrussow process from methane and ammonia ${ }^{278,279}$ and a subsequent reaction with lye producing only water as the co-product. ${ }^{474}$ Considering that synthetic natural gas is a widely established concept, ${ }^{280} \mathrm{NaCN}$ is a potentially bio-based carbon source. ${ }^{281}$ Trimethyl orthoformate is accessible by the reaction of sodium methanolate with chloroform, another methane- or methanolderived chemical (vide supra). ${ }^{\mathbf{1 8 2}}$

The synthesis is not perfectly carbon-atom efficient as atoms are lost in the oxidation process of starting material $\mathbf{3 0 2}$.

A replacement for $\mathrm{NaCN}$ with a non-toxic source for cyanideanions would be favorable regarding "green" aspects. ${ }^{\mathbf{2 8 1 , 4 7 5}}$

2.5.2.3. (-)-Majucin and (-)-jiadifenoxolane A. Maimone et al. reported the first synthetic route to complex majucin-type natural products (-)-majucin ((-)-320) and (-)-jiadifenoxolane A ((-)-321) starting from the abundant feedstock (+)-cedrol $((+)-304) .{ }^{\mathbf{2 8 4 , 4 7 6 - 4 7 9}}$ The synthesis commenced with a Suárez oxidation, followed by a hydroboration/double oxidation

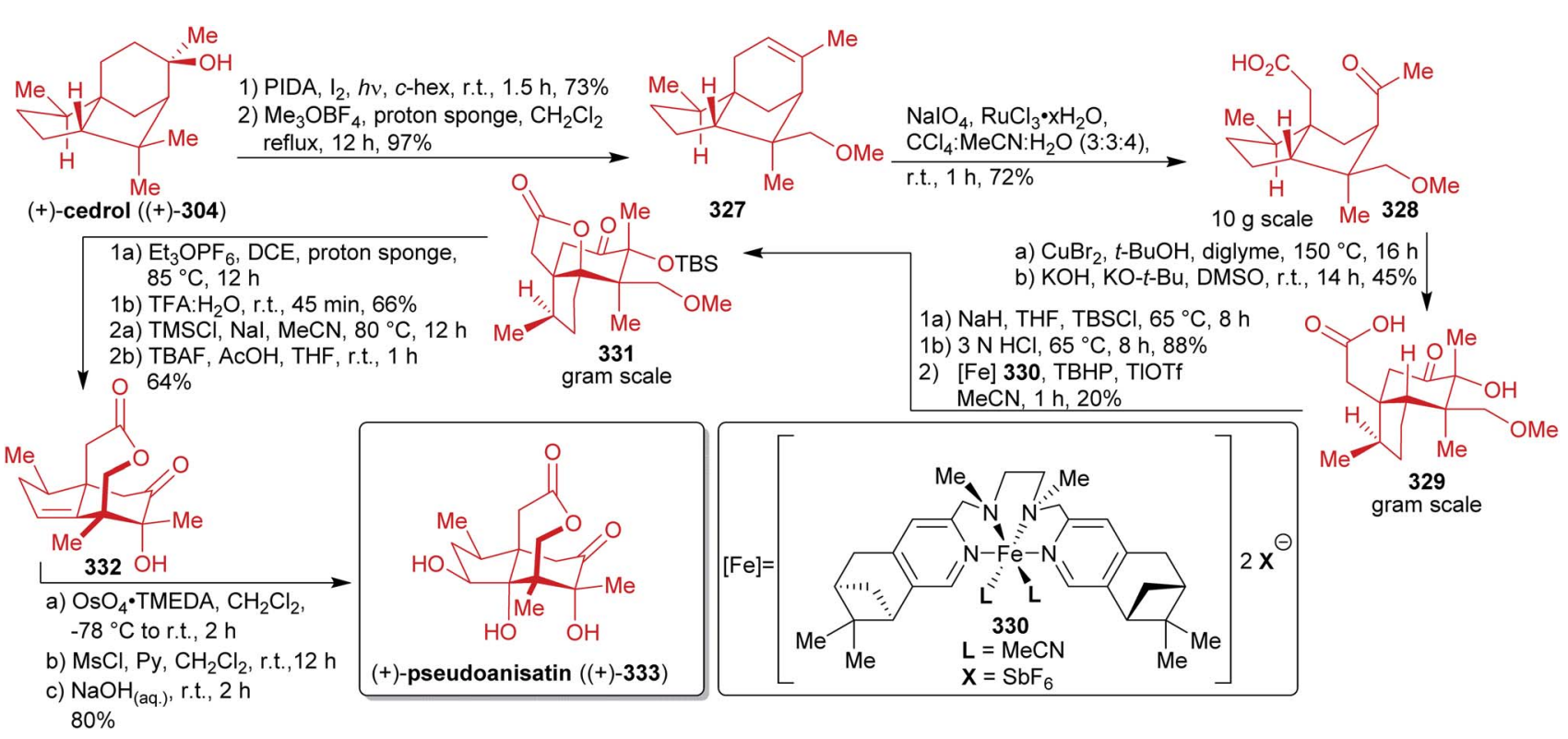

Scheme 51 Use of chiral starting material (+)-cedrol ((+)-304) for the first synthesis of (+)-pseudoanisatin ((+)-333). 
sequence and $\mathrm{NaBH}_{4}$ reduction yielding alcohol 316. The C-4 methine position was oxidized under Suárez conditions to afford ether 317. Oxidation with in situ-generated $\mathrm{RuO}_{4}$, Riley oxidation and treatment with L-selectride led to the tetracyclic enol lactone 318. The latter was transformed via DMDOoxidation to an $\alpha$-hydroxyketone, bond reorganization by heating in trifluorotoluene, selective reduction of the $\alpha$-ketol group using $\mathrm{Me}_{4} \mathrm{NBH}(\mathrm{OAc})_{3}$ and treatment with acid to furnish the $\delta$ lactone 319. (-)-Majucin ((-)-320) was obtained via an enolate oxidation using Vedejs' MoOPH reagent, subsequent epimerization via Ru-catalyzed transfer hydrogenation and final dihydroxylation. Majucin (320) was converted into (-)-jiadifenoxolane A ((-)-321) via an intramolecular etherification promoted by regioselective mesylation and nucleophilic displacement (Scheme 49).

Overall, 13 oxidations were employed while three reduction steps were necessary to achieve the correct oxidation state and for stereochemical adjustments. Favorable aspects in the light of "green" chemistry are the use of a photocatalyzed reaction, and of green solvents (acetone, $\mathrm{H}_{2} \mathrm{O}, \mathrm{MeOH}$ ), yet undesired solvents like $\mathrm{CCl}_{4}$ or $\mathrm{PhCF}_{3}$ also occur.

2.5.2.4. (+)-Mikanokryptin. Maimone et al. reported the first gram-scale total synthesis of a guaianolide natural product, $(+)$-mikanokryptin ((+)-326). The guaianolides are a major subgroup of sesquiterpene lactones and were investigated from both medicinal and synthetic perspectives. ${ }^{\mathbf{4 8 0}}$

The synthesis commenced with a one-pot chlorination and Luche reduction of the renewable $(+)$-carvone $((+)-302) .{ }^{481,482}$ This was followed by $O$-silylation and a regioselective ozonolysis of the trisubstituted $\mathrm{C}=\mathrm{C}$-double bond. Reductive quenching led to an intramolecular aldol condensation affording enal 322. The first of two allylation reactions afforded compound 324 and utilized allylic bromide 323 , which can be prepared from woodbased renewable resources methanol and glyoxal furnishing dimethoxyacetaldehyde. ${ }^{\mathbf{4 8 3 , 4 8 4}}$ The latter can be reacted with methyl acrylate ${ }^{485}$ and subsequently brominated to obtain

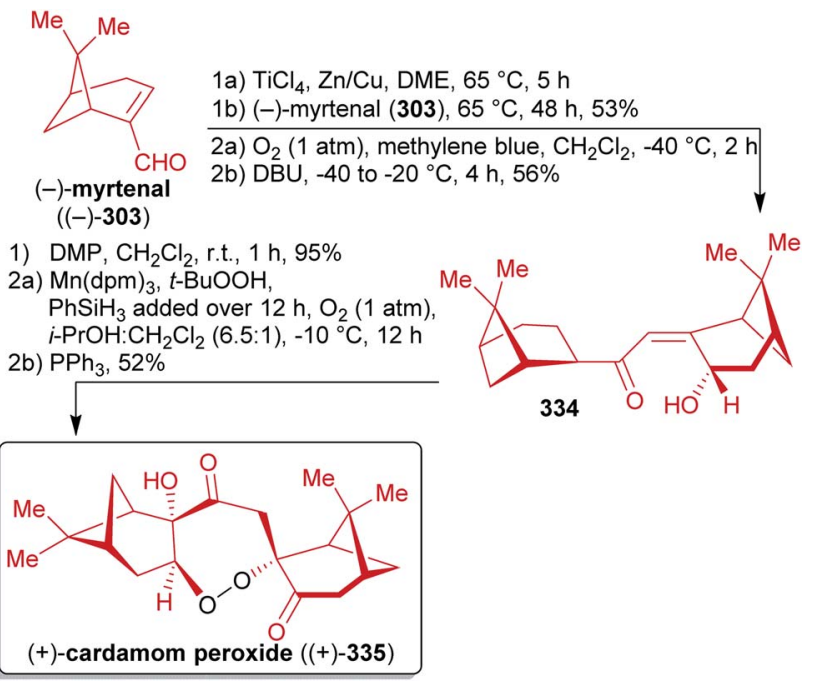

Scheme 52 Synthesis of (+)-cardamom peroxide ((+)-335) from (-)-myrtenal ((-)-303).

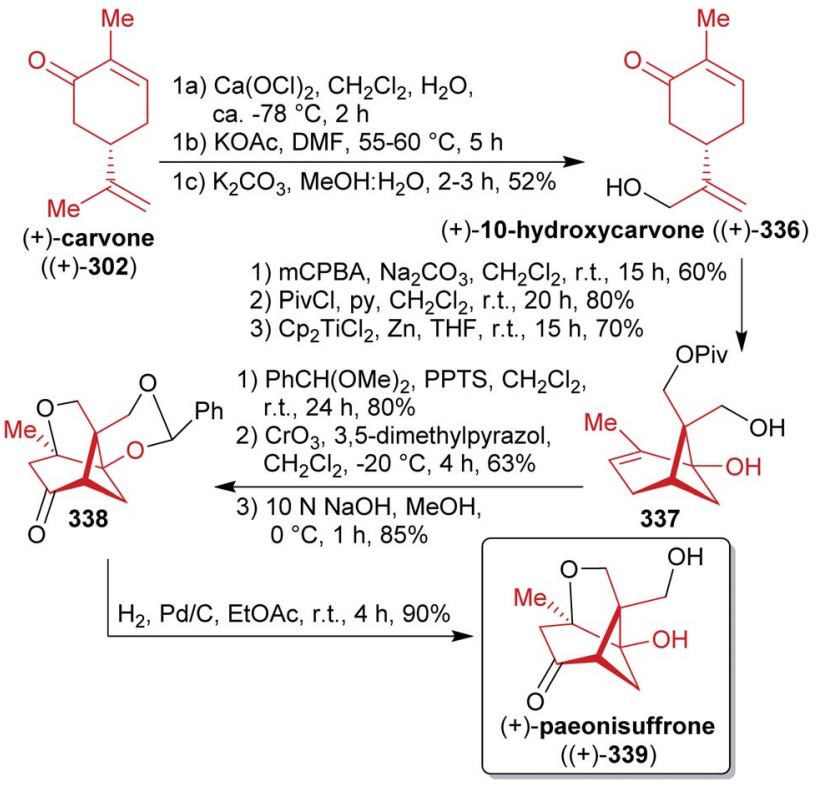

Scheme 53 Synthesis of (+)-paeonisuffrone ((+)-339) employing a Ti(III)-promoted epoxide opening and Ti(III)-catalyzed reductive $\mathrm{C}-\mathrm{C}$ formation as key step.

desired building block $323{ }^{480}$ The dehydration of lactic acid as a cheap and bio-based starting material for acrylic acid is of growing interest and could become a future source for this commodity chemical. ${ }^{\mathbf{1 7 7 - 1 8 1}}$ With the second (intramolecular) allylation reaction, the seven-memberd ring was formed, completing the full guaianolide skeleton 325. Via a reduction using Adams catalyst, subsequent desilylation and allylic oxidation using $\mathrm{MnO}_{2}$, the natural product (+)-mikanokryptin $((+)-326)$ was obtained (Scheme 50). ${ }^{\mathbf{4 8 6}}$

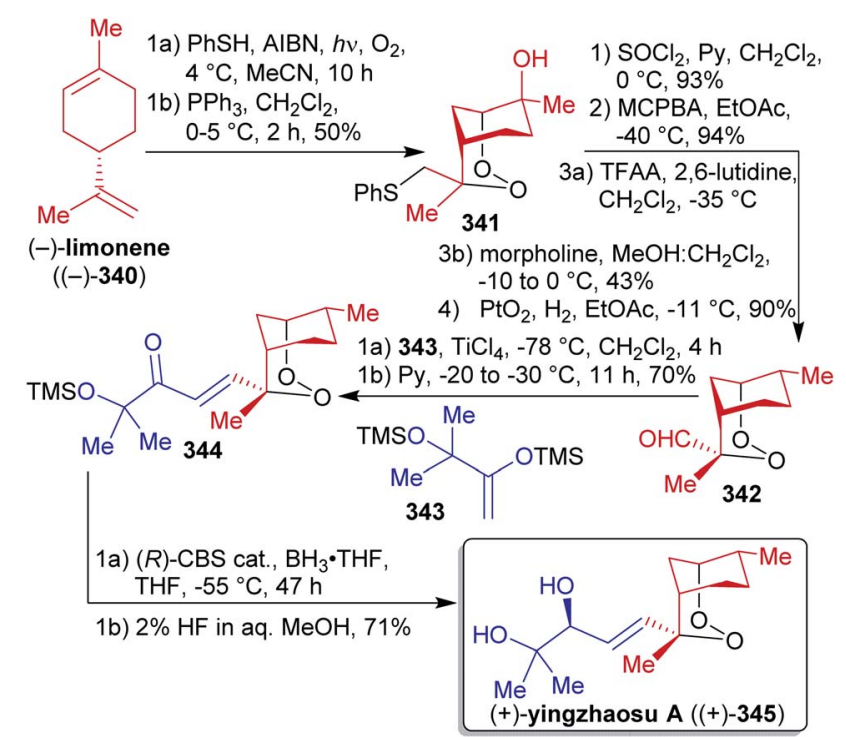

Scheme 54 Synthesis of natural product and antimalarial agent (+)-yingzhaosu A ((+)-345). 


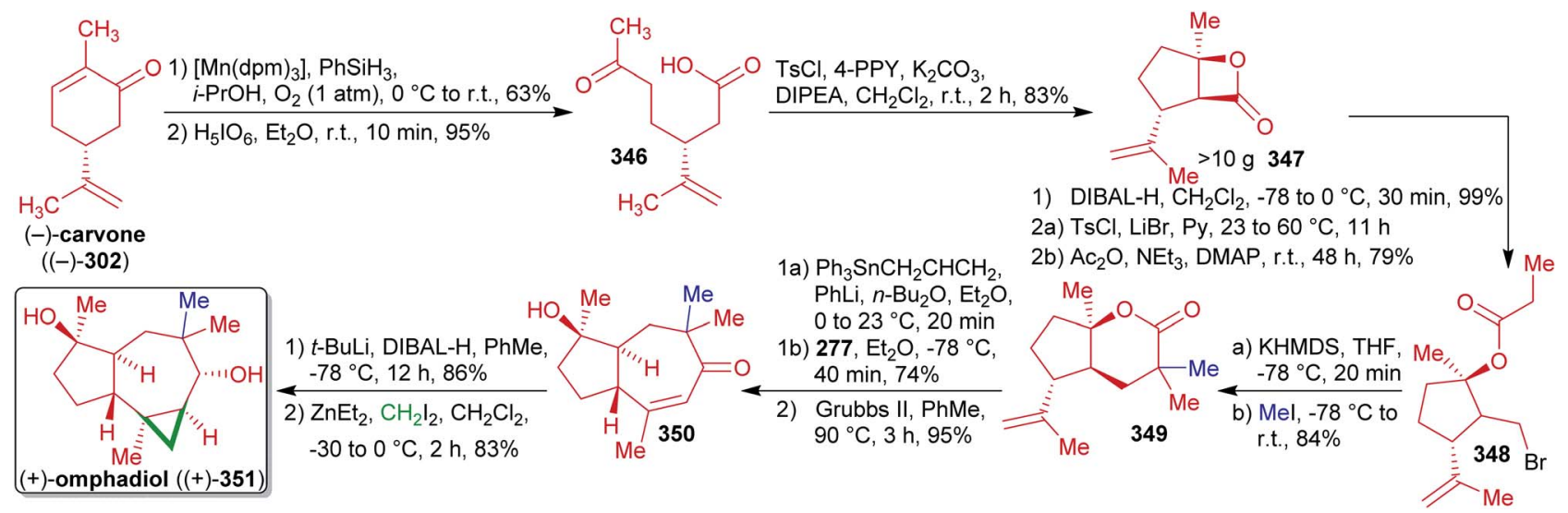

Scheme 55 Synthesis of (+)-omphadiol ((+)-351) from (-)-carvone ((-)-302). 4-PPY = 4-(1-pyrrolidinyl)pyridine.

2.5.2.5. (+)-Pseudoanisatin. In 2016, Maimone et al. reported the conversion of sesquiterpene $(+)$-cedrol $((+)-304)$, an inexpensive terpene feedstock obtained from biomass, ${ }^{487}$ into the Illicium-sesquiterpene (+)-pseudoanisatin $((+)-333) .{ }^{\mathbf{4 8 8 , 4 8 9}}$

The synthesis started with the remote oxidation of one of the geminal methyl groups of cedrol (304), methylation and elimination of the formed tetrahydrofuran ring using Meerwein's salt and proton sponge to furnish methoxycedrene 327 (Scheme 51). The $\mathrm{C}=\mathrm{C}$-double bond was oxidatively cleaved, lactonization and subsequent lactone hydrolysis, followed by an $\alpha$-ketol rearrangement then led to compound 329. This crucial intermediate already bears the correct stereochemistry for the final product. Silylation and $\mathrm{C}-\mathrm{H}$-oxidation using the terpene-derived homochiral iron catalyst $\mathbf{3 3 0}$ afforded lactone 331.

Subsequently, 331 was $O$-ethylated and $\mathrm{H}_{2} \mathrm{O}$ eliminated. Through action of in situ-formed TMSI, the methyl ether was dealkylated and subsequent treatment with TBAF produced the $\varepsilon$-lactone characteristic of pseudoanisatin 333. Dihydroxylation and secondary alcohol inversion completed the enantioselective synthesis of natural (+)-pseudoanisatin ((+)-333).

2.5.2.6. ( + -Cardamom peroxide. Starting from natural $(-)$-myrtenal $\quad((-)-303),{ }^{490}$ the antimalarial terpene $(+)$-cardamom peroxide $((+)-335)^{491}$ was obtained in a four-step synthesis by Maimone et al. in 2014 (Scheme 52), proving the absolute configuration of the latter natural product. ${ }^{492}$

The synthesis started with a McMurry coupling of (-)-myrtenal ((-)-303), affording the dimeric $\mathrm{C}_{20}$ carbon skeleton of the final product, followed by a $[4+2]$-cycloaddition with singlet oxygen furnishing enone 334. Subsequent oxidation with DMP and manganese-catalyzed tandem hydroperoxidation completed the synthesis of (+)-cardamom peroxide $((+)-335)$. Highlights of the synthesis are the high atom-efficiency, the use of molecular oxygen and the application of a photocatalytic reaction.

2.5.2.7. (+)-Paeonisuffrone. In 2008, Bermejo et al. used $(+)$-carvone $((+)-302)$ for the synthesis of the non-natural enantiomer $(+)$-paeonisuffrone $((+)-339) \cdot{ }^{493,494}$ Natural $(+)$-carvone $((+)-302)$ was converted into $(+)-10$-hydroxycarvone $((+)-336)$ following a known procedure (Scheme 53). ${ }^{495} \mathrm{Via}$ epoxidation and protection of the hydroxy function, the subsequent Ti(III)promoted reaction was enabled. A stereoselective radical cyclization, initiated by reductive epoxide opening, produced triol pivalate 337. The synthesis was completed via protection of the diol moiety, an allylic oxidation using $\mathrm{CrO}_{3}$ and an oxa-Michael addition to the resulting enone to furnish compound 338. A Pd/ $\mathrm{C}$ promoted reductive deprotection ultimately afforded (+)-paeonisuffrone $((+)-339)$. The first synthesis of the naturally

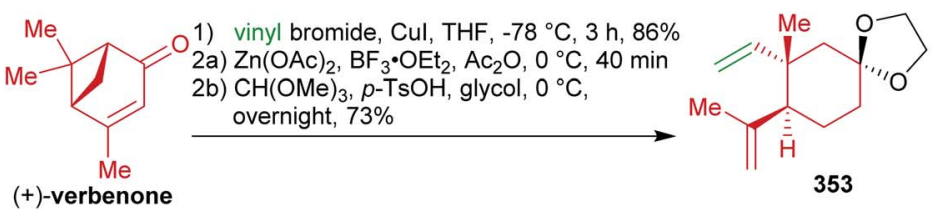

$((+)-352)$

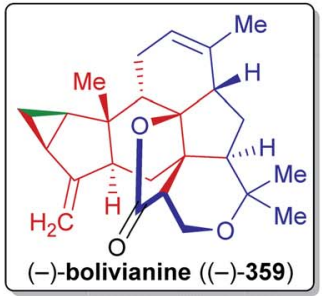

1) IBX, EtOAc, reflux, $2 \mathrm{~h}, 67 \%$ 2) $\beta$-(E)-ocimene (358), PhMe, sealed tube, $150^{\circ} \mathrm{C}, 2 \mathrm{~h}, 52 \%$

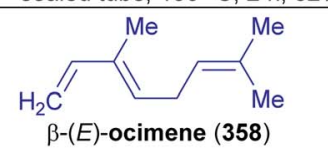

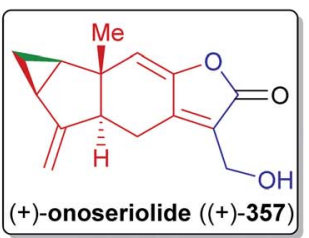

1) $\mathrm{SeO}_{2}, t-\mathrm{BuOOH}, \mathrm{CH}_{2} \mathrm{Cl}_{2}$, r.t., $15 \mathrm{~h}, 71 \%$

2) $\mathrm{TsNHNH}_{2}, \mathrm{MeOH}$, reflux, $1 \mathrm{~h}, 83 \%$

3) cat. $\mathrm{Pd}_{2}(\mathrm{dba})_{3}, \mathrm{NaOMe} / \mathrm{MeOH}$

THF, $40^{\circ} \mathrm{C}, 4 \mathrm{~h}, 65 \%$

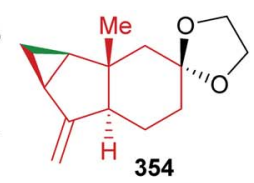

1) cat. $\mathrm{TsOH}, \mathrm{Me}_{2} \mathrm{CO}: \mathrm{H}_{2} \mathrm{O}$, r.t., $16 \mathrm{~h}, 90 \%$ 2a) LDA, $\mathrm{ZnCl}_{2}$, THF, $355,0{ }^{\circ} \mathrm{C}, 30 \mathrm{~min}$ 2b) $6 \mathrm{~N} \mathrm{HCl}, 0{ }^{\circ} \mathrm{C}, 5 \mathrm{~h}, 95 \%$ brsm

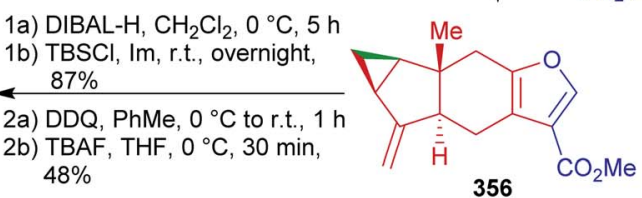

Scheme 56 Synthesis of (-)-bolivianine ((-)-359) from (+)-verbenone ((+)-352). 


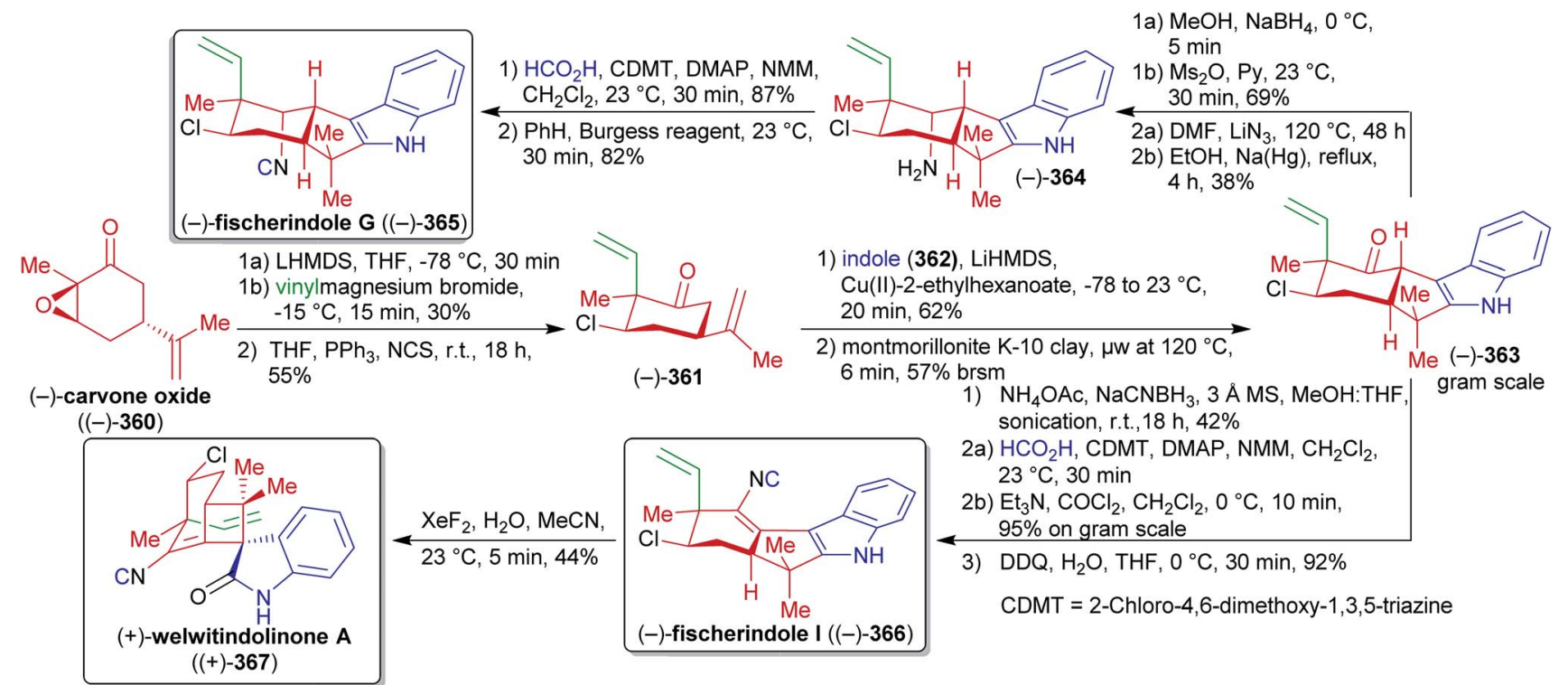

Scheme 57 Synthesis of (-)-fischerindole G ((-)-365) and I ((-)-366) and (+)-welwitindolinone A ((+)-367). CDMT =2-chloro-4,6-dimethoxy1,3,5-triazine.

occurring enantiomer, (-)-paeonisuffrone, was published by Hatakeyama et al. in 1995..$^{494,496}$

2.5.2.8. (+)-Yingzhaosu A. The synthesis of the natural product $(+)$-yingzhaosu $\mathrm{A}((+)-345)$, including the first evaluation of its antimalarial and cytotoxic activities, was reported by Bachi et al. in 2005. ${ }^{497}$ The $\beta$-sulfenyl endoperoxide $\mathbf{3 4 1}$ was prepared via a four component sequential free radical reaction of $(-)$-limonene ((-)-340) with thiophenol and oxygen, in which five bonds were formed. This was followed by in situ-reduction of the formed hydroperoxy group (Scheme 54). ${ }^{498}$ The starting material (-)-limonene ((-)-340) is accessible from biomass. ${ }^{499,500}$ Subsequently, compound $\mathbf{3 4 1}$ was dehydrated, the thioether functionality was selectively oxidized and subjected to a Pummerer rearrangement followed by hydrolysis of the formed hemithioacetal ester, to afford bicyclic aldehyde $\mathbf{3 4 2}$ after hydrogenation of the $\mathrm{C}=\mathrm{C}$-double bond.

The second major synthon $\mathbf{3 4 3}$ can be synthesized in three steps from acetone and acetylene (accessible via electric arc pyrolysis of methane or from wood-derived charcoal through calcium carbide). ${ }^{501}$ First, a reaction to 2-methylbut-3-yn-2-ol is conducted, ${ }^{502}$ followed by oxidation ${ }^{503}$ and completed by enolization and protection of the afforded hydroxy groups. ${ }^{504}$

Both synthons were linked through a Mukaiyama aldol reaction followed by in situ base-induced dehydration affording the $\alpha, \beta$-unsaturated ketone 344 . The synthesis was completed by selective reduction of ketone $\mathbf{3 4 4}$ and acidic workup furnishing the natural product $(+)$-yingzhaosu A $((+)-345) . .^{505,506}$ The obtained product was then subjected to in vitro and in vivo tests. ${ }^{497}$

2.5.2.9. (+)-Omphadiol. The natural product (+)-omphadiol $((+)-351)$ was first isolated from the basidiomycete Omphalotus illudens ${ }^{507}$ and the first total synthesis was reported by the group of Romo in 2011 (Scheme 55). ${ }^{508}$ The key intermediate in the synthesis of (+)-omphadiol ((+)-351) is bicyclic $\beta$-lactone 347, which was prepared from (-)-carvone $((-)-302) .{ }^{452,471,472}$ The

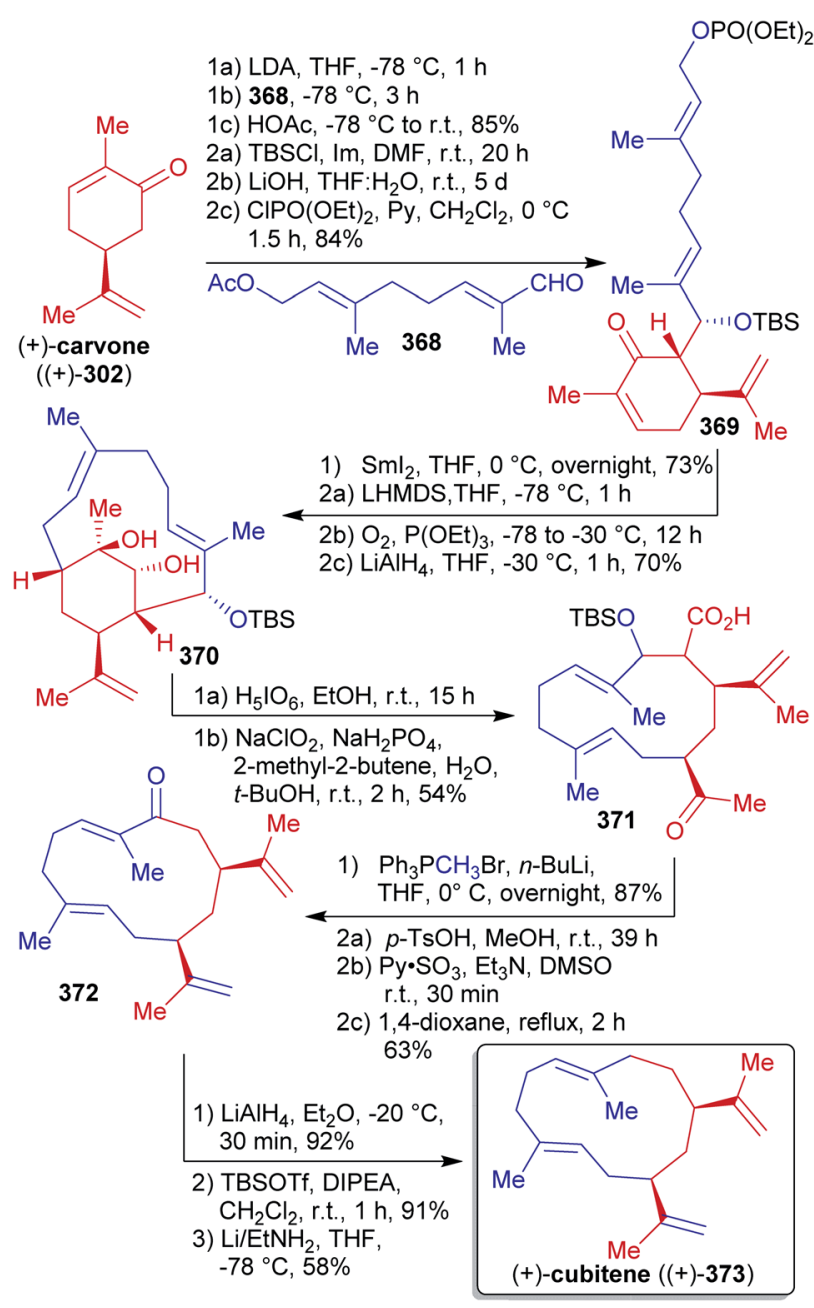

Scheme 58 Synthesis of $(+)$-cubitene $((+)$-373) from (+)-carvone $((+)-302)$ and geraniol derived aldehyde (368). 


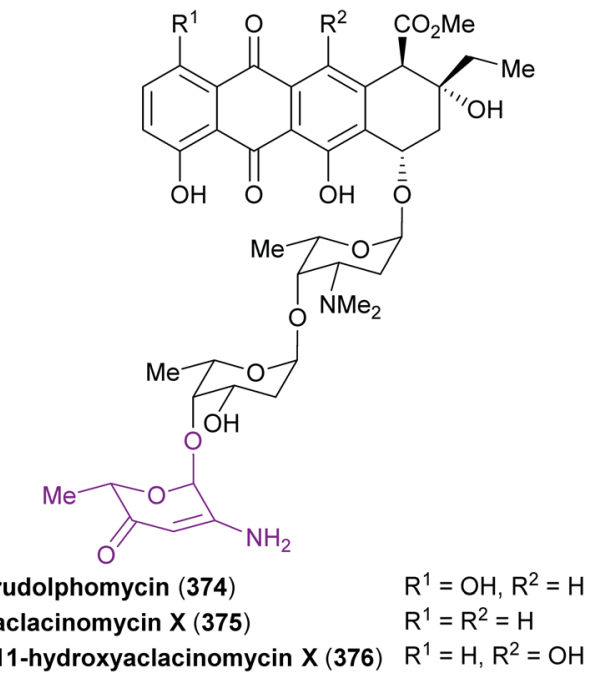

Scheme 59 Tetracycline natural products containing an L-rednose ( $L-$ 204) moiety.

synthesis commenced with catalyzed hydration of the enone moiety, followed by an oxidative $\mathrm{C}=\mathrm{C}$-cleavage. An aldol lactonization afforded bicyclic $\beta$-lactone 347 , which was then reduced to the corresponding diol, subjected to a one-pot tosylation/bromination sequence and a subsequent acylation reaction to furnish ester 348. Treatment with base and iodomethane formed two C-C-bonds in a single operation, affording $\delta$-lactone 349. With in situ-formed allyllithium, a conversion into a ring-opened $\beta, \gamma$-unsaturated ketone was performed and an olefin isomerization/RCM sequence led to cycloheptenone 350. After reduction and cyclopropanation, the natural product $(+)$-omphadiol $((+)-351)$ was obtained. Diiodomethane is available from iodoform, ${ }^{509}$ the latter being a product of the wellknown reaction from ethanol with $\mathrm{I}_{2}$ in alkaline medium. ${ }^{300}$ The synthesis proceeds in a highly efficient manner, using onepot, sequential and tandem processes, and avoids the use of protecting groups.

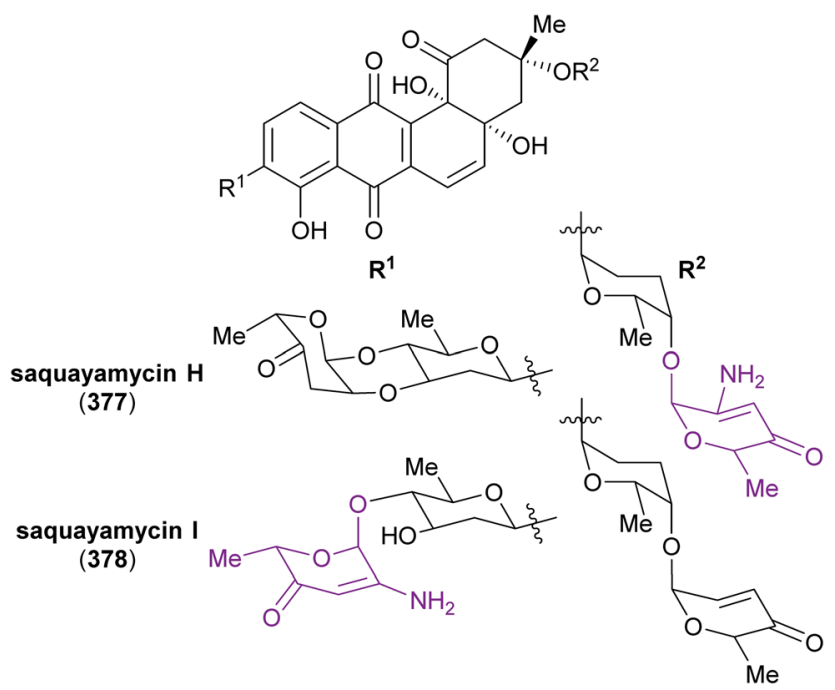

Scheme 60 Anthracycline natural products containing an L-rednose (L-204) moiety.
2.5.2.10. (-)-Bolivianine and (+)-onoseriolide. In 2013, Liu et al. reported the first total synthesis of (-)-bolivianine $((-)-359)$ in 14 steps, including the synthesis of (+)-onoseriolide $((+)-357) .{ }^{510}$ The synthesis commenced with a Michael addition of vinyl reagent 244 to $(+)$-verbenone $((+)-352)$ (accessible via bioconversion of (+)- $\alpha$-pinene), ${ }^{511}$ ring-opening of the cyclobutane moiety and formation of 1,3-dioxolane 353 under acidic conditions (Scheme 56). Through Riley oxidation and intermediate preparation of a tosylhydrazone, a diazoalkane was produced, which was subsequently subjected to a metal-catalyzed carbene insertion reaction affording cyclopropane 354. Acid-catalyzed deprotection enabled the reaction with functionalized pyruvate 355 to afford furan 356. Building block 355 could be prepared in two steps from natural methyl glycerate by silylation and oxidation. ${ }^{510,512}$ DIBAL-H reduction of furan $\mathbf{3 5 6}$ and modification of the furan ring furnished the natural product (+)-onoseriolide $((+)-357) .{ }^{513-515}$ By oxidizing the furan moiety, the formed electronwithdrawing group activates the dienophile by decreasing its LUMO energy. This enables a one-pot Diels-Alder/intramolecular hetero-Diels-Alder reaction cascade with natural $\beta-(E)$-ocimene $(358)^{516,517}$ generating three rings, four $\mathrm{C}-\mathrm{C}$-bonds, and five stereogenic centers and ultimately furnishing the natural product (-)-bolivianine ((-)-359). ${ }^{510,518}$ Vinyl bromide (244) can be

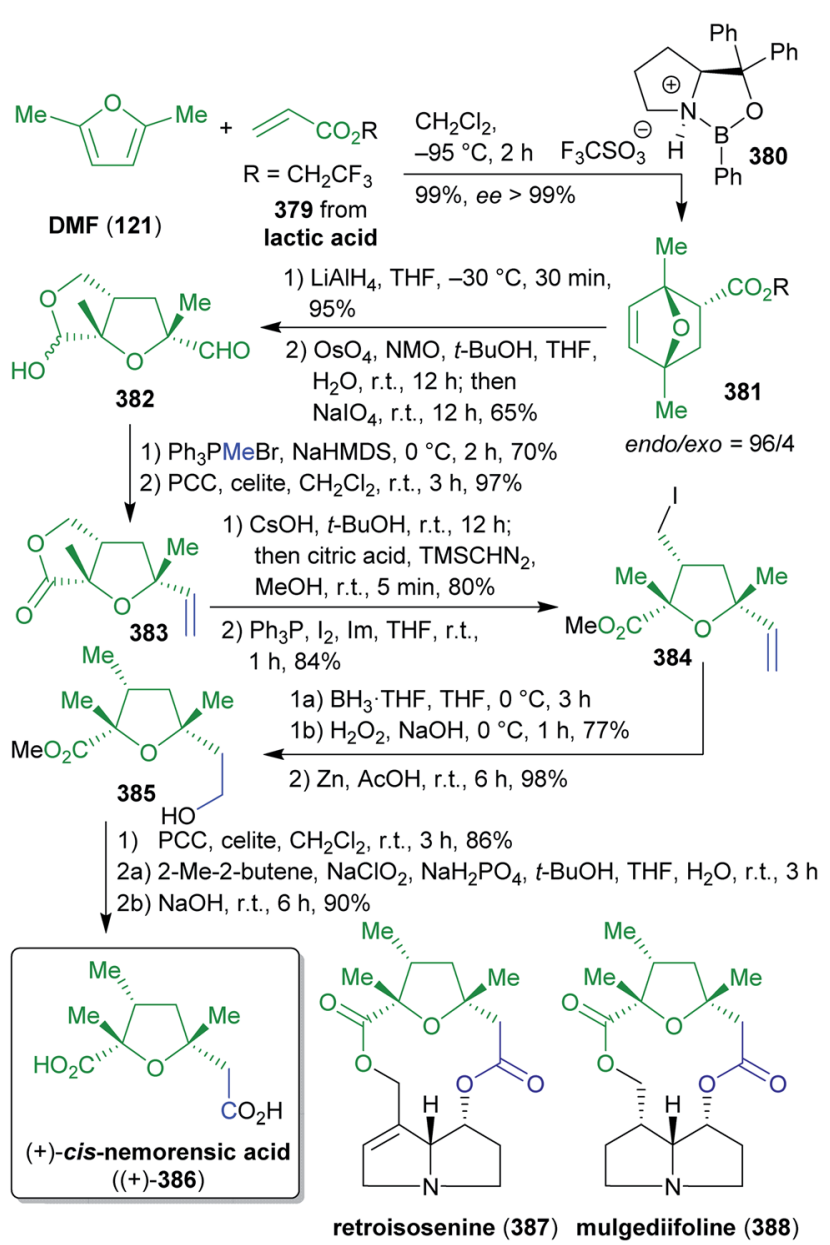

Scheme 61 First asymmetric synthesis of $(+)$-cis-nemorensic acid $((+)-386)$ based on cellulose derived 121. 
prepared from acrylic acid (available from biomass e.g. through lactic acid) ${ }^{174,177-181}$ via ultrasonically assisted Vilsmeier-Haack reaction. ${ }^{175}$ The use of Diels-Alder reactions in the synthesis of natural products is quite attractive against the backdrop of "green" chemistry because of their flawless atom economy. The choice of solvents in the synthesis is exemplary in most cases (acetone, $\mathrm{H}_{2} \mathrm{O}$, EtOAc).

2.5.2.11. ( + )-Welwitindolinone A, (-)-fischerindole I and G. In 2007, Baran et al. were able to synthesize several natural products in a protecting group-free synthesis starting from (-)-carvone oxide ((-)-360) (Scheme 57). Intermediate 363 was synthesized on a gram scale by vinylation and chlorination of $(-)$-carvone oxide $((-)-360)$ affording chloroketone $361,{ }^{519}$ followed by coupling with indole (362) and an acid catalyzed Friedel-Crafts cyclization. Reduction of the ketone, mesylation and nucleophilic substitution with azide, followed by reduction afforded amine 364. The latter was formylated and dehydrated to furnish the natural product (-)-fischerindole G ((-)-365). .19,520 $^{-10}$

Along the other path, a reductive amination of intermediate 363, followed by formylation, immediate dehydration with phosgene and an oxidation with DDQ in the presence of water led to (-)-fischerindole I ((-)-366). In a cascade reaction, the natural product 366 was converted to the spirocyclic, natural product $(+)$-welwitindolinone A $((+)-367) .{ }^{520}$ The reaction proceeded through electrophilic fluorination of the indole nucleus

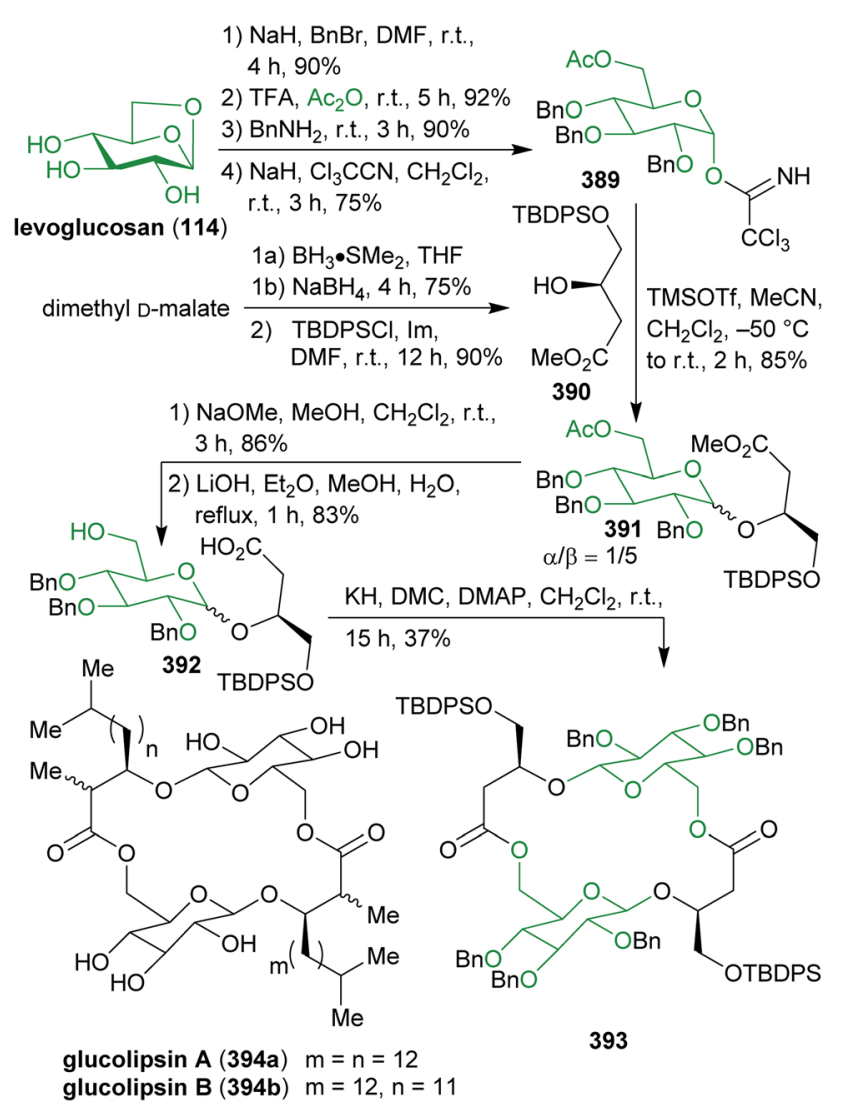

Scheme 62 Synthesis of macrocyclic building block 393 from levoglucosan (114) for formal synthesis of glucolipsins 394a, b. DMC $=2$ chloro-1,3-dimethylimidazolinium chloride.

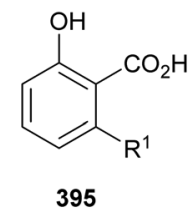<smiles>[R]c1cccc(O)c1</smiles><smiles>[R]c1cc(O)cc(O)c1</smiles>

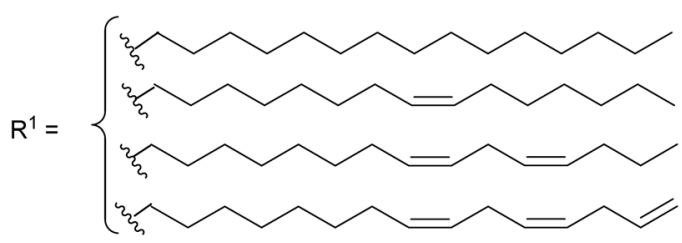

Scheme 63 CNSL constituents: anacardic acid (395), cardanol (396) and cardol (397).

with $\mathrm{XeF}_{2}$ and trapping with $\mathrm{H}_{2} \mathrm{O}$. Subsequently, fluoride was eliminated and a [1,5]-sigmatropic rearrangement took place. ${ }^{521}$

Vinylmagnesium bromide (71) can be synthesized from biomass-derived building blocks (vide supra). Indole (362) can e.g. be prepared from tryptophan or from indigo. ${ }^{522}(-)$-Carvone oxide ((-)-360) can be prepared from (-)-carvone $((-)-302) .{ }^{523}$

The oxidation states of intermediates gradually escalated over the course of the synthesis with the sole exception of a stereoselective reductive amination.

2.5.2.12. (+)-Cubitene. Lindel et al. reported an enantioselective total synthesis of the diterpene $(+)$-cubitene $((+)-373) .{ }^{\mathbf{5 2 4}}$ $(+)$-Carvone $((+)-302)$ was reacted first with aldehyde 368 and subsequently $O$-phosphorylated to furnish allyl phosphate 369

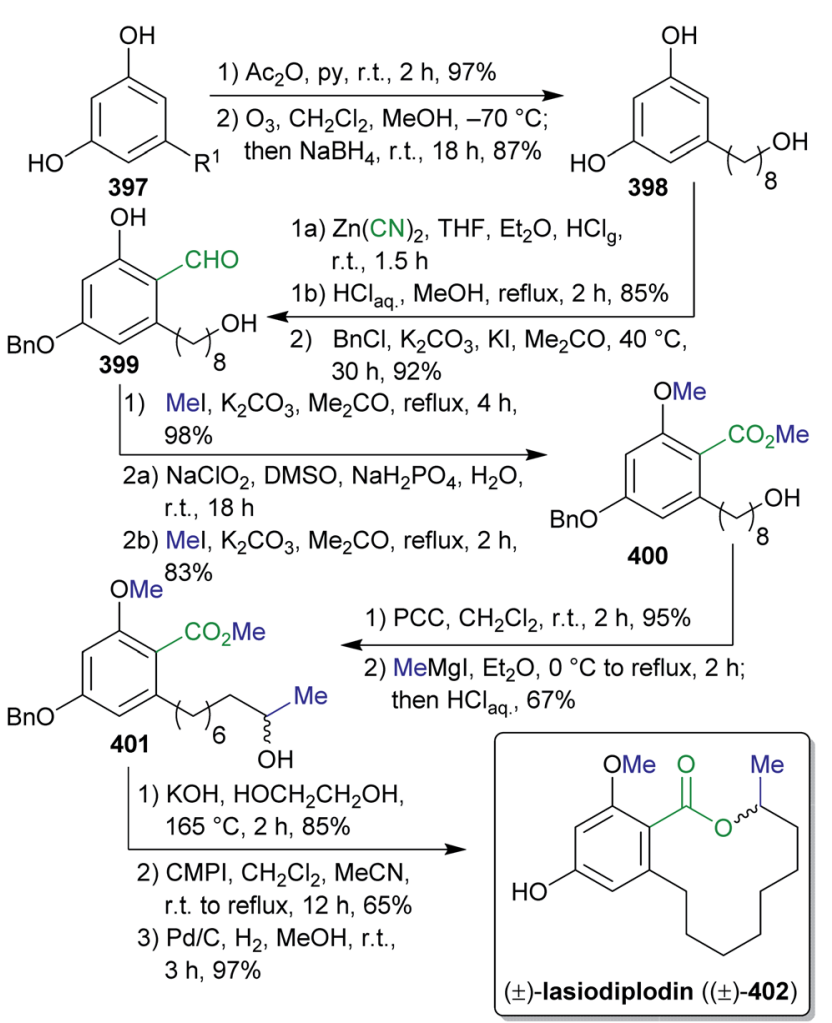

Scheme 64 Lasiodiplodin (402) synthesis from cardol (397). 
(Scheme 58). ${ }^{525}$ By treating the latter with $\mathrm{SmI}_{2}$, an intramolecular coupling reaction afforded an [8.2.2]-bicyclic compound, which was converted into an acyloin and subsequently reduced to diol 370. The latter was cleaved with $\mathrm{H}_{5} \mathrm{IO}_{6}$, followed by an oxidation under Pinnick conditions, affording macrocycle 371. Subsequently, 371 was subjected to a Wittig reaction, followed by deprotection and an oxidation of the hydroxyl group under Parikh-Doering conditions promoting a decarboxylation to ultimately form ketone 372. A three-step sequence, comprising a reduction of the keto group, silylation of the resulting hydroxy group and an allylic deoxygenation using $\mathrm{Li} / \mathrm{EtNH}_{2}$, afforded the natural product (+)-cubitene $((+)-373) \cdot{ }^{524,526}$

Aldehyde 368 is available from natural geraniol via an allylic oxidation. ${ }^{479,527,528}$

\subsection{Miscellaneous}

Since natural products can be very complex molecules and the total synthesis often is already challenging, the construction of the entire carbon framework from bio-based starting materials may constitute a considerable challenge. In addition, it is not always possible to adhere to green synthetic methods and guidelines throughout the entire sequence so that conventional methodology has to be employed where the available ecofriendly alternatives failed. An efficient step in the right direction is the synthesis of fragments and to build at least as much as possible from biomass derived starting materials.

2.6.1. L-Rednose-containing antibiotics. A concise example is the L-rednose (L-204) building block synthesized by Sperry and coworkers from 3A5AF (203) (Scheme 32). ${ }^{342}$ It is part of the complex tetracycline-type natural products rudolphomycin (374), ${ }^{529,530}$ aclacinomycin X (375), 11-hydroxyaclacinomycin X $(376)^{531,532}$ as well as saquayamycins $H(377)$ and $I(378)^{533,534}$ which have not been synthesized so far (Schemes 59 and 60). A viable synthesis of an advanced intermediate like 204 based on eco-friendly methods and starting materials already constitutes a significant progress in the total synthesis of these compounds.

2.6.2. (+)-cis-Nemorensic acid. For the synthesis of $(+)$-cisnemorensic acid $((+)-386$, Scheme 61$)$, a component of the macropyrrolizidine alkaloids retroisosenine (387) and mulgediifoline (388), ${ }^{535-540}$ Ryu and coworkers used 2,5-dimethylfuran (121) as the cellulose-derived starting material. ${ }^{541}$ Key step of the synthesis was a catalytic enantioselective DielsAlder reaction with 2,2,2-trifluoroethyl acrylate (only the acrylate portion of which will become part of the product) with excellent endo-selectivity using the chiral catalyst 380. As mentioned earlier, acrylic acid and derivatives are readily available from lactic acid as the bio-based starting material. ${ }^{177-181}$ The carboxylate group of the Diels-Alder product 381 was reduced and after oxidative olefin cleavage, lactol 382 was obtained. Subsequent Wittig reaction with methylphosphonium bromide (accessible from $\mathrm{PPh}_{3}$ and $\mathrm{MeBr}$ ) and lactol oxidation furnished lactone $\mathbf{3 8 3}$ with a terminal double bond. The lactone was hydrolyzed, the carboxylic acid esterified and the alcohol was converted into the iodo derivative by means of an Appel reaction. The iodomethylene moiety was reduced to a methyl group after hydroboration and oxidation of the olefin to furnish 385. Two step oxidation of the primary alcohol with PCC and Pinnick conditions as well as ester hydrolysis provided enantiopure (+)-cis-nemorensic acid $((+)-386)$.

The eco-friendliness of this route is quite favorable regarding the carbon efficiency. Furthermore, almost every carbon atom introduced into the molecule during the synthesis is retained (except for the trifluoroethyl and methyl groups), further increasing the carbon efficiency. Further circumstantial protecting group operations are completely avoided.

2.6.3. Macrolide precursor for glucolipsin synthesis. In 2003, Cleophax and coworkers utilized cellulose-derived 114 and dimethyl malate for the synthesis of the macrocyclic moiety $393{ }^{542}$ which could be converted into the antibiotic glucolipsins (394a-b, Scheme 62) ${ }^{543}$ and cycloviracins (not shown). ${ }^{544-547}$ Although a number of total and formal syntheses which also use bio-based starting materials in the form of e.g. glucose $\mathrm{e}^{547}$ have been published, ${ }^{548-553}$ we chose this work to showcase the value of levoglucosan as a less common starting material.

After benzyl protection, 114 was transformed into the monocyclic trichloracetimidate $\mathbf{3 8 9}$, which was reacted with the dimethyl D-malate-derived building block 390 in a Schmidt glycosylation. Both ester groups were saponified and subsequent ring forming esterification furnished 393.

This approach makes exemplary use of enantiopure biobased starting materials to furnish a pivotal building block for the syntheses of fairly complex natural products, but is hampered by extensive protecting group usage well known from carbohydrate chemistry. ${ }^{554}$

2.6.4. ( \pm )-Lasiodiplodin from Cashew Nut Shell Liquid (CNSL). A highly promising renewable feedstock, although rather unusual for natural product synthesis, is cashew nut shell liquid, a waste product of the cashew nut production and is the cold ethanol extract of the waste shells. It contains in up to $95 \%$ the three phenolic compounds anacardic acid (395), cardanol (396) and cardol (397) which all carry a $\mathrm{C}_{15}$ chain with one to three double bonds (Scheme 63). ${ }^{555}$ This unique moiety in combination with the origin from a waste stream of food production makes it the ideal renewable resource. ${ }^{556-559}$ The for natural product synthesis, the long alkyl/alkenyl chain is rather impractical but CNSL has found numerous applications in fuel research, ${ }^{560}$ polymer chemistry, ${ }^{561-563}$ synthesis of fine chemicals ${ }^{564-566}$ and for the synthesis of functional materials like surfactants ${ }^{567,568}$ and UV absorbers. ${ }^{116,569}$

Magalhães and dos Santos ${ }^{570}$ managed to utilize CNSLderived cardol (397) for the synthesis of antileukemic lasiodiplodin (402). ${ }^{571,572}$ Acetyl protected cardol was subjected to ozonolysis and following reductive treatment to yield a truncated alcohol (Scheme 64).

After saponification of the acetates, formylation was performed by means of a Gattermann reaction and the $p$-hydroxy group was benzylated to furnish aldehyde 399 . The second aromatic hydroxy group was converted to the methyl ether and aldehyde oxidation was achieved under Pinnick conditions. The respective carboxylic acid was $O$-alkylated with iodomethane 
and the remaining primary hydroxy group was oxidized to an aldehyde, which was subjected to a Grignard reaction with methylmagnesium iodide to yield secondary alcohol 401. After saponification and macrolactone formation through the action of 2-chloro-1-methylpyridinium iodide (CMPI), the benzyl group was cleaved to furnish racemic lasiodiplodin.

Although this very concise approach makes formidable use of this particular starting material, it also demonstrates an issue when used for total synthesis: The $\mathrm{C}_{15}$ moiety often has to be truncated so that a non-negligible part of the molecule (in this case about one third) is not retained in the desired final product. Therefore, the carbon and atom efficiency is decreased - however, the $\mathrm{C}_{7}$-fragment split off may e.g. find application in the synthesis of the fragrance jasmin aldehyde. ${ }^{573}$

\section{Future challenges and outlook}

The use of fossil carbon sources as the basis of the vast majority of current activities in synthetic organic chemistry is only rarely questioned by practitioners and scholars. Nevertheless, the current discussion on the necessity of $\mathrm{CO}_{2}$ reduction and the size of the doubtlessly finite underground deposits of fossil carbon brings up interesting challenges for current and future chemists. Atom awareness among the chemical community, i.e. the knowledge of the origin of the matter that we deal with in our work, certainly leaves some room for improvement. As outlined in the Introduction, chemists were never shy to accept new challenges, e.g. to utilize the seemingly unattractive, black and smelly coal tar to produce beautiful dyestuffs or life-saving drugs. The combination of starting materials from renewable feedstocks with eco-friendly solvents, reagents, and methodologies as well as a reduced energy consumption can ultimately lead to processes with minimal impact on our ecosystem. Therefore, existing methods, synthetic routes and processes need to be revisited constantly. A big part of whether or how quickly those concepts will be applied on a large scale is dependent on the economic competitiveness.

Furthermore, the conception of bio-based starting materials has also reached other organic chemical fields like pharmaceutical and agrochemistry. The synthesis of the anti-ulcer drug ranitidine $e^{574}$ and the insecticide prothrin from CMF $(\mathbf{1 2 0})^{575}$ as well as the synthesis of norfenefrine and fenoprofen from cashew nut shell liquid-derived cardanol $^{576}$ are pioneering examples of this development.

Another attractive trend in organic chemistry in terms of sustainability is the conception of protecting group free sequences $^{577-580}$ as already demonstrated for the synthesis of fischerindole $\mathrm{G}$ (365) and I (366) as well as of welwitindolinone A (367) (Scheme 57). ${ }^{521,577-580}$ This could particularly influence natural product synthesis, a field in which the extensive use of protecting group transformations is commonplace. Atom- and step-efficiency of synthetic routes could be significantly increased if alternative methods for achieving selectivity can be employed instead.

\section{Conflicts of interest}

There are no conflicts of interest to declare.

\section{Acknowledgements}

We thank the members of the STANCE consortium for helpful discussions.

\section{Notes and references}

1 F. Wöhler, Ann. Phys., 1828, 87, 253-256.

2 F. W. Serturner, Trommsdorffs J. Pharm., 1806, 14, 47-98.

3 F. W. Serturner, Ann. Phys., 1817, 25, 56-89.

4 K. C. Morrison and P. J. Hergenrother, Nat. Prod. Rep., 2014, 31, 6-14.

5 D. J. Newman, G. M. Cragg and K. M. Snader, J. Nat. Prod., 2003, 66, 1022-1037.

6 W. R. Roush, J. Am. Chem. Soc., 2008, 130, 6654-6656.

7 C. A. Kuttruff, M. D. Eastgate and P. S. Baran, Nat. Prod. Rep., 2014, 31, 419-432.

8 E. M. Carreira, Isr. J. Chem., 2018, 58, 114-121.

9 As a counterevidence to this statement, we recommend the literature on putaminoxin, which has been synthesized several times with the assumed absolute configuration until, more than 20 years after its isolation, Pietruszka and coworkers noticed for the first time that the configuration of one of its two stereocenters had been missassigned: C. Bisterfeld, C. Holec, D. Böse, P. Marx and J. Pietruszka, J. Nat. Prod., 2017, 80, 1563-1574.

10 The reader may be referred to the story of patchouli alcohol, for which a wrong structure had been proposed and the natural product was accidentally formed in an unforeseen rearrangement of this (wrong) structure. Dunitz and coworkers only later discovered that the synthesis was not the proof of a correct structural assignment: G. Büchi, R. E. Erickson and N. Wakabayashi, J. Am. Chem. Soc., 1961, 83, 927-938.

11 G. Büchi and W. D. MacLeod, J. Am. Chem. Soc., 1962, 84, 3205-3206.

12 D. Dickmann, M. Diekmann, C. Holec and J. Pietruszka, Tetrahedron, 2019, 75, 689-696.

13 M. Dobler, J. D. Dunitz, B. Gubler, H. P. Weber, G. Büchi and J. Padilla, Proc. Chem. Soc., 1963, 357-392.

14 A. Evidente, R. Lanzetta, R. Capasso, A. Andolfi, A. Bottalico, M. Vurro and M. C. Zonno, Phytochemistry, 1995, 40, 16371641.

15 J. Fuchser and A. Zeeck, Liebigs Ann./Recl., 1997, 1997, 8795.

16 K. Götz, J. C. Liermann, E. Thines, H. Anke and T. Opatz, Org. Biomol. Chem., 2010, 8, 2123-2130.

17 J. B. McAlpine, S.-N. Chen, A. Kutateladze, J. B. MacMillan, G. Appendino, A. Barison, M. A. Beniddir, M. W. Biavatti, S. Bluml, A. Boufridi, M. S. Butler, R. J. Capon, Y. H. Choi, D. Coppage, P. Crews, M. T. Crimmins, M. Csete, P. Dewapriya, J. M. Egan, M. J. Garson, G. Genta-Jouve, W. H. Gerwick, H. Gross, M. K. Harper, P. Hermanto, J. M. Hook, L. Hunter, D. Jeannerat, N.-Y. Ji, T. A. Johnson, D. G. I. Kingston, H. Koshino, H.-W. Lee, G. Lewin, J. Li, R. G. Linington, M. Liu, K. L. McPhail, T. F. Molinski, B. S. Moore, J.-W. Nam, R. P. Neupane, 
M. Niemitz, J.-M. Nuzillard, N. H. Oberlies, F. M. M. Ocampos, G. Pan, R. J. Quinn, D. S. Reddy, J.-H. Renault, J. Rivera-Chávez, W. Robien, C. M. Saunders, T. J. Schmidt, C. Seger, B. Shen, C. Steinbeck, H. Stuppner, S. Sturm, O. TaglialatelaScafati, D. J. Tantillo, R. Verpoorte, B.-G. Wang, C. M. Williams, P. G. Williams, J. Wist, J.-M. Yue, C. Zhang, Z. Xu, C. Simmler, D. C. Lankin, J. Bisson and G. F. Pauli, Nat. Prod. Rep., 2019, 36, 35-107.

18 K. C. Nicolaou and S. A. Snyder, Angew. Chem., Int. Ed., 2005, 44, 1012-1044.

19 G. Sabitha, K. Yadagiri, R. Swapna and J. S. Yadav, Tetrahedron Lett., 2009, 50, 5417-5419.

20 H.-D. Yoo, S.-J. Nam, Y.-W. Chin and M.-S. Kim, Arch. Pharmacal Res., 2016, 39, 143-153.

21 K. C. Nicolaou, Isr. J. Chem., 2018, 58, 104-113.

22 M. A. Sierra and M. C. de la Torre, Angew. Chem., Int. Ed., 2000, 39, 1538-1559.

23 M. Eissen, J. O. Metzger, E. Schmidt and U. Schneidewind, Angew. Chem., Int. Ed., 2002, 41, 414-436.

24 P. Anastas and J. Warner, Green Chemistry: Theory and Practice, Oxford University Press, New York, 1998.

25 P. T. Anastas and J. B. Zimmerman, Environ. Sci. Technol., 2003, 37, 94A-101A.

26 C. M. Alder, J. D. Hayler, R. K. Henderson, A. M. Redman, L. Shukla, L. E. Shuster and H. F. Sneddon, Green Chem., 2016, 18, 3879-3890.

27 P. T. Anastas, Crit. Rev. Anal. Chem., 1999, 29, 167-175.

28 P. T. Anastas, M. M. Kirchhoff and T. C. Williamson, Appl. Catal., A, 2001, 221, 3-13.

29 J. H. Clark, R. Luque and A. S. Matharu, Annu. Rev. Chem. Biomol. Eng., 2012, 3, 183-207.

30 A. B. Eldin, O. A. Ismaiel, W. E. Hassan and A. A. Shalaby, J. Anal. Chem., 2016, 71, 861-871.

31 J. H. Clark, Green Chem., 1999, 1, 1-8.

32 S. C. Hammer, A. M. Knight and F. H. Arnold, Curr. Opin. Green Sustainable Chem., 2017, 7, 23-30.

33 J. G. Ibanez, M. Hernandez-Esparza, C. Doria-Serrano, A. Fregoso-Infante and M. M. Singh, Environmental Chemistry: Fundamentals, Springer, New York, NY, 2007.

34 M. Koel, Green Chem., 2016, 18, 923-931.

35 J. Li, J. Albrecht, A. Borovika and M. D. Eastgate, ACS Sustainable Chem. Eng., 2018, 6, 1121-1132.

36 J. A. Linthorst, Found. Chem., 2010, 12, 55-68.

37 D. Prat, J. Hayler and A. Wells, Green Chem., 2014, 16, 45464551.

38 P. A. Ramachandran, D. Shonnard, R. Hesketh, D. Fichana, C. Stewart Slater, A. Lindner, N. Nguyen and R. Engler, in Handbook of Industrial Chemistry and Biotechnology, ed. J. A. Kent, T. V. Bommaraju and S. D. Barnicki, Springer International Publishing, Cham, 2017, pp. 1921-1994.

39 N. Ran, L. Zhao, Z. Chen and J. Tao, Green Chem., 2008, 10, 361-372.

40 P. A. Schulte, L. T. McKernan, D. S. Heidel, A. H. Okun, G. S. Dotson, T. J. Lentz, C. L. Geraci, P. E. Heckel and C. M. Branche, Environ. Health, 2013, 12, 31.

41 R. A. Sheldon, Chem. Commun., 2008, 3352-3365.
42 R. A. Sheldon, in Green Biocatalysis, ed. R. N. Patel, WileyVCH, Delft, Johannesburg, Weinheim, 2016.

43 R. A. Sheldon, Curr. Opin. Green Sustainable Chem., 2019, 18, 13-19.

44 R. A. Sheldon, I. W. C. E. Arends and U. Hanefeld, Green Chemistry and Catalysis, Wiley-VCH, Delft, Weinheim, 2007.

45 R. A. Sheldon and J. M. Woodley, Chem. Rev., 2018, 118, 801-838.

46 J. Sherman, B. Chin, D. T. H. Paul, R. Garcia-Valls and T. A. Hatton, Environ. Health Perspect., 1998, 106, 253-271.

47 H. F. Sneddon, Green Chem., 2016, 18, 5082-5085.

48 S. Stolte, S. Steudte, A. Igartua and P. Stepnowski, Curr. Org. Chem., 2011, 15, 1946-1973.

49 J. Tao and R. J. Kazlauskas, Biocatalysis for Green Chemistry and Chemical Process Development, Wiley-VCH, Weinheim, 2011.

50 N. P. Tarasova, F. I. Ingel' and A. S. Makarova, Russ. J. Phys. Chem. B, 2015, 9, 406-411.

51 A. Tiwari, A. M. Ramirez, R. Jain and A. Saxena, Key Eng. Mater., 2012, 517, 755-762.

52 V. G. Zuin, M. L. Segatto and L. Z. Ramin, in Encyclopedia of Sustainability Science and Technology, ed. R. A. Meyers, Springer New York, New York, NY, 2018, pp. 1-24.

53 R. A. Sheldon, ACS Sustainable Chem. Eng., 2018, 6, 32-48.

54 B. M. Trost, Science, 1991, 254, 1471-1478.

55 B. M. Trost, Angew. Chem., Int. Ed. Engl., 1995, 34, 259-281. 56 R. A. Sheldon, Chem. Ind., 1992, 903-906.

57 R. A. Sheldon, Industrial Environmental Chemistry, ed. D. T. Sawyer and A. E. Martell, Plenum, New York, 1992.

58 R. A. Sheldon, Green Chem., 2007, 9, 1273-1283.

59 J. Andraos, Org. Process Res. Dev., 2005, 9, 149-163.

60 P. J. Dunn, Chem. Soc. Rev., 2012, 41, 1452-1461.

61 T. Hudlicky, D. A. Frey, L. Koroniak, C. D. Claeboe and L. E. Brammer Jr, Green Chem., 1999, 1, 57-59.

62 D. J. C. Constable, A. D. Curzons and V. L. Cunningham, Green Chem., 2002, 4, 521-527.

63 A. D. Curzons, D. J. C. Constable, D. N. Mortimer and V. L. Cunningham, Green Chem., 2001, 3, 1-6.

64 N. Brun, P. Hesemann and D. Esposito, Chem. Sci., 2017, 8, 4724-4738.

65 A. Corma, S. Iborra and A. Velty, Chem. Rev., 2007, 107, 2411-2502.

66 M. J. Hülsey, H. Yang and N. Yan, ACS Sustainable Chem. Eng., 2018, 6, 5694-5707.

67 A. Nzihou, Waste Biomass Valorization, 2010, 1, 3-7.

68 A. Baeyer and H. Caro, Ber. Dtsch. Chem. Ges., 1874, 7, 968976.

69 A. Baeyer, Ber. Dtsch. Chem. Ges., 1880, 13, 2254-2263.

70 F. Beilstein and A. Kuhlberg, Justus Liebigs Ann. Chem., 1872, 163, 121-143.

71 W. H. Perkin, J. Chem. Soc., 1877, 31, 388-427.

72 A. Ladenburg, Ber. Dtsch. Chem. Ges., 1886, 19, 2578-2583.

73 O. Lange, Ber. Dtsch. Chem. Ges., 1885, 18, 3436-3441.

74 F. Beilstein and A. Kuhlberg, Justus Liebigs Ann. Chem., 1870, 155, 1-29.

75 F. Sachs and R. Kempf, Ber. Dtsch. Chem. Ges., 1902, 35, 1224-1240. 
76 F. Sachs and E. Sichel, Ber. Dtsch. Chem. Ges., 1904, 37, 1861-1874.

77 E. Steingruber, in Ullmann's Encyclopedia of Industrial Chemistry, Wiley-VCH, Weinheim, 2004.

78 F. Hoffmann, US Pat., US644077 (A), 1900.

79 N. C. Lloyd, H. W. Morgan, B. K. Nicholson and R. S. Ronimus, Angew. Chem., Int. Ed., 2005, 44, 941-944.

80 Z. G. Brill, M. L. Condakes, C. P. Ting and T. J. Maimone, Chem. Rev., 2017, 117, 11753-11795.

81 H. U. Blaser, Chem. Rev., 1992, 92, 935-952.

82 D. Ager, Handbook of chiral chemicals, CRC Press and Taylor and Francis Group, Boca Raton, 2005.

83 J. M. Brown and S. G. Davies, Nature, 1989, 342, 631-636.

84 S. Hanessian, Total synthesis of natural products: The Chiron Approach, Pergamon Press, Elmsford, 1983.

85 T.-L. Ho, Enantioselective synthesis: natural products from chiral terpenes, Wiley, New York, 1992.

86 H. Kunz and K. Rück, Angew. Chem., Int. Ed. Engl., 1993, 32, 336-358.

87 J. Mulzer, K.-D. Graske and B. Kirste, Liebigs Ann. Chem., 1988, 1988, 891-897.

88 IPCC 2014, in Climate Change 2014: Synthesis Report. Contribution of Working Groups I, II and III to the Fifth Assessment Report of the Intergovernmental Panel on Climate Change, ed. Core Writing Team, R. K. Pachauri and L. Meyer, IPCC, Geneva, Switzerland, 2014.

89 A. Gandini, Macromolecules, 2008, 41, 9491-9504.

90 M. J. L. Tschan, E. Brulé, P. Haquette and C. M. Thomas, Polym. Chem., 2012, 3, 836-851.

91 Y. Zhu, C. Romain and C. K. Williams, Nature, 2016, 540, 354-362.

92 E. F. Gomez and A. J. Steckl, ACS Photonics, 2015, 2, 439445.

93 F. Liebner and T. Rosenau, Functional Materials from Renewable Sources, American Chemical Society, Vienna, 2012.

94 K. Y. Sandhya, A. Saritha and K. Joseph, in Liquid Crystalline Polymers: Volume 1-Structure and Chemistry, ed. V. K. Thakur and M. R. Kessler, Springer International Publishing, Cham, 2016, pp. 273-306.

95 N. Thejo Kalyani and S. J. Dhoble, Renewable Sustainable Energy Rev., 2015, 44, 319-347.

96 M. Yusuf, Handbook of Renewable Materials for Coloration and Finishing, Wiley-VCH, Weinheim, 2018.

97 C. A. S. Hill, Wood Modification: Chemical, Thermal and Other Processes, Wiley, 2007.

98 M. Carrier, A. Loppinet-Serani, D. Denux, J.-M. Lasnier, F. Ham-Pichavant, F. Cansell and C. Aymonier, Biomass Bioenergy, 2011, 35, 298-307.

99 J. Zakzeski, P. C. A. Bruijnincx, A. L. Jongerius and B. M. Weckhuysen, Chem. Rev., 2010, 110, 3552-3599.

100 C. Xu, R. A. D. Arancon, J. Labidi and R. Luque, Chem. Soc. Rev., 2014, 43, 7485-7500.

101 C. O. Tuck, E. Pérez, I. T. Horváth, R. A. Sheldon and M. Poliakoff, Science, 2012, 337, 695.

102 L. A. Lucia, BioResources, 2008, 3, 981-982.

103 J. J. Bozell, Science, 2010, 329, 522.
104 X. Wang and R. Rinaldi, ChemSusChem, 2012, 5, 1455-1466.

105 K. Triantafyllidis, A. Lappas and M. Stöcker, The Role of Catalysis for the Sustainable Production of Bio-fuels and Biochemicals, Elsevier-Science, Newnes, 2013.

106 R. Behling, S. Valange and G. Chatel, Green Chem., 2016, 18, 1839-1854.

107 E. Feghali, G. Carrot, P. Thuéry, C. Genre and T. Cantat, Energy Environ. Sci., 2015, 8, 2734-2743.

108 A. Demirbas, Energy Sources, Part A, 2009, 32, 1-9.

109 F. Stecker, I. M. Malkowsky, A. Fischer, S. R. Waldvogel and C. Regenbrecht, US Pat. application, US20130040031A1, 2014.

110 J. Kühlborn, A.-K. Danner, H. Frey, R. Iyer, A. J. Arduengo and T. Opatz, Green Chem., 2017, 19, 3780-3786.

111 T.-Q. Yuan, F. Xu and R.-C. Sun, J. Chem. Technol. Biotechnol., 2013, 88, 346-352.

112 Z. Sun, B. Fridrich, A. de Santi, S. Elangovan and K. Barta, Chem. Rev., 2018, 118, 614-678.

113 K. McCormick and N. Kautto, Sustainability, 2013, 5, 25892608.

114 D. Stubba, G. Lahm, M. Geffe, J. W. Runyon, A. J. Arduengo III and T. Opatz, Angew. Chem., Int. Ed., 2015, 54, 1418714189.

115 J. Kühlborn, M. Konhäuser, J. Groß, P. R. Wich and T. Opatz, ACS Sustainable Chem. Eng., 2019, 7, 4414-4419.

116 T. Opatz, J. Kühlborn, C. B. de Koning, K. J. Ngwira and Q. A. Mgani, South African provisional Pat., ZA2019/ 01514, 2019.

117 C. T. Hammond and P. G. Mahlberg, Phytochemistry, 1994, 37, 755-756.

118 D. Barton, A. Deflorin and O. Edwards, J. Chem. Soc. Resumed, 1956, 530-534.

119 K. Nakagawa-Goto and K.-H. Lee, Tetrahedron Lett., 2006, 47, 8263-8266.

120 O. Thoison, D. D. Cuong, A. Gramain, A. Chiaroni, N. V. Hung and T. Sévenet, Tetrahedron, 2005, 61, 85298535.

121 H. P. Pepper, S. J. Tulip, Y. Nakano and J. H. George, J. Org. Chem., 2014, 79, 2564-2573.

122 F. A. Ramos, Y. Takaishi, M. Shirotori, Y. Kawaguchi, K. Tsuchiya, H. Shibata, T. Higuti, T. Tadokoro and M. Takeuchi, J. Agric. Food Chem., 2006, 54, 3551-3557.

123 X. Wu, Y. Liu, W. Sheng, J. Sun and G. Qin, Planta Med., 1997, 63, 55-57.

124 A. J. Núñez Sellés, H. T. Vélez Castro, J. Agüero-Agüero, J. González-González, F. Naddeo, F. De Simone and L. Rastrelli, J. Agric. Food Chem., 2002, 50, 762-766.

125 J. H. Boyce and J. A. Porco Jr, Angew. Chem., Int. Ed., 2014, 53, 7832-7837.

126 R. D. Hartley and C. H. Fawcett, Phytochemistry, 1968, 7, 1395-1400.

127 S. Y. Chow, H. J. Williams, Q. Huang, S. Nanda and A. I. Scott, J. Org. Chem., 2005, 70, 9997-10003.

128 K. Anjou and E. von SYDOW, Acta Chem. Scand., 1969, 23, 109-114. 
129 Y.-C. Chien, C.-H. Lin, M. Y. Chiang, H.-S. Chang, C.-H. Liao, I.-S. Chen, C.-F. Peng and I.-L. Tsai, Phytochemistry, 2012, 80, 50-57.

130 D. A. Evans, T. C. Britton, R. L. Dorow and J. F. Dellaria, Tetrahedron, 1988, 44, 5525-5540.

131 S. Tahara, Y. Katagiri, J. L. Ingham and J. Mizutani, Phytochemistry, 1994, 36, 1261-1271.

132 M. A. Selepe, S. E. Drewes and F. R. van Heerden, Tetrahedron, 2011, 67, 8654-8658.

133 P. Reveglia, S. Savocchia, R. Billones-Baaijens, A. Cimmino and A. Evidente, J. Agric. Food Chem., 2018, 66, 1760-1764.

134 P. H. Dang, H. X. Nguyen, N. T. Nguyen, H. N. T. Le and M. T. T. Nguyen, Phytother. Res., 2014, 28, 1632-1636.

135 M. Royer, G. Herbette, V. Eparvier, J. Beauchêne, B. Thibaut and D. Stien, Phytochemistry, 2010, 71, 1708-1713.

136 M. A. Selepe, S. E. Drewes and F. R. van Heerden, J. Nat. Prod., 2010, 73, 1680-1685.

137 G. R. Nagarajan and V. S. Parmar, Phytochemistry, 1977, 16, 614-615.

138 E. Chosson, A. Chaboud, A. J. Chulia and J. Raynaud, Phytochemistry, 1998, 47, 87-88.

139 T. Milkova, G. Talev, R. Christov, S. Dimitrova-Konaklieva and S. Popov, Phytochemistry, 1997, 45, 93-95.

140 J. Guyot and L. J. Simon, C. R. Hebd. Seances Acad. Sci., 1919, 169, 795-797.

141 D. Mesnard and L. Miginiac, J. Organomet. Chem., 1989, 373, 1-10.

142 L. Tonucci, M. Nicastro, N. d'Alessandro, M. Bressan, P. D'Ambrosio and A. Morvillo, Green Chem., 2009, 11, 816-820.

143 S. B. Ateba, D. Njamen, S. Medjakovic, M. Zehl, H. Kaehlig, A. Jungbauer and L. Krenn, BMC Complementary Altern. Med., 2014, 14, 294.

144 Y.-Z. Lee, C.-W. Huang, C.-W. Yang, H.-Y. Hsu, I.-J. Kang, Y.-S. Chao, I.-S. Chen, H.-Y. Chang and S.-J. Lee, Planta Med., 2011, 77, 1932-1938.

145 G. Lahm, A. Stoye and T. Opatz, J. Org. Chem., 2012, 77, 6620-6623.

146 J. Hussain, H. Khan, L. Ali, A. Latif Khan, N. Ur Rehman, S. Jahangir and A. Al-Harrasi, Helv. Chim. Acta, 2015, 98, 719-723.

147 B. Zierer, P. Schieberle and M. Granvogl, J. Agric. Food Chem., 2016, 64, 9515-9522.

148 J. Verduyckt, M. Van Hoof, F. De Schouwer, M. Wolberg, M. Kurttepeli, P. Eloy, E. M. Gaigneaux, S. Bals, C. E. A. Kirschhock and D. E. De Vos, ACS Catal., 2016, 6, 7303-7310.

149 A. Stoye, T. E. Peez and T. Opatz, J. Nat. Prod., 2013, 76, 275278.

150 N. Ünver and G. İ. Kaya, Turk. J. Chem., 2005, 29, 547-553.

151 S. Tian, W. Zi and D. Ma, Angew. Chem., Int. Ed., 2012, 51, 10141-10144.

152 S. Kodama, H. Takita, T. Kajimoto, K. Nishide and M. Node, Tetrahedron, 2004, 60, 4901-4907.

153 S. Ghosal, Y. Kumar and S. Singh, Phytochemistry, 1984, 23, 1167-1171.

154 T. A. Wheaton and I. Stewart, Phytochemistry, 1969, 8, 85-92.
155 H. Matsuda, K. Ninomiya, T. Morikawa, D. Yasuda, I. Yamaguchi and M. Yoshikawa, Bioorg. Med. Chem., 2009, 17, 7313-7323.

156 Y. Zhu, P. Zhang, H. Yu, J. Li, M.-W. Wang and W. Zhao, J. Nat. Prod., 2007, 70, 1570-1577.

157 S. Barradas, G. Hernández-Torres, A. Urbano and M. C. Carreño, Org. Lett., 2012, 14, 5952-5955.

158 T. Mohn, I. Plitzko and M. Hamburger, Phytochemistry, 2009, 70, 924-934.

159 S. Agostini, J.-M. Desjobert and G. Pergent, Phytochemistry, 1998, 48, 611-617.

160 J. Deng, R. Li, Y. Luo, J. Li, S. Zhou, Y. Li, J. Hu and A. Li, Org. Lett., 2013, 15, 2022-2025.

161 J.-X. Zhu, J.-J. Qin, F. Zhang, R.-J. Chang, J. Ren, X.-R. Cheng, Q. Zeng, H.-Z. Jin and W.-D. Zhang, Chem. Nat. Compd., 2013, 49, 383-387.

162 A. Padwa, M. J. Chughtai, J. Boonsombat and P. Rashatasakhon, Tetrahedron, 2008, 64, 4758-4767.

163 C.-I. Chang, J.-Y. Chang, C.-C. Kuo, W.-Y. Pan and Y.-H. Kuo, Planta Med., 2005, 71, 72-76.

164 M. R. Crimmin and A. J. P. White, Chem. Commun., 2012, 48, 1745-1747.

165 S. M. Klein, C. Zhang and Y. L. Jiang, Tetrahedron Lett., 2008, 49, 2638-2641.

166 L. R. Salgueiro, R. Vila, F. Tomi, X. Tomas, S. Cañigueral, J. Casanova, A. P. da Cunha and T. Adzet, Phytochemistry, 1997, 45, 1177-1183.

167 G. A. Burdock, Fenaroli's handbook offlavor ingredients, CRC press and Taylor and Francis Group, Boca Raton, 2016.

168 B. Fang, X. Xie, H. Li, P. Jing, J. Gu and X. She, Tetrahedron Lett., 2013, 54, 6349-6351.

169 A. Briot, C. Baehr, R. Brouillard, A. Wagner and C. Mioskowski, J. Org. Chem., 2004, 69, 1374-1377.

170 J. Ejlertsson, M. Alnervik, S. Jonsson and B. H. Svensson, Environ. Sci. Technol., 1997, 31, 2761-2764.

171 J. R. Vale, T. Rimpiläinen, E. Sievänen, K. Rissanen, C. A. M. Afonso and N. R. Candeias, J. Org. Chem., 2018, 83, 1948-1958.

172 K. Tianpanich, S. Prachya, S. Wiyakrutta, C. Mahidol, S. Ruchirawat and P. Kittakoop, J. Nat. Prod., 2011, 74, 79-81.

173 R. C. C. Martins, J. H. G. Lago, S. Albuquerque and M. J. Kato, Phytochemistry, 2003, 64, 667-670.

174 A. Benavides, C. Bassarello, P. Montoro, W. Vilegas, S. Piacente and C. Pizza, Phytochemistry, 2007, 68, 12771284.

175 M. S. Kumar, K. C. Rajanna, P. Venkanna, M. Venkateswarlu and V. Sudhakar Chary, Synth. React. Inorg., Met.-Org., Nano-Met. Chem., 2016, 46, 642-646.

176 T. Holm, J. Chem. Soc., Perkin Trans. 2, 1981, 464-467.

177 Z. Guo, D. S. Theng, K. Y. Tang, L. Zhang, L. Huang, A. Borgna and C. Wang, Phys. Chem. Chem. Phys., 2016, 18, 23746-23754.

178 C. T. Lira and P. J. McCrackin, Ind. Eng. Chem. Res., 1993, 32, 2608-2613.

179 X. Xu, J. Lin and P. Cen, Chin. J. Chem. Eng., 2006, 14, 419427. 
180 J. Zhang, J. Lin and P. Cen, Can. J. Chem. Eng., 2008, 86, 1047-1053.

181 X. Zhang, L. Lin, T. Zhang, H. Liu and X. Zhang, Chem. Eng. J., 2016, 284, 934-941.

182 P. L. Anelli, M. Brocchetta, D. Copez, D. Palano, M. Visigalli and P. Paoli, Tetrahedron, 1997, 53, 15827-15832.

183 E. Lloyd, C. B. Brown, D. G. R. Bonnell and W. J. Jones, J. Chem. Soc. Resumed, 1928, 658-666.

184 K. G. Lalwani and A. Sudalai, Eur. J. Org. Chem., 2015, 2015, 7344-7351.

185 K. H. Kim, E. Moon, H. K. Kim, J. Y. Oh, S. Y. Kim, S. U. Choi and K. R. Lee, Bioorg. Med. Chem. Lett., 2012, 22, 6155-6159.

186 L. H. Zhang, J. Duan, Y. Xu and W. R. Dolbier, Tetrahedron Lett., 1998, 39, 9621-9622.

187 A. H. G. Siebum, W. S. Woo and J. Lugtenburg, Eur. J. Org. Chem., 2003, 2003, 4664-4678.

188 W. Reif and H. Grassner, Chem. Ing. Tech., 1973, 45, 646652.

189 M. A. A. Endoma-Arias, M. Makarova, H. E. Dela Paz and T. Hudlicky, Synthesis, 2019, 51, 225-232.

190 A. Jakubska, D. Przado, M. Steininger, J. Aniol-Kwiatkowska and M. Kadej, Appl. Ecol. Environ. Res., 2005, 3, 29-38.

191 H.-C. Lin, Z. Wang, C. Boyd, L. Simoni-Wastila and A. Buu, Addict. Behav., 2018, 76, 348-354.

192 Y. Hirose, M. Ogawa and Y. Kusuda, Agric. Biol. Chem., 1962, 26, 526-531.

193 K. M. Markovich, V. Tantishaiyakul, A. Hamada, D. D. Miller, K. J. Romstedt, G. Shams, Y. Shin, P. F. Fraundorfer, K. Doyle and D. R. Feller, J. Med. Chem., 1992, 35, 466-479.

194 H. Koizumi, S. Yokoshima and T. Fukuyama, Chem.-Asian J., 2010, 5, 2192-2198.

195 M. P. Tsyurupa, Z. K. Blinnikova, M. M. Il'in, V. A. Davankov, O. O. Parenago, O. I. Pokrovskii and O. I. Usovich, Russ. J. Phys. Chem. A, 2015, 89, 2064-2071.

196 P. Xing, Z.-g. Huang, Y. Jin and B. Jiang, Synthesis, 2013, 45, 596-600.

197 F. Li, J. Xie, H. Shan, C. Sun and L. Chen, $R S C A d v .$, 2012, 2, 8645-8652.

198 D. Azarifar and F. Soleimanei, RSC Adv., 2014, 4, 1211912126.

199 E. V. Papp and J. Pogany, Angew. Chem., 1941, 54, 55.

200 H. Itokawa, O. Shirota, H. Ikuta, H. Morita, K. Takeya and Y. Iitaka, Phytochemistry, 1991, 30, 3713-3716.

201 W. Wang, J. Guo, J. Zhang, J. Peng, T. Liu and Z. Xin, Food Chem., 2015, 171, 40-49.

202 A. M. Nauth, N. Otto and T. Opatz, Adv. Synth. Catal., 2015, 357, 3424-3428.

203 M. a. D. Guillén and M. a. J. Manzanos, Food Chem., 2002, 79, 283-292.

204 T. R. Nunn, J. B. Howard, J. P. Longwell and W. A. Peters, Ind. Eng. Chem. Process Des. Dev., 1985, 24, 844-852.

205 M. Del Bel, A. R. Abela, J. D. Ng and C. A. Guerrero, J. Am. Chem. Soc., 2017, 139, 6819-6822.

206 J. R. Hanson, M. A. O'Leary, H. J. Wadsworth and L. Y. Boon, Phytochemistry, 1988, 27, 387-389.

207 P. W. Brian, P. J. Curtis, H. G. Hemming and J. C. McGowan, Ann. Appl. Biol., 1946, 33, 190-200.
208 J. M. Barbosa-Filho, M. Yoshida, O. R. Gottlieb, R. de C. S. B. C. Barbosa, A. M. Giesbrecht, M. Claudia and M. Young, Phytochemistry, 1987, 26, 2615-2617.

209 A. Hadfield, H. Schweitzer, M. P. Trova and K. Green, Synth. Commun., 1994, 24, 1025-1028.

210 A. Fürstner and I. Konetzki, Tetrahedron Lett., 1998, 39, 5721-5724.

211 H.-P. Xiong, J.-L. Mi, J.-M. Le, Z.-J. Wu and W.-S. Chen, Chem. Nat. Compd., 2017, 53, 791-793.

212 B. A. Czeskis, P. Baeckström, A. M. Moiseenkov and T. Norin, Bull. Acad. Sci. USSR, Div. Chem. Sci., 1989, 38, 131-134.

213 M. Miyazawa and H. Kameoka, Agric. Biol. Chem., 1988, 52, 1053-1055.

214 B. Giese and U. Erfort, Angew. Chem., Int. Ed., 1982, 21, 130131.

215 Y. Leng, J. Liu and X. Feng, China Pat., CN105503923 (A), 2016.

216 M. Grodzki and G. Kraemer, Ber. Dtsch. Chem. Ges., 1874, 7, 1492-1497.

217 O. Kamm and C. Marvel, Org. Synth., 1921, 1, 15-17.

218 J. Houben, J. Boedler and W. Fischer, Ber. Dtsch. Chem. Ges., 1936, 69, 1766-1788.

219 M. V. Kazantseva, B. V. Timokhin, A. V. Rokhin, D. G. Blazhev, A. I. Golubin and Y. V. Rybakova, Russ. J. Gen. Chem., 2001, 71, 1233-1235.

220 H. Shi, C. Du, X. Zhang, F. Xie, X. Wang, S. Cui, X. Peng, M. Cheng, B. Lin and Y. Liu, J. Org. Chem., 2018, 83, 1312-1319.

221 M.-J. Cheng, I.-L. Tsai and I.-S. Chen, J. Chin. Chem. Soc., 2001, 48, 235-239.

222 S. Kobayashi, T. Tokumoto and Z. Taira, J. Chem. Soc., Chem. Commun., 1984, 1043-1044.

223 H. Meshulam and D. Lavie, Phytochemistry, 1980, 19, 26332635.

224 A. Lipp, D. Ferenc, C. Gütz, M. Geffe, N. Vierengel, D. Schollmeyer, H. J. Schäfer, S. R. Waldvogel and T. Opatz, Angew. Chem., Int. Ed., 2018, 57, 11055-11059.

225 S. Ghosal and R. S. Srivastava, Phytochemistry, 1973, 12, 193-197.

226 B. Pfundstein, S. K. El Desouky, W. E. Hull, R. Haubner, G. Erben and R. W. Owen, Phytochemistry, 2010, 71, 11321148.

227 A. Lipp, M. Selt, D. Ferenc, D. Schollmeyer, S. R. Waldvogel and T. Opatz, Org. Lett., 2019, 21, 1828-1831.

228 L. Hu, Z. Qiuyun, R. Anders and Y. Song, Curr. Nanosci., 2015, 11, 1-14.

229 W. Den, V. K. Sharma, M. Lee, G. Nadadur and R. S. Varma, Front. Chem., 2018, 6, 141.

230 J. N. Chheda, G. W. Huber and J. A. Dumesic, Angew. Chem., Int. Ed., 2007, 46, 7164-7183.

231 Z. Xue, Q. Liu, J. Wang and T. Mu, Green Chem., 2018, 20, 4391-4408.

232 K. N. Onwukamike, S. Grelier, E. Grau, H. Cramail and M. A. R. Meier, ACS Sustainable Chem. Eng., 2019, 7, 1826-1840.

233 P. Gallezot, Chem. Soc. Rev., 2012, 41, 1538-1558. 
234 Z. Xue, M.-G. Ma, Z. Li and T. Mu, RSC Adv., 2016, 6, 9887498892.

235 P. K. Rout, A. D. Nannaware, O. Prakash, A. Kalra and R. Rajasekharan, Chem. Eng. Sci., 2016, 142, 318-346.

236 F. Menegazzo, E. Ghedini and M. Signoretto, Molecules, 2018, 23, 2201.

237 H. H. Szmant and D. D. Chundury, J. Chem. Technol. Biotechnol., 1981, 31, 205-212.

238 M. Mascal, ACS Sustainable Chem. Eng., 2019, 7, 5588-5601.

239 G. A. Halliday, R. J. Young and V. V. Grushin, Org. Lett., 2003, 5, 2003-2005.

240 Q. Girka, B. Estrine, N. Hoffmann, J. Le Bras, S. Marinković and J. Muzart, React. Chem. Eng., 2016, 1, 176-182.

241 Y. Qian, L. Zhu, Y. Wang and X. Lu, Renewable Sustainable Energy Rev., 2015, 41, 633-646.

242 M. Braun and M. Antonietti, Green Chem., 2017, 19, 38133819.

243 X. Zheng, X. Gu, Y. Ren, Z. Zhi and X. Lu, Biofuels, Bioprod. Biorefin., 2016, 10, 917-931.

244 S. Kang, J. Fu and G. Zhang, Renewable Sustainable Energy Rev., 2018, 94, 340-362.

245 A. M. R. Galletti, C. Antonetti, V. De Luise, D. Licursi and N. Nassi, BioResources, 2012, 7, 1824-1835.

246 C. Antonetti, D. Licursi, S. Fulignati, G. Valentini and A. M. Raspolli Galletti, Catalysts, 2016, 6, 196.

247 M. S. Miftakhov, F. A. Valeev and I. N. Gaisina, Russ. Chem. Rev., 1994, 63, 869-882.

248 J. He, M. Liu, K. Huang, T. W. Walker, C. T. Maravelias, J. A. Dumesic and G. W. Huber, Green Chem., 2017, 19, 3642-3653.

249 M. B. Comba, Y.-h. Tsai, A. M. Sarotti, M. I. Mangione, A. G. Suárez and R. A. Spanevello, Eur. J. Org. Chem., 2018, 2018, 590-604.

250 A. V. Bridgwater, D. Meier and D. Radlein, Org. Geochem., 1999, 30, 1479-1493.

251 S. Maduskar, V. Maliekkal, M. Neurock and P. J. Dauenhauer, ACS Sustainable Chem. Eng., 2018, 6, 7017-7025.

252 M. S. Mettler, A. D. Paulsen, D. G. Vlachos and P. J. Dauenhauer, Energy Environ. Sci., 2012, 5, 7864-7868.

253 X. Zhang, W. Yang and C. Dong, J. Anal. Appl. Pyrolysis, 2013, 104, 19-27.

254 B. T. Sharipov, A. N. Davidova, A. S. Ryabova, N. F. Galimzyanova and F. A. Valeev, Chem. Heterocycl. Compd., 2019, 55, 31-37.

255 A. L. Flourat, A. A. M. Peru, A. R. S. Teixeira, F. Brunissen and F. Allais, Green Chem., 2015, 17, 404-412.

256 M. Moreaux, G. Bonneau, A. Peru, F. Brunissen, M. Janvier, A. Haudrechy and F. Allais, Eur. J. Org. Chem., 2019, 2019, 1600-1604.

257 Z. J. Witczak and K. Tatsuta, in ACS Symp. Ser., American Chemical Society, 2002, vol. 841, p. 228.

258 A. Tauss, T. M. Wrodnigg and A. E. Stütz, Recent Res. Dev. Org. Chem., 1999, 3, 319-342.

259 K. Tatsuta and S. Hosokawa, Sci. Technol. Adv. Mater., 2006, 7, 397-410.
260 K. C. Nicolaou and H. J. Mitchell, Angew. Chem., Int. Ed., 2001, 40, 1576-1624.

261 T. Hudlicky, Chem. Rev., 1996, 96, 3-30.

262 N. Chida and T. Sato, in Comprehensive Chirality, ed. E. M. Carreira and H. Yamamoto, Elsevier, Amsterdam, 2012, pp. 207-239.

263 P. P. Deshpande, K. N. Price and D. C. Baker, Bioorg. Med. Chem. Lett., 1995, 5, 1059-1060.

264 C. Zhengxiong, H. Huizhu, W. Chengrui, L. Yuhui, D. Jianmi, U. Sankawa, H. Noguchi and Y. Iitaka, Heterocycles, 1984, 22, 691-694.

265 C. Zhengxiong, H. Huizhu, W. Chengrui, L. I. Yuhui, D. Jianmi, U. Sankawa, H. Noguchi and Y. Iitaka, Chem. Pharm. Bull., 1986, 34, 2743-2746.

266 J. S. Swenton, J. N. Freskos, P. Dalidowicz and M. L. Kerns, J. Org. Chem., 1996, 61, 459-464.

267 M. Dischmann, T. Frassetto, M. A. Breuning and U. Koert, Chem.-Eur. J., 2014, 20, 11300-11302.

268 European Food Safety Authority, EFSA J., 2005, 3, 246.

269 A. Latrasse, E. Guichard, C. Piffaut, N. Fournier and L. Dufosse, Chirality, 1993, 5, 379-384.

270 A. A. M. Peru, A. L. Flourat, C. Gunawan, W. Raverty, M. Jevric, B. W. Greatrex and F. Allais, Molecules, 2016, 21, 988.

271 M. Wang, M. Chen, Y. Fang and T. Tan, Biotechnol. Biofuels, 2018, 11, 30 .

272 G. B. Bachman and A. J. Hill, J. Am. Chem. Soc., 1934, 56, 2730-2732.

273 A. Fürstner, K. Radkowski, C. Wirtz, R. Goddard, C. W. Lehmann and R. Mynott, J. Am. Chem. Soc., 2002, 124, 7061-7069.

274 J. Fausto Rivero-Cruz, G. García-Aguirre, C. M. CerdaGarcía-Rojas and R. Mata, Tetrahedron, 2000, 56, 53375344.

275 A. Nickel and R. L. Pederson, in Olefin Metathesis, ed. K. Grela, Wiley-VCH, Weinheim, 2014.

276 P. Jiao, D. C. Swenson, J. B. Gloer and D. T. Wicklow, J. Nat. Prod., 2006, 69, 636-639.

277 M. Ostermeier and R. Schobert, J. Org. Chem., 2014, 79, 4038-4042.

278 L. Andrussow, Ber. Dtsch. Chem. Ges., 1927, 60, 2005-2018. 279 L. Andrussow, Angew. Chem., 1935, 48, 593-595.

280 A. Tilche and M. Galatola, Water Sci. Technol., 2008, 57, 1683-1692.

281 A. M. Nauth and T. Opatz, Org. Biomol. Chem., 2019, 17, 1123.

282 H. J. Bestmann and D. Sandmeier, Angew. Chem., Int. Ed. Engl., 1975, 14, 634.

283 R. Schobert, R. K. Boeckman Jr and J. E. Pero, Org. Synth., 2005, 82, 140-143.

284 M. Kubo, C. Okada, J.-M. Huang, K. Harada, H. Hioki and Y. Fukuyama, Org. Lett., 2009, 11, 5190-5193.

285 L. Trzoss, J. Xu, M. H. Lacoske, W. C. Mobley and E. A. Theodorakis, Chem.-Eur. J., 2013, 19, 6398-6408.

286 J. Xu, L. Trzoss, W. K. Chang and E. A. Theodorakis, Angew. Chem., Int. Ed., 2011, 50, 3672-3676.

287 K. Shimizu and F. Matsushita, US Pat., US7897802B2, 2011. 
288 E. Lacoste, E. Vaique, M. Berlande, I. Pianet, J.-M. Vincent and Y. Landais, Eur. J. Org. Chem., 2007, 2007, 167-177.

289 L. Trzoss, J. Xu, M. H. Lacoske, W. C. Mobley and E. A. Theodorakis, Org. Lett., 2011, 13, 4554-4557.

290 A. W. Schorger, Ind. Eng. Chem., 1925, 17, 944.

291 Pyrénéenne de Carburants et Solvants, France Pat., FR993861A, 1944.

292 H. Siegel and M. Eggersdorfer, in Ullmann's Encyclopedia of Industrial Chemistry, Wiley-VCH, Weinheim, 2000.

293 A. L. Wilds, R. M. Nowak and K. E. McCaleb, Org. Synth., 1957, 37, 18.

294 S. H. Park and A. K. Bose, Bull. Chem. Soc. Jpn., 2001, 74, 1917-1925.

295 K. S. Pitzer and H. S. Gutowsky, J. Am. Chem. Soc., 1946, 68, 2204-2209.

296 S. M. Hande and J. i. Uenishi, Tetrahedron Lett., 2009, 50, 189-192.

297 K. Kito, R. Ookura, S. Yoshida, M. Namikoshi, T. Ooi and T. Kusumi, Org. Lett., 2008, 10, 225-228.

298 O. Ryuhei, K. Keijiro, S. Yota, K. Takenori and O. Takashi, Chem. Lett., 2009, 38, 384.

299 P. F. Koh and T. P. Loh, Green Chem., 2015, 17, 3746-3750. 300 A. Bouchardat, Ann. Pharm., 1837, 22, 225-236.

301 B. H. Lipshutz, S. Ghorai, A. R. Abela, R. Moser, T. Nishikata, C. Duplais, A. Krasovskiy, R. D. Gaston and R. C. Gadwood, J. Org. Chem., 2011, 76, 4379-4391.

302 P. Klumphu and B. H. Lipshutz, J. Org. Chem., 2014, 79, 888-900.

303 A. Krasovskiy, C. Duplais and B. H. Lipshutz, Org. Lett., 2010, 12, 4742-4744.

304 B. H. Lipshutz, N. A. Isley, J. C. Fennewald and E. D. Slack, Angew. Chem., Int. Ed., 2013, 52, 10952-10958.

305 H. Fuwa, H. Yamaguchi and M. Sasaki, Org. Lett., 2010, 12, 1848-1851.

306 M. Kanematsu, M. Yoshida and K. Shishido, Angew. Chem., Int. Ed., 2011, 50, 2618-2620.

307 J. H. Cardellina II, R. L. Hendrickson, K. P. Manfredi, S. A. Strobel and J. Clardy, Tetrahedron Lett., 1987, 28, 727-730.

308 U. Daisuke, T. Yoshiaki, W. Ichiro and H. Yoshimasa, Chem. Lett., 1979, 8, 1481-1482.

309 M. Brehm, W. G. Dauben, P. Köhler and F. W. Lichtenthaler, Angew. Chem., 1987, 1318-1319.

310 M. Brehm, V. H. Göckel, P. Jarglis and F. W. Lichtenthaler, Tetrahedron: Asymmetry, 2008, 19, 358-373.

311 P. Jarglis and F. W. Lichtenthaler, Angew. Chem., 1982, 94, 140-141.

312 R. J. Ferrier and G. H. Sankey, J. Chem. Soc. C, 1966, 23392345.

313 H. Fletcher, Methods Carbohydr. Chem., 1963, 2, 226-228.

314 K. Maurer and R. Böhme, Ber. Dtsch. Chem. Ges. A/B, 1936, 1399-1410.

315 H. Zhao, S. Hans, X. Cheng and D. R. Mootoo, J. Org. Chem., 2001, 66, 1761-1767.

316 H. Zhao and D. R. Mootoo, J. Org. Chem., 1996, 61, 67626763.
317 L. D. Hohenschutz, E. A. Bell, P. J. Jewess, D. P. Leworthy, R. J. Pryce, E. Arnold and J. Clardy, Phytochemistry, 1981, 20, 811-814.

318 S. Czernecki, S. Horns and J.-M. Valery, J. Org. Chem., 1995, 60, 650-655.

319 H. Hashimoto, K. Asano, F. Fujii and J. Yoshimura, Carbohydr. Res., 1982, 104, 87-104.

320 A. Lipták, I. Jodál and P. Nánási, Carbohydr. Res., 1975, 44, 1-11.

321 N. Yan and X. Chen, Nature, 2015, 524, 155-157.

322 M. J. Hülsey, Green Energy \& Environment, 2018, 3, 318-327.

323 X. Chen, Y. Gao, L. Wang, H. Chen and N. Yan, ChemPlusChem, 2015, 80, 1565-1572.

324 X. Chen, H. Yang and N. Yan, Chem.-Eur. J., 2016, 22, 13402-13421.

325 F. M. Kerton, Y. Liu, K. W. Omari and K. Hawboldt, Green Chem., 2013, 15, 860-871.

326 R. A. Muzzarelli, C. Jeuniaux and G. W. Gooday, Chitin in nature and technology, Springer, Boston, 1986.

327 S. Salmon and S. M. Hudson, J. Macromol. Sci., Chem., 1997, 37, 199-276.

328 K. Y. Zhu, H. Merzendorfer, W. Zhang, J. Zhang and S. Muthukrishnan, Annu. Rev. Entomol., 2016, 61, 177-196.

329 M. N. V. R. Kumar, R. A. A. Muzzarelli, C. Muzzarelli, H. Sashiwa and A. J. Domb, Chem. Rev., 2004, 104, 6017-6084.

330 K. Müller, C. Zollfrank and M. Schmid, Macromol. Mater. Eng., 2019, 1800760.

331 Q. Yan, E. Hong and S. S. Fong, Appl. Microbiol. Biotechnol., 2017, 101, 7567-7578.

332 I. Younes and M. Rinaudo, Mar. Drugs, 2015, 13, 1133.

333 R. N. Tharanathan and F. S. Kittur, Crit. Rev. Food Sci. Nutr., 2003, 43, 61-87.

334 S. Hitoshi, F. Shizu, Y. Naoko, K. Norioki, N. Atsuyoshi, M. Einosuke and A. Sei-ichi, Chem. Lett., 2001, 30, 308-309.

335 J. H. Yoon, Enzyme Microb. Technol., 2005, 37, 663-668.

336 W. Xia, P. Liu and J. Liu, Bioresour. Technol., 2008, 99, 67516762.

337 G. Sibi, K. Dhananjaya, K. Ravikumar, H. Mallesha, R. Venkatesha, D. Trivedi, K. Bhusal and K. Gowda, Am.Eurasian J. Sci. Res., 2013, 8, 63-67.

338 X. Chen, Y. Liu, F. M. Kerton and N. Yan, $R S C A d v .$, 2015, 5, 20073-20080.

339 M. W. Drover, K. W. Omari, J. N. Murphy and F. M. Kerton, RSC Adv., 2012, 2, 4642-4644.

340 K. W. Omari, L. Dodot and F. M. Kerton, ChemSusChem, 2012, 5, 1767-1772.

341 X. Chen, S. L. Chew, F. M. Kerton and N. Yan, Green Chem., 2014, 16, 2204-2212.

342 T. T. Pham, G. Gözaydın, T. Söhnel, N. Yan and J. Sperry, Eur. J. Org. Chem., 2019, 2019, 1355-1360.

343 T. N. Makarieva, V. A. Denisenko, V. A. Stonik, Y. M. Milgrom and Y. V. Rashkes, Tetrahedron Lett., 1989, 30, 6581-6584.

344 T. N. Makarieva, P. S. Dmitrenok, A. M. Zakharenko, V. A. Denisenko, A. G. Guzii, R. Li, C. K. Skepper, T. F. Molinski and V. A. Stonik, J. Nat. Prod., 2007, 70, 1991-1998. 
345 J. Ko and T. F. Molinski, J. Org. Chem., 2013, 78, 498-505. 346 A. Behr, J. Eilting, K. Irawadi, J. Leschinski and F. Lindner, Green Chem., 2008, 10, 13-30.

347 D. Yoffe, R. Frim, S. D. Ukeles, M. J. Dagani, H. J. Barda, T. J. Benya and D. C. Sanders, in Ullmann's Encyclopedia of Industrial Chemistry, 2013.

348 S. Warwel, P. Bavaj, M. R. g. Klaas and B. Wolff, in Perspektiven nachwachsender Rohstoffe in der Chemie, ed. H. Eierdanz, Wiley-VCH, Weinheim, 1996, pp. 119-135.

349 S. Warwel, F. Brüse, C. Demes, M. Kunz and M. R. g. Klaas, Chemosphere, 2001, 43, 39-48.

350 Y. Nakagawa and K. Tomishige, Catal. Today, 2012, 195, 136-143.

351 H. P. Thomas and C. L. Wilson, J. Am. Chem. Soc., 1951, 73, 4803-4805.

352 J. Cason and W. N. Baxter, J. Org. Chem., 1958, 23, 13021305.

353 H. Usuki, M. Toyo-oka, H. Kanzaki, T. Okuda and T. Nitoda, Bioorg. Med. Chem., 2009, 17, 7248-7253.

354 Y. Kitamura, H. Koshino, T. Nakamura, A. Tsuchida, T. Nitoda, H. Kanzaki, K. Matsuoka and S. Takahashi, Tetrahedron Lett., 2013, 54, 1456-1459.

355 L. Cai, W. Guan, M. Kitaoka, J. Shen, C. Xia, W. Chen and P. G. Wang, Chem. Commun., 2009, 2944-2946.

356 M. Nakata, S. Akazawa, S. Kitamura and K. Tatsuta, Tetrahedron Lett., 1991, 32, 5363-5366.

357 S. Takahashi, H. Terayama and H. Kuzuhara, Tetrahedron Lett., 1991, 32, 5123-5126.

358 N. S. Simpkins, S. Stokes and A. J. Whittle, Tetrahedron Lett., 1992, 33, 793-796.

359 N. S. Simpkins, S. Stokes and A. J. Whittle, J. Chem. Soc., Perkin Trans. 1, 1992, 2471-2477.

360 T. Kitahara, N. Suzuki, K. Koseki and K. Mori, Biosci., Biotechnol., Biochem., 1993, 57, 1906-1909.

361 T. J. Donohoe and C. P. Rosa, Org. Lett., 2007, 9, 5509-5511.

362 S. Sakuda, A. Isogai, S. Matsumoto, A. Suzuki and K. Koseki, Tetrahedron Lett., 1986, 27, 2475-2478.

363 S. Sakuda, A. Isogai, S. Matsumoto and A. Suzuki, J. Antibiot., 1987, 40, 296-300.

364 P. J. Somers, R. C. Yao, L. E. Doolin, M. J. Mcgowan, D. S. Fukuda and J. S. Mynderse, J. Antibiot., 1987, 40, 1751-1756.

365 Y. Nishimoto, S. Sakuda, S. Takayama and Y. Yamada, J. Antibiot., 1991, 44, 716-722.

366 S. Sakuda and A. Isogai, Agric. Biol. Chem., 1988, 52, 1615.

367 I. Mochida, A. Yasutake, H. Fujitsu and K. Takeshita, J. Catal., 1983, 82, 313-321.

368 A. D. Sadiq, X. Chen, N. Yan and J. Sperry, ChemSusChem, 2018, 11, 532-535.

369 F. Brucoli, A. Natoli, P. Marimuthu, M. T. Borrello, P. Stapleton, S. Gibbons and A. Schätzlein, Bioorg. Med. Chem., 2012, 20, 2019-2024.

370 F. E. Wolter, K. Schneider, B. P. Davies, E. R. Socher, G. Nicholson, O. Seitz and R. D. Süssmuth, Org. Lett., 2009, 11, 2804-2807.

371 L. Cassar, La Chimica \& L'Industria, 1989, 18-22.

372 P. Tundo and M. Selva, Acc. Chem. Res., 2002, 35, 706-716.
373 M. A. Pacheco and C. L. Marshall, Energy Fuels, 1997, 11, $2-$ 29.

374 P. Tundo, L. Rossi and A. Loris, J. Org. Chem., 2005, 70, 2219-2224.

375 A. El-Faham, R. S. Funosas, R. Prohens and F. Albericio, Chem.-Eur. J., 2009, 15, 9404-9416.

376 H. Baumann, M. Bühler, H. Fochem, F. Hirsinger, H. Zoebelein and J. Falbe, Angew. Chem., Int. Ed., 1988, 27, 41-62.

377 U. Biermann, U. Bornscheuer, M. A. R. Meier, J. O. Metzger and H. J. Schäfer, Angew. Chem., Int. Ed., 2011, 50, 38543871.

378 F. D. Gunstone, Lipid Technol., 2008, 20, 48.

379 A. S. Berenblyum, V. Y. Danyushevsky, P. S. Kuznetsov, E. A. Katsman and R. S. Shamsiev, Pet. Chem., 2016, 56, 663-671.

380 H. Brännström, H. Kumar and R. Alén, BioEnergy Res., 2018, 11, 592-613.

381 B. Zhang, J. Wu, C. Yang, Q. Qiu, Q. Yan, R. Li, B. Wang, J. Wu and Y. Ding, BioEnergy Res., 2018, 11, 689-702.

382 M. A. R. Meier, J. O. Metzger and U. S. Schubert, Chem. Soc. Rev., 2007, 36, 1788-1802.

383 U. Biermann, W. Friedt, S. Lang, W. Lühs, G. Machmüller, J. O. Metzger, M. Rüsch gen. Klaas, H. J. Schäfer and M. P. Schneider, Angew. Chem., Int. Ed., 2000, 39, 22062224.

384 J. O. Metzger, Eur. J. Lipid Sci. Technol., 2009, 111, 865-876. 385 J. O. Metzger and M. A. R. Meier, Eur. J. Lipid Sci. Technol., 2008, 110, 787.

386 S. Chornaja, E. Sproge, K. Dubencovs, L. Kulikova, V. Serga, A. Cvetkovs and V. Kampars, Key Eng. Mater., 2014, 604, 138-141.

387 A. El Roz, P. Fongarland, F. Dumeignil and M. Capron, Front. Chem., 2019, 7, 1-9.

388 A. Martin, U. Armbruster and H. Atia, Eur. J. Lipid Sci. Technol., 2012, 114, 10-23.

389 M. R. Sahasrabudhe, J. Am. Oil Chem. Soc., 1977, 54, 323324.

390 H. Neischlag, I. Wolff, T. Manley and R. Holland, Ind. Eng. Chem. Prod. Res. Dev., 1967, 6, 120-123.

391 D. A. Knauft and K. M. Moore, J. Hered., 1989, 80, 252-253. 392 J. E. Villarreal-Lozoya, L. Lombardini and L. CisnerosZevallos, Food Chem., 2007, 102, 1241-1249.

393 S.-P. Chang and J. A. Rothfus, J. Am. Oil Chem. Soc., 1977, 54, 549-552.

394 C. R. Smith, M. O. Bagby, T. K. Miwa, R. L. Lohmar and I. A. Wolff, J. Org. Chem., 1960, 25, 1770-1774.

395 T. Takagi, M. Kaneniwa, Y. Itabashi and R. G. Ackman, Lipids, 1986, 21, 558-565.

396 U. Ahmad Viqar, A. Basha and W. Haque, Z. Naturforsch., B: Chem. Sci., 1978, 33, 347-348.

397 T. M. Smalberger, G. J. H. Rall, H. L. de Waal and R. R. Arndt, Tetrahedron, 1968, 24, 6417-6421.

398 A. N. Collins, G. Sheldrake and J. Crosby, Chirality in Industry: The Commercial Manufacture and Applications of Optically Active Compounds, Wiley-VCH, Heidelberg, 1995. 
399 M. J. Ford, J. G. Knight, S. V. Ley and S. Vile, Synlett, 1990, 1990, 331-332.

400 P. Dydio, R. J. Detz and J. N. H. Reek, J. Am. Chem. Soc., 2013, 135, 10817-10828.

401 P. Dydio, W. I. Dzik, M. Lutz, B. de Bruin and J. N. H. Reek, Angew. Chem., Int. Ed., 2011, 50, 396-400.

402 H. W. Yang and D. Romo, J. Org. Chem., 1997, 62, 4-5.

403 H. W. Yang, C. Zhao and D. Romo, Tetrahedron, 1997, 53, 16471-16488.

404 M. Mutoh, N. Nakada, S. Matsukuma, S. Ohshima, K. Yoshinri, J. Watanabe and M. Arisawa, J. Antibiot., 1994, 47, 1369-1375.

405 K. Yoshinari, M. Aoki, T. Ohtsuka, N. Nakayama, Y. Itezono, M. Mutoh, J. Watanabe and K. Yokose, J. Antibiot., 1994, 47, 1376-1384.

406 D. J. Anneken, S. Both, R. Christoph, G. Fieg, U. Steinberner and A. Westfechtel, in Ullmann's Encyclopedia of Industrial Chemistry, Wiley-VCH, Weinheim, 2006.

407 J. L. Beare-Rogers, A. Dieffenbacher and J. V. Holm, Pure Appl. Chem., 2001, 73, 685-744.

408 J. Gajewski, R. Pavlovic, M. Fischer, E. Boles and M. Grininger, Nat. Commun., 2017, 8, 14650-14657.

409 Z. Tan, J. M. Yoon, A. Chowdhury, K. Burdick, L. R. Jarboe, C. D. Maranas and J. V. Shanks, Biotechnol. Biofuels, 2018, 11, 87.

410 J. Wu, X. Zhang, X. Xia and M. Dong, Metab. Eng., 2017, 41, 115-124.

411 L. A. Kucek, C. M. Spirito and L. T. Angenent, Energy Environ. Sci., 2016, 9, 3482-3494.

412 L. A. Kucek, J. Xu, M. Nguyen and L. T. Angenent, Front. Microbiol., 2016, 7, 1892.

413 D. Webb and T. F. Jamison, Org. Lett., 2012, 14, 568-571.

414 Q. Khuonghuu, R. Goutarel, X. Monseur and G. Ratle, Bull. Soc. Chim. Belg., 1972, 81, 443-458.

415 Q. Khuong-Huu, G. Ratle, X. Monseur and R. Goutarel, Bull. Soc. Chim. Belg., 1972, 81, 425-441.

416 G. Ratle, X. Monseur, B. Das, J. Yassi, Q. Khuong-Huu and R. Goutarel, Bull. Soc. Chim. Fr., 1966, 9, 2945-2947.

417 C. Gnamm, K. Brödner, C. M. Krauter and G. Helmchen, Chem.-Eur. J., 2009, 15, 10514-10532.

418 C. Gnamm, G. Franck, N. Miller, T. Stork, K. Brödner and G. Helmchen, Synthesis, 2008, 2008, 3331-3350.

419 C. Nguyen, G. F. Ruda, A. Schipani, G. Kasinathan, I. Leal, A. Musso-Buendia, M. Kaiser, R. Brun, L. M. Ruiz-Pérez, B.-L. Sahlberg, N. G. Johansson, D. González-Pacanowska and I. H. Gilbert, J. Med. Chem., 2006, 49, 4183-4195.

420 N. A. Milas, Org. Synth., 1943, 2, 302.

421 S. Takkellapati, T. Li and M. A. Gonzalez, Clean Technol. Environ., 2018, 20, 1615-1630.

422 T. P. West, Fermentation, 2017, 3, 14.

423 X. Qin, T. Tzvetkov, X. Liu, D.-C. Lee, L. Yu and D. C. Jacobs, J. Am. Chem. Soc., 2004, 126, 13232-13233.

424 I. Kuroda, M. Musman, I. I. Ohtani, T. Ichiba, J. Tanaka, D. G. Gravalos and T. Higa, J. Nat. Prod., 2002, 65, 15051506.

425 V. Ledroit, C. Debitus, C. Lavaud and G. Massiot, Tetrahedron Lett., 2003, 44, 225-228.
426 P. Bhaket, K. Morris, C. S. Stauffer and A. Datta, Org. Lett., 2005, 7, 875-876.

427 Y. Du, J. Liu and R. J. Linhardt, J. Org. Chem., 2006, 71, 1251-1253.

428 Y. Génisson, L. Lamandé, Y. Salma, N. Andrieu-Abadie, C. André and M. Baltas, Tetrahedron: Asymmetry, 2007, 18, 857-864.

429 J. Liu, Y. Du, X. Dong, S. Meng, J. Xiao and L. Cheng, Carbohydr. Res., 2006, 341, 2653-2657.

430 M. Passiniemi and A. M. P. Koskinen, Tetrahedron Lett., 2008, 49, 980-983.

431 K. R. Prasad and A. Chandrakumar, J. Org. Chem., 2007, 72, 6312-6315.

432 C. V. Ramana, A. G. Giri, S. B. Suryawanshi and R. G. Gonnade, Tetrahedron Lett., 2007, 48, 265-268.

433 L. V. R. Reddy, P. V. Reddy and A. K. Shaw, Tetrahedron: Asymmetry, 2007, 18, 542-546.

434 C. Ribes, E. Falomir, M. Carda and J. A. Marco, Tetrahedron, 2006, 62, 5421-5425.

435 N. Sudhakar, A. R. Kumar, A. Prabhakar, B. Jagadeesh and B. V. Rao, Tetrahedron Lett., 2005, 46, 325-327.

436 T. Yakura, S. Sato and Y. Yoshimoto, Chem. Pharm. Bull., 2007, 55, 1284-1286.

437 M. Pagliaro, R. Ciriminna, H. Kimura, M. Rossi and C. Della Pina, Angew. Chem., Int. Ed., 2007, 46, 4434-4440.

438 A. Evidente and A. Kornienko, Phytochem. Rev., 2009, 8, 449-459.

439 L. Ingrassia, F. Lefranc, V. Mathieu, F. Darro and R. Kiss, Transl. Oncol., 2008, 1, 1-13.

440 F. Cagide-Fagín, O. Nieto-García, H. Lago-Santomé and R. Alonso, J. Org. Chem., 2012, 77, 11377-11382.

441 P. Martínez-Bescos, F. Cagide-Fagín, L. F. Roa, J. C. OrtizLara, K. Kierus, L. Ozores-Viturro, M. Fernández-González and R. Alonso, J. Org. Chem., 2008, 73, 3745-3753.

442 J. Liu, Liquid Explosives, Springer, Berlin, Heidelberg, 2015. 443 D. Roberge, C. Noti, E. Irle, M. Eyholzer, B. Rittiner, G. Penn, G. Sedelmeier and B. Schenkel, J. Flow Chem., 2013, 4, 26-34.

444 K. Show and P. Kumar, Eur. J. Org. Chem., 2016, 2016, 46964710.

445 H. L. Ohrem and F. Westmeier, United States Pat., US5770411A, 1998.

446 C. Weizmann, Great Britain Pat., GB191504845 (A), 1919.

447 F. Mussgnug, Naturwissenschaften, 1941, 29, 256.

448 D. Hellwinkel and T. Kosack, Liebigs Ann. Chem., 1985, 1985, 226-238.

449 W. C. Still and C. Gennari, Tetrahedron Lett., 1983, 24, 44054408.

450 M. R. Thomsett, T. E. Storr, O. R. Monaghan, R. A. Stockman and S. M. Howdle, Green Mater., 2016, 4, 115-134.

451 M. N. Belgacem and A. Gandini, Monomers, polymers and composites from renewable resources, Elsevier-Science, Aveiro, 2011.

452 W. Schwab, C. Fuchs and F. C. Huang, Eur. J. Lipid Sci. Technol., 2013, 115, 3-8. 
453 T. J. Maimone and P. S. Baran, Nat. Chem. Biol., 2007, 3, 396.

454 S. Zwenger and C. Basu, Biotechnol. Mol. Biol. Rev., 2008, 3, 1.

455 S.-M. Paek, M. Jeong, J. Jo, M. Y. Heo, T. Y. Han and H. Yun, Molecules, 2016, 21, 951.

456 M. Nakata, in Glycoscience: Chemistry and Chemical Biology, ed. B. O. Fraser-Reid, K. Tatsuta and J. Thiem, Springer Berlin Heidelberg, Berlin, Heidelberg, 2008, pp. 957-994.

457 T. Money and M. K. C. Wong, in Stud. Nat. Prod. Chem., ed. R. Atta ur, Elsevier, 1995, vol. 16, pp. 123-288.

458 W. A. Nugent, T. V. RajanBabu and M. J. Burk, Science, 1993, 259, 479.

459 M. A. Rude and A. Schirmer, Curr. Opin. Microbiol., 2009, 12, 274-281.

460 E. Breitmaier, Terpenes: flavors, fragrances, pharmaca, pheromones, Wiley-VCH, Weinheim, 2006.

461 V. J. Martin, D. J. Pitera, S. T. Withers, J. D. Newman and J. D. Keasling, Nat. Biotechnol., 2003, 21, 796.

462 K. A. D. Swift, Top. Catal., 2004, 27, 143-155.

463 F. M. Kerton and R. Marriott, Alternative solvents for green chemistry, Royal Society of chemistry, St. John's, 2013.

$464 \mathrm{~J}$. Schrader, in Flavours and Fragrances: Chemistry, Bioprocessing and Sustainability, ed. R. G. Berger, Springer, Berlin, Heidelberg, 2007, pp. 507-574.

465 J. Schrader and R. G. Berger, in Biotechnology, ed. H. J. Rehm, G. Reeed, A. Pühler and P. Stadler, John Wiley \& Sons, Ltd, Weinheim, 2001, pp. 373-422.

466 D.-K. Ro, E. M. Paradise, M. Ouellet, K. J. Fisher, K. L. Newman, J. M. Ndungu, K. A. Ho, R. A. Eachus, T. S. Ham, J. Kirby, M. C. Y. Chang, S. T. Withers, Y. Shiba, R. Sarpong and J. D. Keasling, Nature, 2006, 440, 940-943.

467 M. Phillips and H. D. Gibbs, J. Int. Eng. Chem., 1920, 12, 733-734.

468 M. S. Ali, M. Saleem and V. U. Ahmad, Z. Naturforsch., B: Chem. Sci.f, 1999, 54, 807-810.

469 M. Kuhnt, A. Pröbstle, H. Rimpler, R. Bauer and M. Heinrich, Planta Med., 1995, 61, 227-232.

470 K. Mori and K. Fukamatsu, Liebigs Ann. Chem., 1992, 1992, 489-493.

471 M. Ping Zhao, X. Chao Liu, D. Lai, L. Zhou and Z. Long Liu, Helv. Chim. Acta, 2016, 99, 90-94.

472 A. El Mebtoul, M. Rouani, M. Chammache, H. Bouidida and A. Ilidrissi, Helv. Chim. Acta, 2011, 94, 433-437.

473 N. Hoffmann and H.-D. Scharf, Liebigs Ann. Chem., 1991, 1991, 1273-1277.

474 A. Rubo, R. Kellens, J. Reddy, N. Steier and W. Hasenpusch, in Ullmann's Encyclopedia of Industrial Chemistry, WileyVCH, Weinheim, 2006.

475 C. Grundke and T. Opatz, Green Chem., 2019, 21, 23622366.

476 C.-S. Yang, I. Kouno, N. Kawano and S. Sato, Tetrahedron Lett., 1988, 29, 1165-1168.

477 M. L. Condakes, K. Hung, S. J. Harwood and T. J. Maimone, J. Am. Chem. Soc., 2017, 139, 17783-17786.
478 S.-S. Cheng, M.-J. Chung, C.-Y. Lin, Y.-N. Wang and S.-T. Chang, J. Agric. Food Chem., 2011, 60, 124-128.

479 K. Bauer, D. Garbe and H. Surburg, Common Fragrance and Flavor Materials, Wiley-VCH, Weinheim, New York, 1997.

$480 \mathrm{X} . \mathrm{Hu}, \mathrm{S} . \mathrm{Xu}$ and T. J. Maimone, Angew. Chem., Int. Ed., 2017, 56, 1624-1628.

481 Y.-r. Naves, Helv. Chim. Acta, 1949, 32, 967-968.

482 C. C. C. R. de Carvalho and M. M. R. da Fonseca, Food Chem., 2006, 95, 413-422.

483 Y. Shimizu, S. Matsuto, Y. Mizunuma and I. Okada, Agric. Biol. Chem., 1970, 34, 437-441.

484 F. H. Sangsari, F. Chastrette and M. Chastrette, Synth. Commun., 1988, 18, 1343-1348.

485 J. Švenda and A. G. Myers, Org. Lett., 2009, 11, 2437-2440. 486 W. Herz, A. Srińivasan and P. S. Kalyanaraman, Phytochemistry, 1975, 14, 233-237.

487 H. O. Yang, D.-Y. Suh and B. H. Han, Planta Med., 1995, 61, 37-40.

488 H. Jianmei and Y. Chunshu, Phytochemistry, 1996, 42, 13751376.

489 K. Hung, M. L. Condakes, T. Morikawa and T. J. Maimone, J. Am. Chem. Soc., 2016, 138, 16616-16619.

490 F. M. Couchman, A. R. Pinder and N. H. Bromham, Tetrahedron, 1964, 20, 2037-2045.

491 S. Kamchonwongpaisan, C. Nilanonta, B. Tarnchompoo, C. Thebtaranonth, Y. Thebtaranonth, Y. Yuthavong, P. Kongsaeree and J. Clardy, Tetrahedron Lett., 1995, 36, 1821-1824.

492 X. Hu and T. J. Maimone, J. Am. Chem. Soc., 2014, 136, 5287-5290.

493 M. Martín-Rodríguez, R. Galán-Fernández, A. MarcosEscribano and F. A. Bermejo, J. Org. Chem., 2009, 74, 1798-1801.

494 M. Yoshikawa, E. Hadrada, A. Kawaguchi, J. Yamahara, N. Murakami and I. Kitagawa, Chem. Pharm. Bull., 1993, 41, 630-632.

495 K. Weinges and G. Schwarz, Liebigs Ann. Chem., 1993, 1993, 811-814.

496 S. Hatakeyama, M. Kawamura, Y. Mukugi and H. Irie, Tetrahedron Lett., 1995, 36, 267-268.

497 A. M. Szpilman, E. E. Korshin, H. Rozenberg and M. D. Bachi, J. Org. Chem., 2005, 70, 3618-3632.

498 E. E. Korshin, R. Hoos, A. M. Szpilman, L. Konstantinovski, G. H. Posner and M. D. Bachi, Tetrahedron, 2002, 58, 24492469.

499 M. Persson, K. Sjödin, A.-K. Borg-Karlson, T. Norin and I. Ekberg, Phytochemistry, 1996, 42, 1289-1297.

500 C. Suire, Y. Asakawa, M. Toyota and T. Takemoto, Phytochemistry, 1982, 21, 349-352.

501 K. Sennewald, E. Schallus and F. Pohl, Chem. Ing. Tech., 1963, 35, 1-6.

502 P. V. S. N. Vani, A. S. Chida, R. Srinivasan, M. Chandrasekharam and A. K. Singh, Synth. Commun., 2001, 31, 219-224.

503 Q.-W. Song, Q.-N. Zhao, J.-Y. Li, K. Zhang and P. Liu, Synthesis, 2019, 51, 739-746. 
504 D. Limat and M. Schlosser, Tetrahedron, 1995, 51, 57995806.

505 X.-T. Liang, D.-Q. Yu, W.-L. Wu and H.-C. Deng, Acta Chim. Sin., 1979, 37, 215-230.

506 F.-M. Xi, Y.-B. Liu, J. Qu, Y. Li, Z.-H. Tang, L. Li, Y.-H. Li, X.-G. Chen, S.-G. Ma and S.-S. Yu, Tetrahedron, 2017, 73, 571-582.

507 T. C. McMorris, R. Lira, P. K. Gantzel, M. J. Kelner and R. Dawe, J. Nat. Prod., 2000, 63, 1557-1559.

508 G. Liu and D. Romo, Angew. Chem., 2011, 123, 7679-7682.

509 A. W. v. Hofman, Justus Liebigs Ann. Chem., 1860, 115, 267269.

510 C. Yuan, B. Du, L. Yang and B. Liu, J. Am. Chem. Soc., 2013, 135, 9291-9294.

511 R. P. Limberger, A. M. Aleixo, A. G. Fett-Neto and A. T. Henriques, Electron. J. Biotechnol., 2007, 10, 500-507.

512 H.-H. Ko, W.-L. Chang and T.-M. Lu, J. Nat. Prod., 2008, 71, 1930-1933.

513 L. Acebey, V. Jullian, D. Sereno, S. Chevalley, Y. Estevez, C. Moulis, S. Beck, A. Valentin, A. Gimenez and M. Sauvain, Planta Med., 2010, 76, 365-368.

514 F. Bohlmann, C. Zdero, R. M. King and H. Robinson, Phytochemistry, 1980, 19, 689-691.

515 F. Bohlmann, H. Suding, J. Cuatrecasas, R. M. King and H. Robinson, Phytochemistry, 1980, 19, 267-271.

516 N. J. Sadgrove, M. Gonçalves-Martins and G. L. Jones, Phytochemistry, 2014, 104, 60-71.

517 G. M. Petrović, J. G. Stamenković, I. R. Kostevski, G. S. Stojanović, V. D. Mitić and B. K. Zlatković, Chem. Biodiversity, 2017, 14, e1600367.

518 L. Acebey, M. Sauvain, S. Beck, C. Moulis, A. Gimenez and V. Jullian, Org. Lett., 2007, 9, 4693-4696.

519 P. S. Baran and J. M. Richter, J. Am. Chem. Soc., 2005, 127, 15394-15396.

520 K. Stratmann, R. E. Moore, R. Bonjouklian, J. B. Deeter, G. M. Patterson, S. Shaffer, C. D. Smith and T. A. Smitka, J. Am. Chem. Soc., 1994, 116, 9935-9942.

521 P. S. Baran, T. J. Maimone and J. M. Richter, Nature, 2007, 446, 404-408.

522 A. Baeyer, Justus Liebigs Ann. Chem., 1866, 140, 295-296.

523 H. Weinstabl, T. Gaich and J. Mulzer, Org. Lett., 2012, 14, 2834-2837.

524 K. Simon, J. Wefer, E. Schöttner and T. Lindel, Angew. Chem., Int. Ed., 2012, 51, 10889-10892.

525 E. Schöttner, M. Wiechoczek, P. G. Jones and T. Lindel, Org. Lett., 2010, 12, 784-787.

526 G. D. Prestwich, D. F. Wiemer, J. Meinwald and J. Clardy, J. Am. Chem. Soc., 1978, 100, 2560-2561.

527 M. A. Umbreit and K. B. Sharpless, J. Am. Chem. Soc., 1977, 99, 5526-5528.

528 T. Takeo, Phytochemistry, 1981, 20, 2145-2147.

529 T. W. Doyle, D. E. Nettleton, R. E. Grulich, D. M. Balitz, D. L. Johnson and A. L. Vulcano, J. Am. Chem. Soc., 1979, 101, 7041-7049.

530 D. E. Nettleton Jr, D. M. Balitz, T. W. Doyle, W. T. Bradner, D. L. Johnson, F. A. O'Herron, R. H. Schreiber, A. B. Coon,
J. E. Moseley and R. W. Myllymaki, J. Nat. Prod., 1980, 43, 242-258.

531 H. S. Kim, Y. H. Kim, O. J. Yoo and J. J. Lee, Biosci., Biotechnol., Biochem., 1996, 60, 906-908.

532 H.-S. Kim, Y.-S. Hong, Y.-H. Kim, O.-J. Yoo and J.-J. Lee, J. Antibiot., 1996, 49, 355-360.

533 S. M. Salem, S. Weidenbach and J. Rohr, ACS Chem. Biol., 2017, 12, 2529-2534.

534 K. A. Shaaban, T. A. Ahmed, M. Leggas and J. Rohr, J. Nat. Prod., 2012, 75, 1383-1392.

535 A. Klasek, P. Sedmera, A. Boeva and F. Šantavý, Collect. Czech. Chem. Commun., 1973, 38, 2504-2512.

536 A. Klásek, P. Sedmera, J. Vokoun, A. Boeva, S. Dvoráčková and F. Šantavý, Collect. Czech. Chem. Commun., 1980, 45, 548-558.

537 N. T. Nghia, P. Sedmera, A. Klasek, A. Boeva, L. Drjanovska, L. Dolejš and F. Šantavý, Collect. Czech. Chem. Commun., 1976, 41, 2952-2963.

538 A.-L. Pérez-Castorena, A. Arciniegas, A. Castro, J. L. Villaseñor, R. A. Toscano and A. Romo de Vivar, J. Nat. Prod., 1997, 60, 1322-1325.

539 D. Robins, Nat. Prod. Rep., 1995, 12, 413-418.

540 A. Romo de Vivar, A.-L. Pérez, A. Arciniegas, P. Vidales, R. Gaviño and J. L. Villaseñor, Tetrahedron, 1995, 51, 12521-12528.

541 J. Y. Sim, G.-S. Hwang, K. H. Kim, E. M. Ko and D. H. Ryu, Chem. Commun., 2007, 5064-5065.

542 V. Bailliez, R. M. de Figueiredo, A. Olesker and J. Cleophax, Tetrahedron Lett., 2003, 44, 9151-9153.

543 J. Qian-Cutrone, T. Ueki, S. Huang, K. A. Mookhtiar, R. Ezekiel, S. S. Kalinowski, K. S. Brown, J. Golik, S. Lowe and D. M. Pirnik, J. Antibiot., 1999, 52, 245-255.

544 K. Tomita, Y. Hoshino and T. Miyaki, Int. J. Syst. Evol. Microbiol., 1993, 43, 297-301.

545 M. Tsunakawa, N. Komiyama, O. Tenmyo, K. Tomita, K. Kawano, C. Kotake, M. Konishi and T. Oki, J. Antibiot., 1992, 45, 1467-1471.

546 M. Tsunakawa, C. Kotake, T. Yamasaki, T. Moriyama, M. Konishi and T. Oki, J. Antibiot., 1992, 45, 1472-1480.

547 S. Velarde, J. Urbina and M. R. Peña, J. Org. Chem., 1996, 61, 9541-9545.

548 A. Fürstner, Eur. J. Org. Chem., 2004, 2004, 943-958.

549 A. Fürstner, M. Albert, J. Mlynarski and M. Matheu, J. Am. Chem. Soc., 2002, 124, 1168-1169.

550 A. Fürstner, M. Albert, J. Mlynarski, M. Matheu and E. DeClercq, J. Am. Chem. Soc., 2003, 125, 13132-13142.

551 A. Fürstner, J. Mlynarski and M. Albert, J. Am. Chem. Soc., 2002, 124, 10274-10275.

552 A. Fürstner, J. Ruiz-Caro, H. Prinz and H. Waldmann, J. Org. Chem., 2004, 69, 459-467.

553 D. V. Jarikote and P. V. Murphy, Eur. J. Org. Chem., 2010, 2010, 4959-4970.

554 V. Dimakos and M. S. Taylor, Chem. Rev., 2018, 118, 1145711517.

555 R. Paramashivappa, P. P. Kumar, P. J. Vithayathil and A. S. Rao, J. Agric. Food Chem., 2001, 49, 2548-2551. 
556 J. Mgaya, G. B. Shombe, S. C. Masikane, S. Mlowe, E. B. Mubofu and N. Revaprasadu, Green Chem., 2019, 21, 1186-1201.

557 E. B. Mubofu, Pure Appl. Chem., 2016, 88, 17-27.

558 C. N. Subbarao, K. Krishna Prasad and V. Prasad, The Pharma Research Journal, 2011, 6, 21-41.

559 E. A. Taiwo, in Advances in Petrochemicals, IntechOpen, IleIfe, 2015.

560 S. Kumar, P. Dinesha and M. A. Rosen, Energy Fuels, 2018, 32, 7237-7244.

561 M. C. Lubi and E. T. Thachil, Des. Monomers Polym., 2000, 3, 123-153.

562 A. S. Trita, L. C. Over, J. Pollini, S. Baader, S. Riegsinger, M. A. R. Meier and L. J. Gooßen, Green Chem., 2017, 19, 3051-3060.

563 C. Voirin, S. Caillol, N. V. Sadavarte, B. V. Tawade, B. Boutevin and P. P. Wadgaonkar, Polym. Chem., 2014, 5, 3142-3162.

564 L. Kisula, S. J. M. Mdachi, C. B. d. Koning and Q. A. Mgani, Tanz. J. Sci., 2015, 41, 27-37.

565 J. E. Mgaya, E. B. Mubofu, Q. A. Mgani, D. B. Cordes, A. M. Slawin and D. J. Cole-Hamilton, Eur. J. Lipid Sci. Technol., 2015, 117, 190-199.

566 J. A. Mmongoyo, Q. A. Mgani, S. J. M. Mdachi, P. J. Pogorzelec and D. J. Cole-Hamilton, Eur. J. Lipid Sci. Technol., 2012, 114, 1183-1192.
567 V. Bragoni, R. K. Rit, R. Kirchmann, A. S. Trita and L. J. Gooßen, Green Chem., 2018, 20, 3210-3213.

568 P. Peungjitton, P. Sangvanich, S. Pornpakakul, A. Petsom and S. Roengsumran, J. Surfactants Deterg., 2009, 12, 85-89.

569 N. D. Ghatge and S. P. Vernekar, Die Angewandte Makromolekulare Chemie, 1971, 20, 165-174.

570 M. L. d. Santos and G. C. d. Magalhães, J. Braz. Chem. Soc., 1999, 10, 13-20.

571 D. C. Aldridge, S. Galt, D. Giles and W. B. Turner, J. Chem. Soc. C, 1971, 1623-1627.

572 K.-H. Leet, N. Hayashi, M. Okano, I. H. Hall, R.-Y. Wu and A. T. McPhailti, Phytochemistry, 1982, 21, 1119-1121.

573 M. Pérez-Sánchez and P. D. de María, Catal. Sci. Technol., 2013, 3, 2732-2736.

574 M. Mascal and S. Dutta, Green Chem., 2011, 13, 3101-3102.

575 F. Chang, S. Dutta, J. J. Becnel, A. S. Estep and M. Mascal, J. Agric. Food Chem., 2014, 62, 476-480.

576 Y. Shi, P. C. J. Kamer and D. J. Cole-Hamilton, Green Chem., 2019, 21, 1043-1053.

577 R. A. Fernandes, Protecting-Group-Free Organic Synthesis: Improving Economy and Efficiency, Wiley-VCH, Mumbai, Weinheim, 2018.

578 R. W. Hoffmann, Synthesis, 2006, 2006, 3531-3541.

579 E. Roulland, Angew. Chem., Int. Ed., 2011, 50, 1226-1227.

580 I. S. Young and P. S. Baran, Nat. Chem., 2009, 1, 193-205. 